\title{
Dynamic Modelling of Submersible Pump Based Solar Water-Pumping System with Three-Phase Induction Motor Using MATLAB
}

\author{
Faisal Alkarrami, Tariq Iqbal, Kevin Pope, Geoff Rideout \\ Faculty of Engineering and Applied Science, Memorial University of Newfoundland, St. John's, Canada \\ Email: faaa51@mun.ca, tariq@mun.ca,kpope@mun.ca,g.rideout@mun.ca
}

How to cite this paper: Alkarrami, F., Iqbal, T., Pope, K. and Rideout, G. (2020) Dynamic Modelling of Submersible Pump Based Solar Water-Pumping System with Three-Phase Induction Motor Using MATLAB. Journal of Power and Energy Engineering, 8, 20-64. https://doi.org/10.4236/jpee.2020.82002

Received: December 6, 2019

Accepted: February 22, 2020

Published: February 25, 2020

Copyright $\odot 2020$ by author(s) and Scientific Research Publishing Inc. This work is licensed under the Creative Commons Attribution International License (CC BY 4.0).

http://creativecommons.org/licenses/by/4.0/ (c) (i) Open Access

\begin{abstract}
The main purpose of this paper is to design and model a water-pumping system using a submersible multi-stage centrifugal pump driven by a three-phase induction motor. The system is intended for pumping water to the surface from a deep well using three power supply systems: a general network, a photo-voltaic (PV) system, and a PV system with a battery bank. These systems are used to compare two three-phase induction motors-namely, a motor with a drive and another one without a drive. The systems dynamic models are simulated in MATLAB/Simulink and the results compared with the manufacturer's data for validation purposes. The simulation results generally show system dynamics and expected performance over a range of operation.
\end{abstract}

\section{Keywords}

Dynamic Modeling, Induction Motor, Water Pumping System, Submersible Pump, PV System, Battery Bank, MATLAB/Simulink

\section{Introduction}

Of the several different types of water pumps commercially available, the two most common ones are centrifugal pumps and positive displacement pumps. Centrifugal pumps use a rotating impeller to generate a centrifugal force that sucks the water while the impeller directs the water to the pump outlet with high velocity and pressure [1] [2]. These types of pumps tend to be installed as part of PV pumping systems, given that the motors in PV systems are DC- or AC-driven. The hydraulic efficiency of these systems is in the range of $30 \%$ [3]. Some of the 
other pumps that can be used include diaphragm pumps and progressing cavity pumps. In general, these pumps have relatively high efficiency, along with minimal capital costs and PV input power needs [3]. Positive displacement pumps are designed to provide a fixed amount of water through the contraction and expansion of a diaphragm.

Both centrifugal and positive placement pumps are used for the same purpose, which is to reduce downtime from main events and to continuously move water from point $A$ to point $B$ [1] [2]. In the present work, we investigate a dynamic pump, which is a type of centrifugal pump. We chose the dynamic pump mainly because of its low maintenance needs. However, centrifugal pumps can be problematic in that their efficiency reduces under low levels of solar radiation. To offset the problem, we modify motor speeds depending on the irradiance that is available at any given time. Note that the pump's torque is generally proportional to the rotor speed's square [4] [5].

Especially in rural areas and places that are underserved by national or regional grids, photovoltaic water pumping systems (PVPSs) have been shown to have great promise for providing solar energy [6] [7]. PVPSs are not only cost-effective but also dependable in comparison to grid- or diesel-based pumps [8]. Currently, the most common forms of water pumps being used in rural areas are diesel generators (DGs), but PVPSs offer a more dependable, less noisy and cleaner option [2] [9]. Diesel and electric water pumps spew 45 million tons of $\mathrm{CO} 2$ into the environment every year. This is equal to around one-tenth of all the world's annual emissions of greenhouse gases (GHGs). In an attempt to deal with these problems sustainably, the government in India initiated a program using solar-powered pumps to supply water for drinking and agricultural purposes. Solar water pumping has been found to be a viable alternative in water supply systems, particularly in light of rising diesel fuel prices [2]. After installing 0.1 million Solar Photovoltaic Water Pumps (SPVWPs) by 2015, the government now aims to add 1 million more by 2021 [10] [11].

Water pumping systems operated by direct coupled DC and AC solar-run water pumps are being used in many places around the world. The key parameters to determine the viability of these systems are as follows: adequate amounts of solar radiation based on geographical location; daily water needs during maximum usage periods; static level measurements; and piping requirements, as determined by pressure drops, height of tanks, and maximum drawdown [12]. In general, standard solar water pump systems include a motor pump set, a water storage tank, a controller, a photovoltaic (PV) array, some form of mounting structure, a tracking system (automatic or manual), and protection devices.

$\mathrm{PV}$ modules can be linked in parallel and in series to operate pump-motor sub-systems. These systems need power in order to generate the required water flow and pressure [3]. PV arrays connect with DC links via a DC/DC boost converter as a means to enable maximum power point tracking (MPPT) control, while three-phase voltage source inverters are used to maintain DC-link voltages [5] [7] [13] [14]. 
Rising energy needs have occurred at the same time as increasing pollution and subsequent concerns over the environment. The cost of energy generation is also a factor in discussions around power generation options and alternatives, including legacy (oil, gas, diesel, etc.) and renewable (solar, wind, water, etc.) options. The issue of GHG emissions is also a factor. The trend to adopt renewable energy options as alternatives to legacy energy resources is growing exponentially, particularly with regard to solar energy options. Although the early solar photovoltaic (PV) energy converters lacked efficiency (5\% - 6\%) and were quite expensive to build and operate, newer PV arrays have achieved 15\% - 16\% and incur much lower costs [7] [12] [13] [15]-[22].

Making a choice from the wide variety of Photovoltaic Pumping System (PVPS) options can be contingent on water flow rate requirements, reduced downtime, low costs, height of discharge, quality of pumped water, and high performance and durability [1] [2] Moreover, researchers have recently shown some of the pumps' weaknesses as well. For example, in 2009, researchers planned to install $10 \mathrm{~K} \mathrm{PV}$ water pumping systems in Bangladesh with a total electrical capacity of 10 megawatts for irrigation purposes, while in 2010, researchers in India also planned to install 50,000 PV water pumping systems with the electrical capacity of 50 megawatts for the same purpose [23]. Table 1 shows a comparison between the two general types of pumps.

There is a growing interest in PV water pumping from deep wells. In such cases, battery storage could be added or, alternatively, multi-stage centrifugal submersible pumps with three-phase motors could offer more advantages [24] In this research, the simulated water-pumping system consists of a submersible pump driven by a three-phase induction motor with a Voltage Source Inverter (VSI) drive and without a drive using first, a normal voltage source; second, a PV energy system with battery bank; and third, a PV without battery bank in order to compere between all the systems. Simulations are done in MATLAB/ Simulink.

Table 1. Comparison between centrifugal and positive displacement pumps [2].

\begin{tabular}{ll}
\hline \multicolumn{1}{c}{ Centrifugal Pump } & \multicolumn{1}{c}{ Positive Displacement Pump } \\
\hline $\begin{array}{l}\text { High pumping water volume } \\
\text { Low maintenance required }\end{array}$ & $\begin{array}{l}\text { Low pumping water volume } \\
\text { Frequent maintenance required }\end{array}$ \\
$\begin{array}{l}\text { High efficiency that is degraded when the } \\
\text { pump deviates from Rated speed }\end{array}$ & $\begin{array}{l}\text { The pump is able to operate efficiently over a wide } \\
\text { speed range away from the Rated speed }\end{array}$ \\
$\begin{array}{l}\text { The pump can pump water with low solar } \\
\text { radiation by using PVPS }\end{array}$ & Requires high starting torque to operate by PVPS \\
$\begin{array}{l}\text { The pumping flow rate varies according to } \\
\text { the pumping head }\end{array}$ & $\begin{array}{l}\text { The pumping flow rate is approximately equal, } \\
\text { regardless of the pumping head }\end{array}$ \\
$\begin{array}{l}\text { As the water viscosity increases, the flow } \\
\text { rate decreases }\end{array}$ & $\begin{array}{l}\text { As water viscosity increases, flow rate also increases } \\
\text { Widely used in PVPS }\end{array}$
\end{tabular}




\section{Submersible Pumps}

Submersible pumps are not only more efficient than jet pumps, but their basic operational principle has remained the same even through years of continuous constructional and operational evolution. The submersible pumps used in electric submersible pump installations featuring multi-stage centrifugal pumps operate in a vertical position [25]. In centrifugal pumps, the rate of water flow aims to be proportional with motor speed to enable continual head operation [26]. These pumps feature an airtight motor tightly coupled to the pump body. Submersible pumps push the water from deep sources to the surface, and jet pumps pull the water from the surface.

Another feature of submersible pumps is that they are completely submerged in the surface of the water and pump water with the help of their sealed body. The main advantage of this approach is avoiding pump cavitation. Other pumps have problems associated with high elevation differences between the pump and fluid surface. The issue with the impeller is that it increases the surface pressure, which forces water to move [27].

\section{Types of Electric Motors}

There are two main kinds of electric motors available for solar water pumping systems: AC (Alternating Current) induction motors and DC (Direct Current) motors. When choosing the most appropriate motor, factors such as size, efficiency requirements, price, reliability of the system, and availability are taken into consideration.

DC motors are a more specialized and expensive product, since they are used on a much smaller scale than AC induction motors. DC motors are also not suitable for high-powered applications (i.e., higher than $7 \mathrm{~kW}$ ). On the other hand, AC induction motors are widely available and relatively low-cost. The most widely available motor for industrial use is the squirrel cage induction motor, which has low manufacturing costs, robust construction, adaptability to submersible and flameproof applications, and the ability to accept a wide range of voltage/power ratings, all of which makes the AC induction motor an obvious choice [28] [29]. Furthermore, AC induction motors are smaller in size, making them better suited for PV applications in remote locations [30]. An added consideration is that many DC motor-driven PV pumps suffer from maintenance problems due to the presence of the commutator and brushes, making AC induction motor-based pumping systems a more viable choice where reliability and maintenance-free options are important factors [30] [31]. Most previous research analyzed systems utilizing permanent magnet motors [32] [33] [34].

A comparison [30] of the types of electric motors and the drawbacks of DC motors is presented in Table 2.

\section{Three-Phase Induction Motor}

A three-phase induction motor is an electromechanical device or motor that converts electrical energy into mechanical energy. The main benefit of using this 
Table 2. Comparison of DC and AC drive systems [35].

\begin{tabular}{cc}
\hline DC Motor & AC Motor \\
\hline $\begin{array}{c}\text { Requires commutator and brushes, making } \\
\text { the motor bulky and heavy }\end{array}$ & Does not require commutator or brushes \\
High cost & Low cost \\
Requires frequent maintenance & Requires less maintenance \\
Requires battery or inverter & Battery not required \\
\hline
\end{tabular}

type of motor is that it does not require any starting device to operate, since it is a self-operated or self-induction motor [36]. The majority of pumping systems have induction motors, as these motor types are relatively simplistic from a mechanical point of view. As well, they are generally reliable and well-constructed, which means they have fewer maintenance issues and related costs. Overall, then, induction motors are a hardy, low-cost device that are also highly efficient and can be used in places that are hazardous to work or are contaminated [5].

Three-phase induction motors have two major parts-a stator and a motor. The stator features a three-phase winding circuit comprising a number of slots and is connected to a three-phase AC source. The rotor has a laminated core which holds conductors like copper and platinum. The slots are present for holding the entire assembly, but they are placed at a slight angle from the main axis, so there is no effect on the RPMs and magnetic field of the motor [37].

Three-phase induction motors have been shown to be a viable alternative in commercial water pumping systems. There are two stages in SPV array-fed water pumping systems that employ induction motors. The first stage restrains the DC-DC boost converter duty ratio in order to extract the solar PV array's maximum power. The second stage uses a controller to handle Voltage Source Inverter (VSI) switching pulses [5]. The two main kinds of source inverters are voltage-controlled (VSI) and current-controlled (CSI).

The VSI voltage source inverter is more popular than the CSI. The VSI is usually applied in systems that use pulse-width modulation (PWM) speed control in three-phase AC motors. The system uses purpose-designed LSI circuits for creating PMW, utilizing sine-wave modulation. Variable-speed induction motor drives have been employed in a number of industry usages, with PWM inverters generally being the first choice on account of their optimal control level in frequency, harmonics and control voltage [38]. As an added bonus, for drives of similar ratings, VSI is usually less expensive than CSI and also has a higher frequency range. Typical AC drives in today's industrial applications use sinusoidal pulse-width modulation (SPWM), with both current source inverters and voltage source inverters featured as part of adjustable speed AC drives [38].

\section{System Description}

Specifications for the pump and motors to be used in the projects:

- Submersible pump power: $7.5 \mathrm{hp}$ 
- Well depth: $50 \mathrm{~m}$

- Total pipe length: $66 \mathrm{~m}$

- Pipe diameter (for transporting water): 2 inches

- Motor voltage: $380 \mathrm{~V}$

- Motor power: $5.5 \mathrm{~kW}$

- Motor frequency: $50 \mathrm{~Hz}$

The system in this paper was designed as shown in Figure 1.

\subsection{Calculation of Total Dynamic Head}

Total dynamic head (TDH) is a major factor that determines the optimal performance of submersible pumps. If the $T D H$ of the system increases, the volume of the discharge will be reduced proportionally until it stops [39].

$$
T D H=P_{l}+V_{r}+F_{l}
$$

where

$$
\begin{aligned}
& P_{l}=\text { Pumping level }=50 \mathrm{~m}=164.04 \mathrm{ft} \\
& V_{r}=\text { Vertical rise }=3 \mathrm{~m}=9.84 \mathrm{ft} \\
& F_{l}=\text { Friction loss, which can be defined as: }
\end{aligned}
$$

$$
F_{l}=\left[L_{t}+\sum\left(n_{f} \cdot f_{e}\right)\right] \times \frac{F_{h}}{100}
$$

where

$L_{t}=$ Total length of pipe in the system $=66 \mathrm{~m}=216.54 \mathrm{ft}$

$f_{e}=$ Fittings, in feet, of pipe, which has a standard value in feet, depending on the pipe's diameter and type $=5$

$n_{f}=$ Number of same fittings in the system $=2$ elbows

$F_{h}=$ Friction loss of head per 100 feet of pipe, depending on the pipe's diameter and flow rate. In this system, which has a 2-inch diameter and an 18 $\mathrm{m}^{3} / \mathrm{h}$ or 80 gpm flow rate, friction loss is equal to 10.9 [39]. The detailed data are given in Appendix.

By substituting the values in Equations (1) and (2), the $T D H$ is:

$$
\begin{aligned}
T D H & =164.04+9.84+[216.54+2 \times 5] \times 10.9 / 100 \\
& =198.58 \mathrm{ft}=60.53 \mathrm{~m}
\end{aligned}
$$

\subsection{Selection of Submersible Pump}

As we require a submersible pump that will deliver $18 \mathrm{~m}^{3} / \mathrm{h}$ to a water tank with TDH $60.5 \mathrm{~m}$ and $7.5 \mathrm{HP}$, the Grundfos SP 17-8-12AB6908 pump, which uses the performance curves of Grundfos (as shown in Figure 2), has been chosen. This submersible borehole pump is suitable for pumping clean water and can be installed vertically or horizontally. All of its steel components are stainless steel, EN 1.4301 (AISI 304), which ensures high corrosive resistance. The pump also carries drinking water approval and is fitted with a $5.5 \mathrm{~kW}$ MS6000 motor with sand shield, mechanical shaft seal, water-lubricated journal bearings, and a volume-compensating diaphragm. The motor is a canned-type submersible motor that offers good mechanical stability and high efficiency, and is suitable for temperatures up to $40^{\circ} \mathrm{C}$ [40] [41]. 


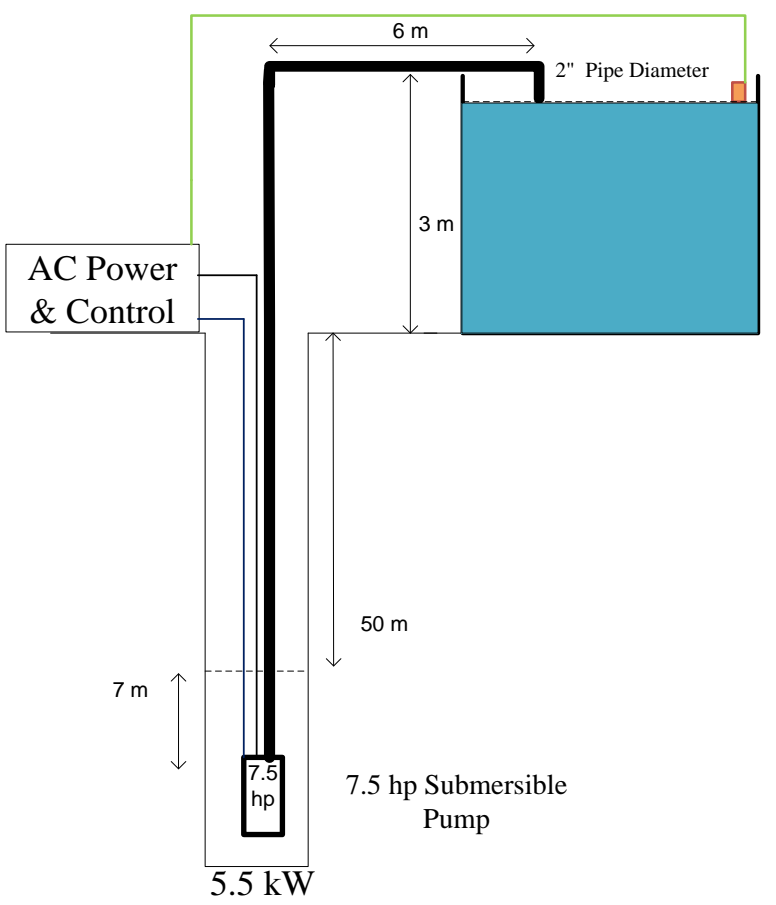

Figure 1. Schematic diagram of water-pumping system.

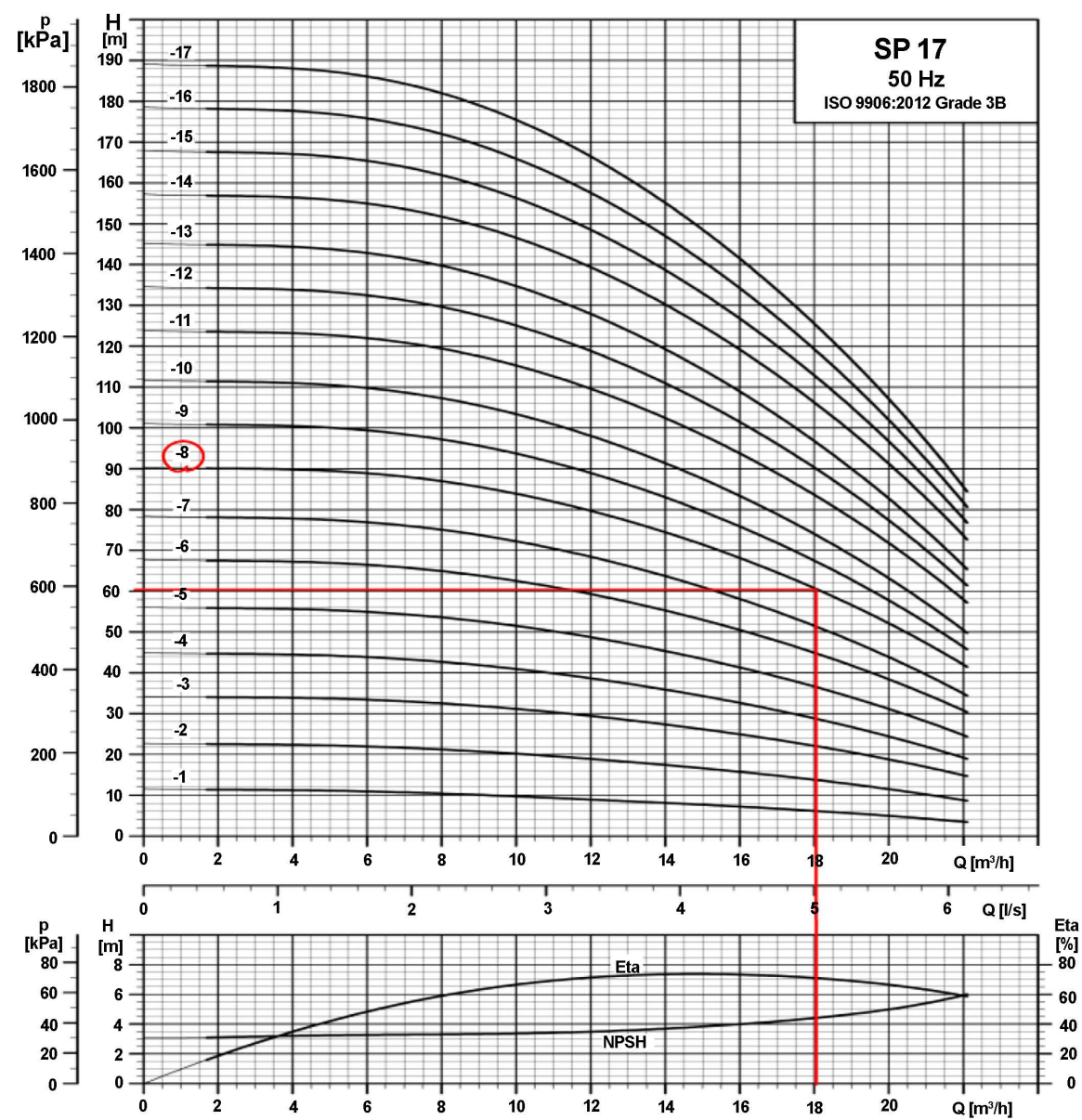

Figure 2. Performance curves of Grundfos SP-17 pumps [41]. 
Figure 3 shows the system curve, pump curve, NPSH curve and efficiency curves. The system curve has the pump curve as the operating point of pump chosen for the $T D H$ and flow rate. The given values of $T D H=60.53 \mathrm{~m}$ and $\mathrm{Q}=$ $18 \mathrm{~m}^{3} / \mathrm{h}$ are shown for the motor power $\mathrm{P}_{1}=5.3 \mathrm{~kW}$ and the shaft power $\mathrm{P}_{2}=$ $4.26 \mathrm{~kW}$, respectively. From the above values, the efficiency of the pump was calculated as $69.6 \%$, while the total efficiency of the system was $56 \%$.

Figure 4 demonstrates the motor curves, efficacy, power factor, current, shaft power, and shaft speed of the motor. The current, power factor, shaft speed and efficiency of the motor were found to be $79.8 \%$, respectively.

The moment of inertia was calculated by choosing the pump size (6") and inserting the number of stages (8) using Equation (3) [41].

$$
J_{p}=(4.0+n \times 4.1) \times 10^{-4}=0.0037\left[\mathrm{~kg} \cdot \mathrm{m}^{2}\right]
$$

where

$n=$ number of stages $=8$.

According to the above data from Figure 3 and Figure 4, the torque can be determined as follows:

$$
\tau_{\text {shaft }}=\frac{P_{\text {shaft }}}{\omega}=\frac{4265}{304.1}=14.03[\mathrm{~N}-\mathrm{m}]
$$

where $P_{\text {shaft }}$ is the power of the pump shaft $\left(P_{2}\right)$ in [W] and $\omega=2 \pi n[\mathrm{rpm}] / 60$ is the angular velocity of the shaft in $[\mathrm{rad} / \mathrm{s}]$.

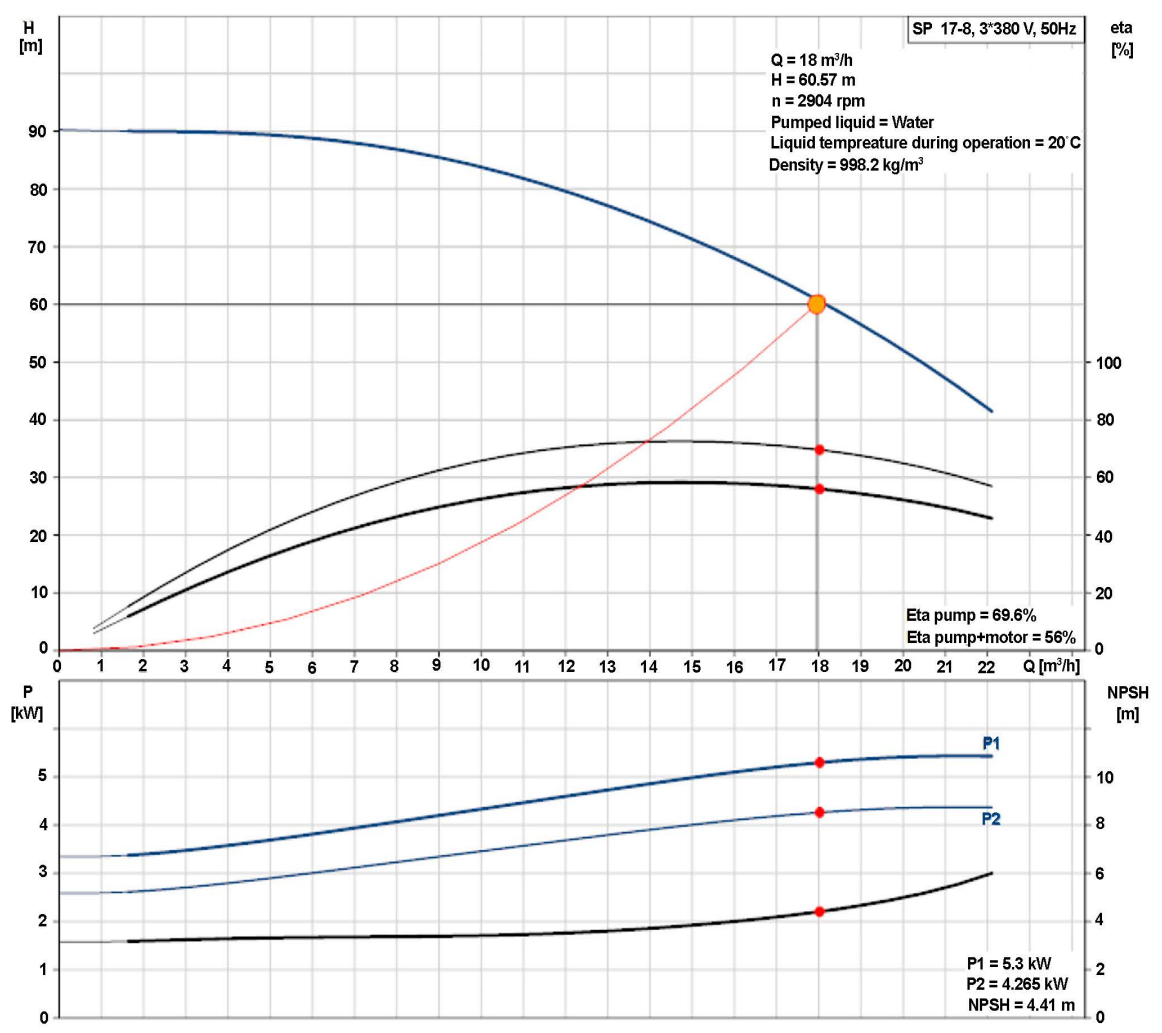

Figure 3. System curve, pump curve, NPSH curve and efficiency curves [40]. 


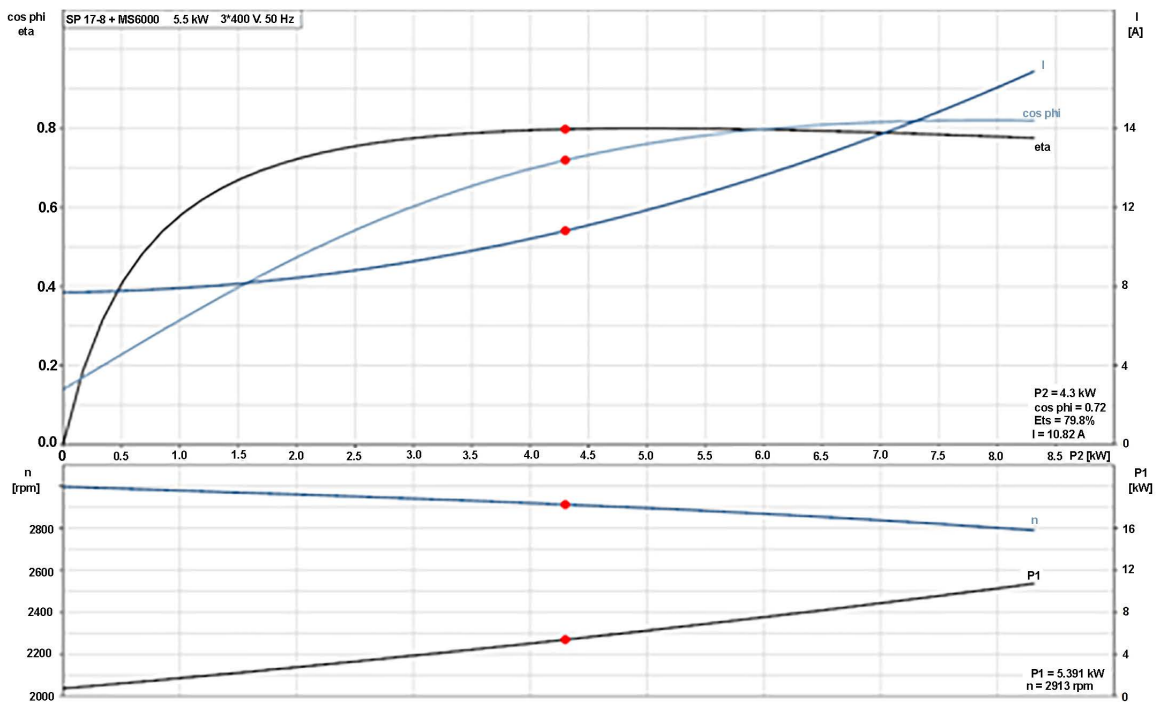

Figure 4. Motor curves [40].

\section{Methodology}

\subsection{Photovoltaic System (PV) and PV Array Dimensions}

Earlier studies helped to determine the dimensions of our PV system [17]. In determining the solar PV array design, we connected 4 modules in parallel and 10 modules in series, creating a $10.7 \mathrm{~kW}$ array that will supply a $6 \mathrm{~kW}$ system. This design has been slightly overrated in order to satisfy the system's needs and losses [26]. The array connects with the DC link via a DC/DC boost converter. This connection offers maximum power point tracking (MPPT) control. Note that a three-phase voltage-source inverter will be used to maintain the DC-link voltage [14]. The radiation of the PV used in the simulation starts at $1000 \mathrm{w} / \mathrm{m}^{2}$ and drops to $600 \mathrm{w} / \mathrm{m}^{2}$ in 1.5 seconds. In addition, the temperature was kept constant at $25^{\circ} \mathrm{C}$.

\subsection{MPPT Controller Algorithms}

We can use MPPT in order to achieve the following:

- Ensure the system functions at or near MPPT conditions if the environmental conditions are in some way altered or in broad variations of conditions.

- Ensure efficiency in conversion.

- Ensure that the output interface has compatibility features that match the battery-charging needs [42].

Several different MPPT algorithms can be employed for obtaining maximum power in PV systems. Among these is the perturbation and observation ( $\mathrm{P} \& \mathrm{O})$ approach. We use the $\mathrm{P} \& \mathrm{O}$ method in the present study due to its simplicity and ease of implementation. For P\&O algorithms, the PV system operating voltages increment at lesser values while also observing PV system power extraction. So, when the system's extracting power is lower compared to the earlier observed PV power, the system's operating voltages are raised by raising the converter's duty cycle. Conversely, when the system's extracting power is higher compared 
to earlier observed PV power, the system's operating voltages are reduced by reducing the converter's duty cycle [26]. An incremental conductance-based MMPT control strategy is then utilized for controlling duty ratio [13] [43]. Figure 5 shows the MPPT P\&O flowchart algorithm.

\subsection{DC/DC Boost Converter}

The DC/DC boost converter is another type of solar PV water pumping system for power conversion. As the name describes, boost converters boost PV voltage levels, such that V DC indicates DC voltage that has been boosted or increased. Boost converters get maximum power out of solar PV arrays through controlling their duty ratios in Insulated Gate Bipolar Transistor (IGBT) inverters.

A boost converter's duty cycle $(D)$ can be formulated as follows:

$$
D=1-\frac{V_{\text {in (min })} \times \eta}{V_{o}}=1-\frac{350 \times 0.9}{390}=0.19
$$

In this calculation, $V_{i n(\min )}$ denotes minimum input voltage and $V_{o}$ expresses output voltage, while $\eta$ indicates converter efficiency [39].

Based on this formulation, we can calculate a boost converter inductor as shown in Equation (6):

$$
L \geq \frac{V_{i n(\min )} \times D}{\Delta I_{l} \times f_{s}}=\frac{350 \times 0.19}{0.3 \times 15000}=0.48 \mathrm{mH}
$$

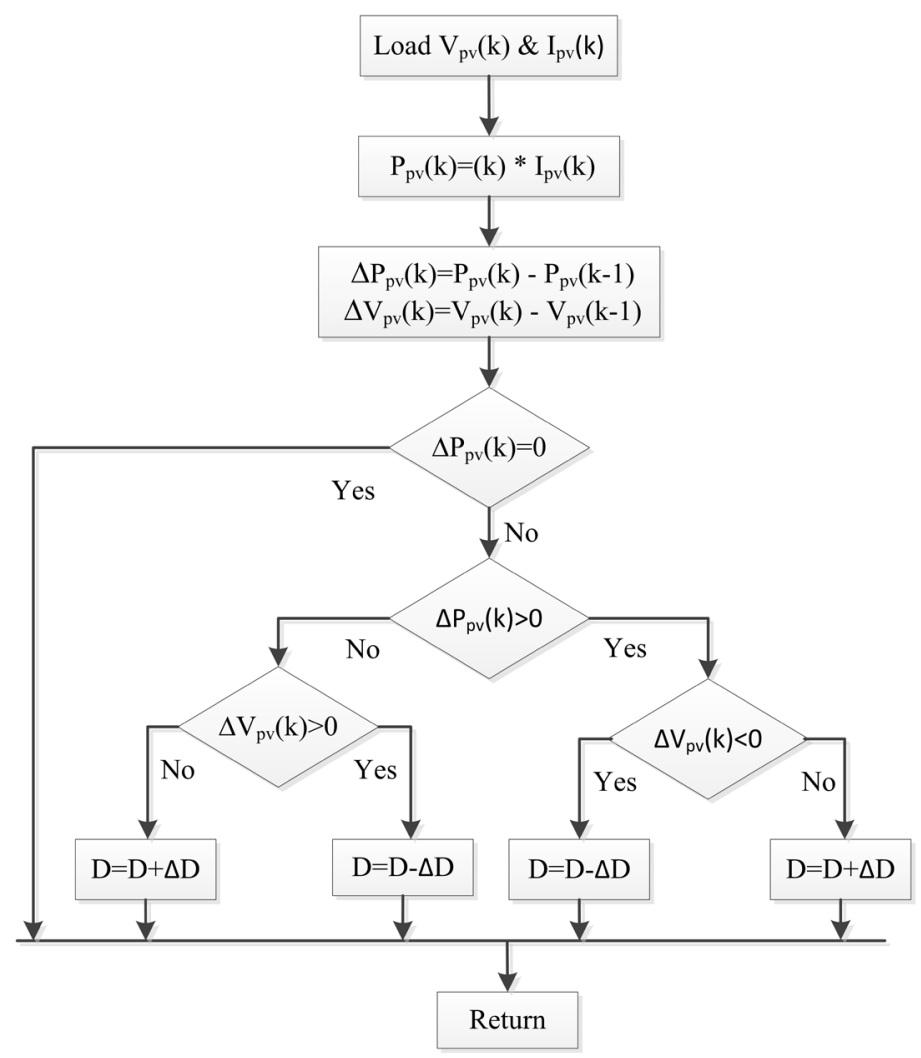

Figure 5. Flowchart for P \& O algorithm of MPPT [26] 
In this calculation, $f_{s}$ denotes switching frequency, while $\Delta I_{l}$ expresses permissible current ripple, estimated to represent $20 \%-40 \%$ of output current.

We can estimate the DC-link capacitor through the following calculation [14] [44]:

$$
C_{1} \geq \frac{I_{o(\max )} \times D}{f_{s} \times \Delta V_{C}}
$$

Here, $I_{o(\max )}$ vindicates maximum output current and $\Delta V_{c}$ denotes capacitor voltage ripple, estimated to be [39]:

$$
\begin{gathered}
\Delta V_{c}=1 \% \text { to } 5 \% \text { of } V_{C}=0.01 * V_{o}=0.01 * 390=3.9 \mathrm{~V} \\
\therefore C_{1}>8.99138 \times 10^{-5} \mathrm{~F}
\end{gathered}
$$

In this simulation, the capacity was chosen to be:

$C_{1}>8.99138 \times 10^{-5} \times 3=2.697 \times 10^{-4} \mathrm{~F}$. The value of the capacity was multiplied by 3 because the lower values of the capacity show instability in the system, especially Model 4.

\subsection{Insulated Gate Bipolar Transistor (IGBT) Inverter}

An IGBT is used for built-in two-phase DC to three-phase AC conversion, with a PI controlling the pulse.

\subsection{Battery Bank}

The battery bank comprises a lead-acid battery featuring $360 \mathrm{~V}$ as nominal voltage and rated capacity at $40 \mathrm{Ah}$.

\subsection{Three-Phase Transformer}

We use a three-phase transformer for boosting voltage output (240 V up to 380 V) from our IGBT inverter to our LC filter.

\subsection{Pump Model}

Different pump models (centrifugal, impulse, etc.) can be used based on the unit's head and water discharge. In centrifugal pumps, water flow rate is generally proportional to motor speed, resulting in consistent and smooth head operation. The decision on the right motor for a given job is dependent in large part on the pump's efficiency level and relevant hydrological data [26]. In the present study, we chose a centrifugal pump, for reasons explained in the "Selection of submersible pump" section.

\subsection{Induction Motor}

The simulation used two different induction motors: a standard motor without a drive, and an induction motor featuring a PWM VSI drive (380 3-phase AC Volts $-50 \mathrm{~Hz}$ ). In both of these induction motors, the torque was identical, with the mechanical load passing from 14 N.m. to -14 N.m. This led the electromagnetic torque into stabilization almost immediately after -14 N.m [45]. 


\section{Matlab/Simulink Simulation}

The simulations in this study were performed using MATLAB/Simulink, as this software can work with extremely complicated simulations [46]. Two induction motor types were simulated-one without drive and one with. Both of the motors were simulated by employing a PV system for each and a suitable voltage source. For comparative purposes, the motors were simulated with and without a battery bank. Finally, calculations for the system and pump were tested in order to validate the pump and induction motor model as well as the auxiliary components and pipes.

\subsection{Model 1: Induction Motor with PWM VSI Drive, Operated Using Ideal Source}

First, the system is simulated using a $380 \mathrm{~V}$ ideal AC voltage source. Figure 6 shows the system components that can be calculated and evaluated, including the shaft motor, shaft torque, shaft power, pump flow rate, motor current and rotor speed. The latter is controlled by a common speed controller, PI. The power supply feeding the induction motor with a PWM VSI drive (380 3-phase AC Volts $-50 \mathrm{~Hz}$ ) can be replaced in the future by any PV or hybrid energy system. Figure 7 presents the torque, power, and speed shaft of the pump calculations in the model.

\subsection{Results and Discussion: Model 1}

From the simulation of the dynamic system model, the following results were found and plotted. Figure 8 illustrates the actual rotor speed of the motor as well as the reference speed, both of which were shown to have nearly the same results. From the figure, it can be seen that the PWM voltage source inverter-driven motor stabilized at $1500 \mathrm{rpm}$ and $2920 \mathrm{rpm}$. Figure 9 shows the angular velocity of the shaft $[\mathrm{rad} / \mathrm{sec}]$ versus the pump speed $[\mathrm{rad} / \mathrm{sec}]$, with the results indicating complete agreement, other than for some isolation due to the inertia effect of the pump.

Figure 10 demonstrates the stator motor current [A] over three seconds. From the figure, it can be seen that the motor speed causes the current to change until it reaches a steady-state current.

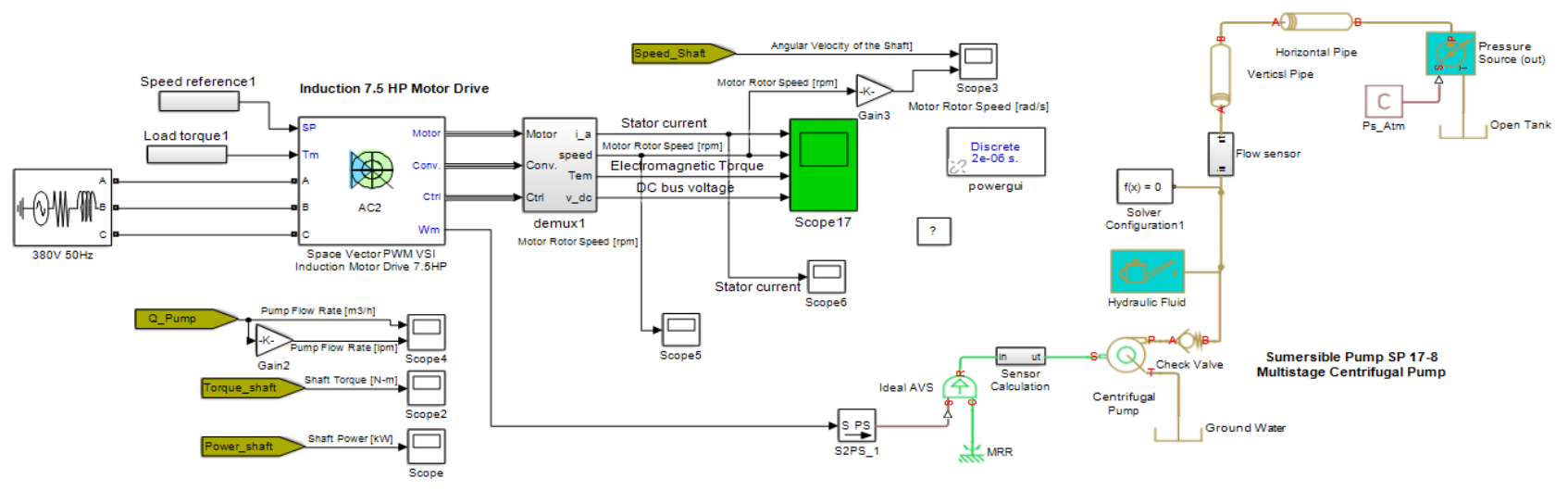

Figure 6. Model 1: MATLAB/Simulink complete model of induction motor with PWM VSI drive operated using ideal source. 


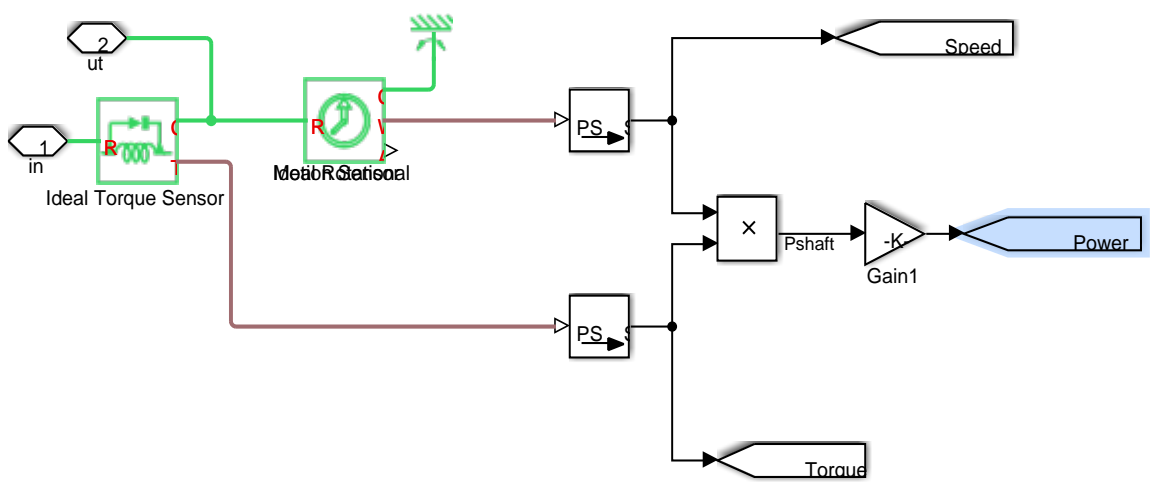

Figure 7. Sensor calculation in model.

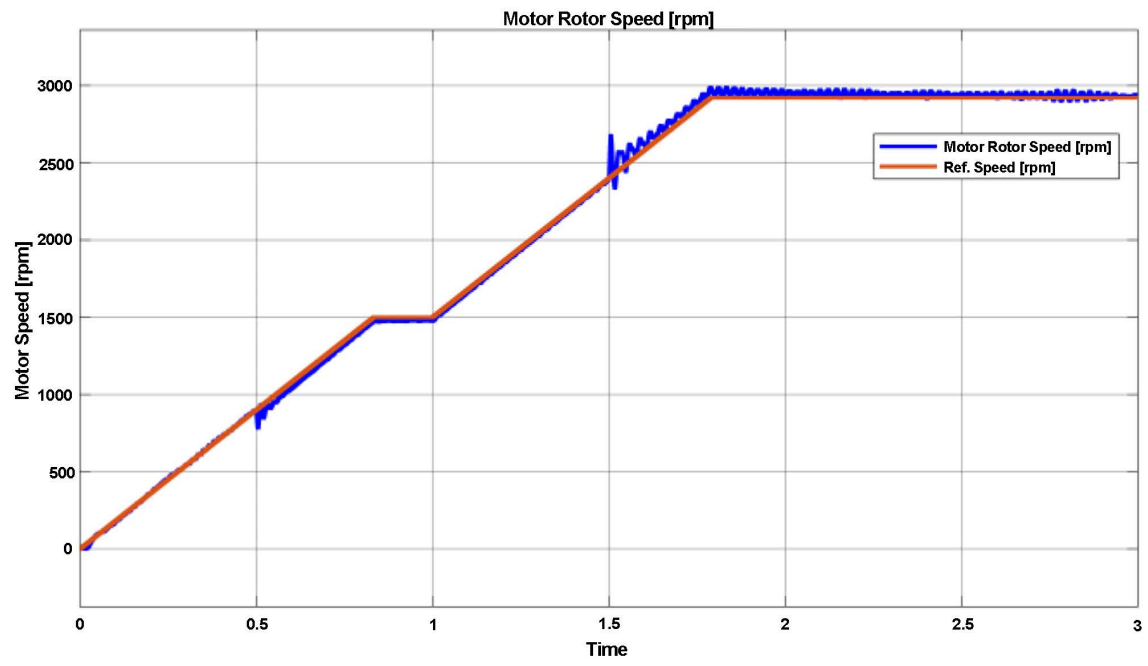

Figure 8. Rotor speed of motor.
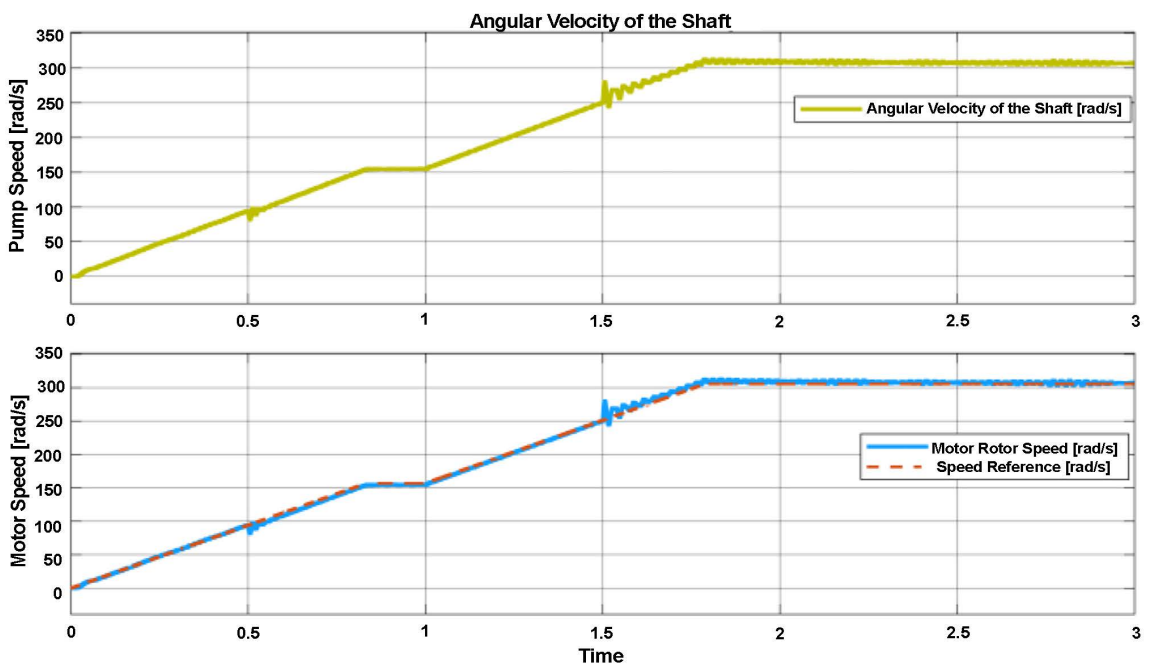

Figure 9. Angular velocity of shaft.

Figure 11 shows the shaft power of the pump [kW] against time [sec]. The shaft power of the pump gives the same results as the motor speed, as shown in the figure. The total power of the shaft is $4.5 \mathrm{~kW}$. Figure 12 illustrates the shaft 


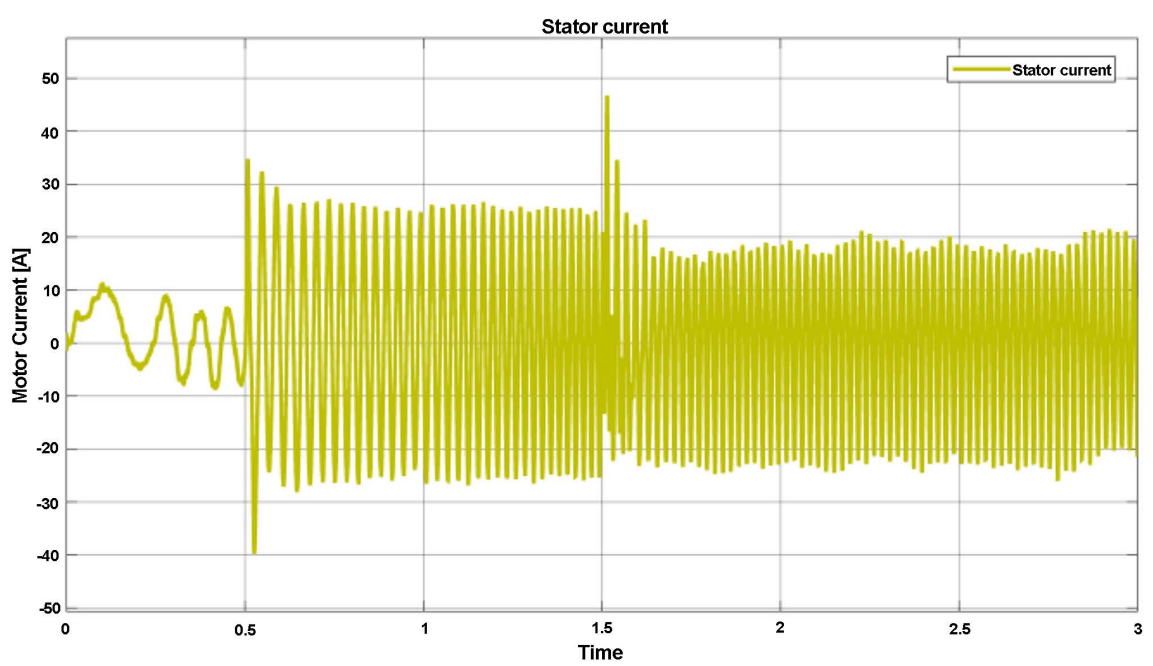

Figure 10. Stator motor current.

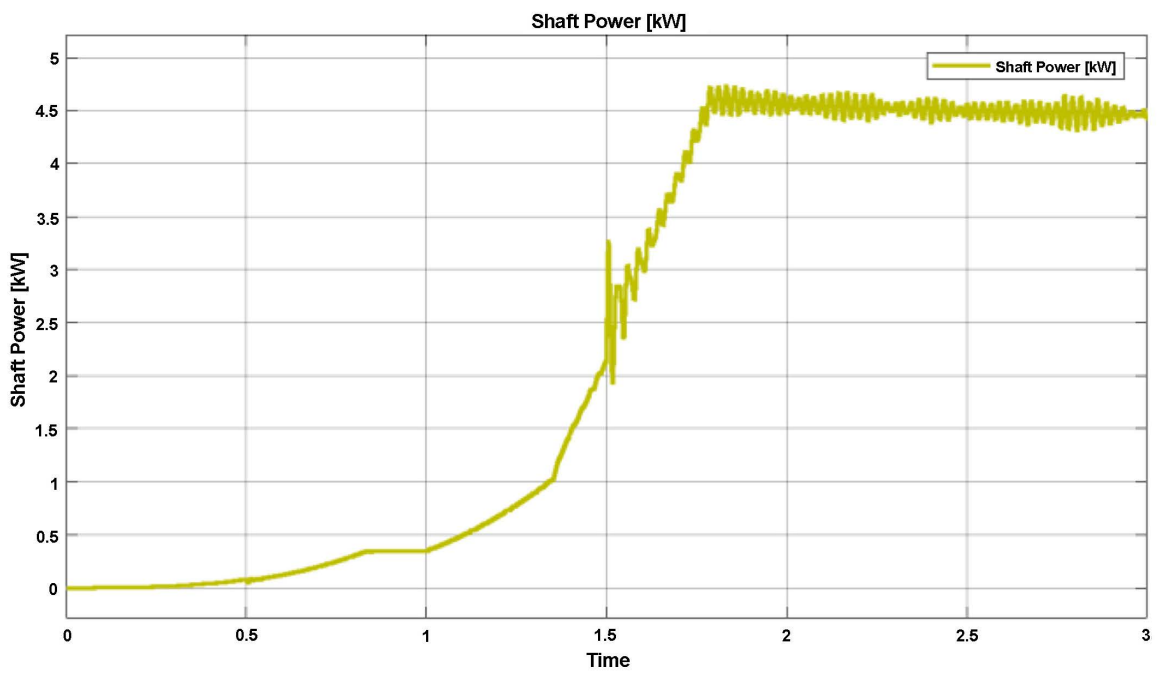

Figure 11. Shaft power of pump.

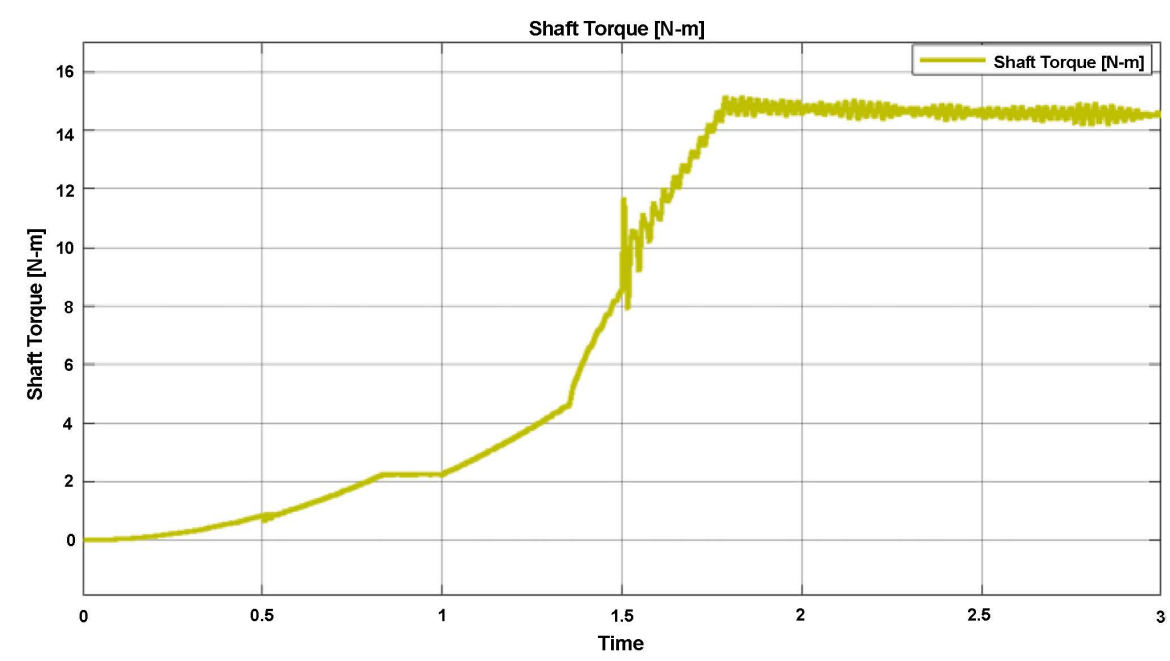

Figure 12. Shaft torque of pump. 
torque of the pump [N-m] versus time, in sec. The results show the shaft power and adjusts its value accordingly. The total torque of the pump is calculated to be $14[\mathrm{~N}-\mathrm{m}]$.

Figure 13 shows the pump flow rate in both cubic meter per sec and liter per minute. Both curves show the pump flow rate as $5.3 \times 10^{-3}\left[\mathrm{~m}^{3} / \mathrm{sec}\right]$ and 318 [lpm], respectively. This is almost the actual calculated value. From the figure, it can be seen that the pump starts to deliver the water after almost $1.5 \mathrm{sec}$ due to the pressure of the check valve and the speed of the shaft. Figure 14 presents the pump flow rate of the system without check valve, showing the pump flow rate reaching up to $340(\mathrm{lpm})$. In addition, the specific difference in the pump flow rate between both of the systems (with and without check valve) can be seen.

\subsection{Model 2: Induction Motor without Drive Operated Using Ideal Source}

In this model, an induction motor with no drive to power the pump has been used. To use the motor in MATLAB/Simulink, the high value of resistance has to be connected in parallel with the motor or the transformer to make the simulation run, as shown in Figure 15.

\subsection{Results and Discussion: Model 2}

From the simulation of the dynamic system in Model 2, the following results were found and plotted. Figure 16 illustrates the actual rotor speed of the motor. From the figure, it can be seen that the motor stabilized at $3000 \mathrm{rpm}$ and 2920 rpm and then changed to $3075 \mathrm{rpm}$.

Figure 17 demonstrates the stator motor current [A] over three seconds. From the figure, it can be seen that the motor speed causes the current to change until it reaches a steady state current, which starts at a very high value and then decreases to $2012 \mathrm{~A}$.

Figure 18 shows the shaft power of the pump [kW] against time [sec]. The shaft power of the pump gives the same results as the motor speed, as shown in
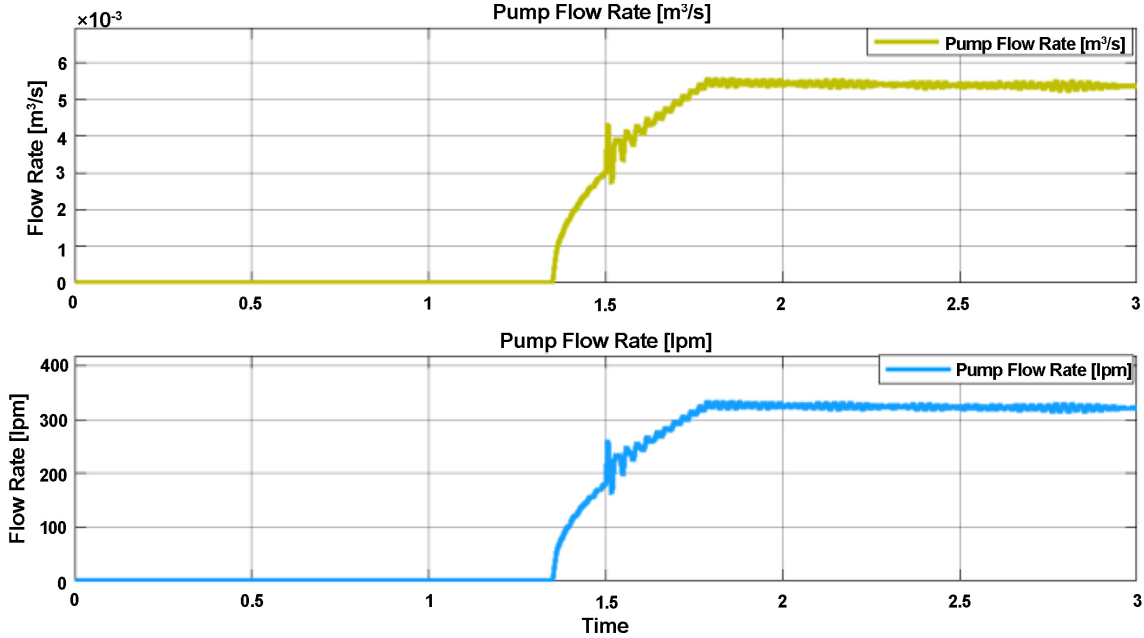

Figure 13. Pump flow rate in $\left[\mathrm{m}^{3} / \mathrm{s}\right]$ and $[\mathrm{lpm}]$. 

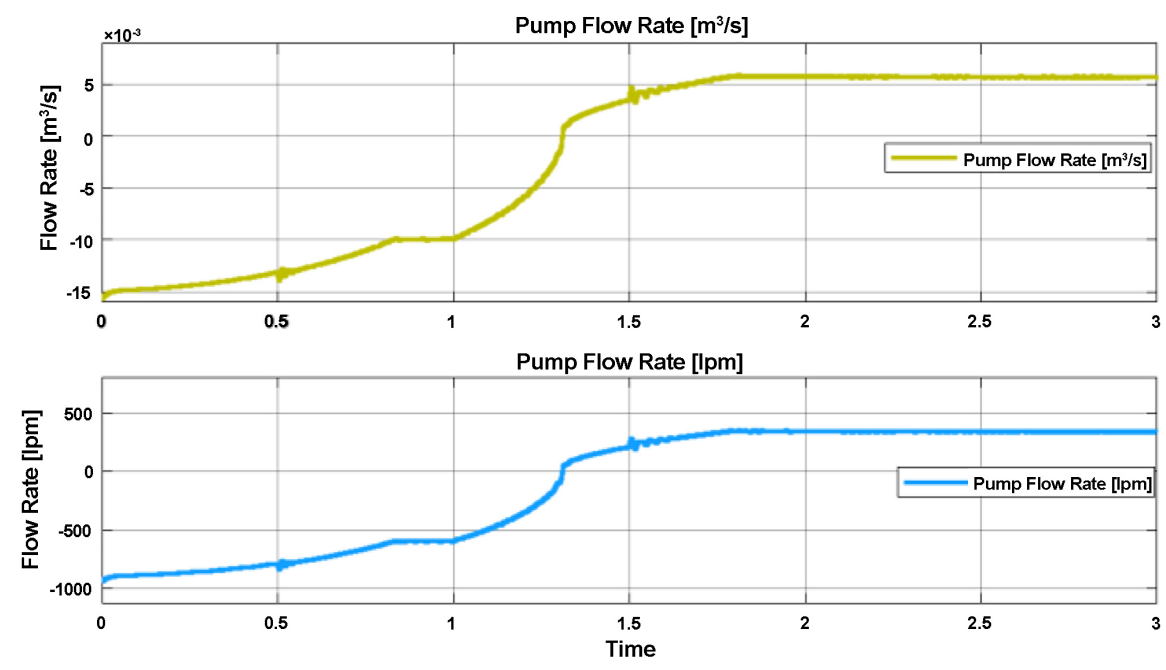

Figure 14. Pump flow rate without check valve in $\left(\mathrm{m}^{3} / \mathrm{s}\right)$ and $(\mathrm{lpm})$.

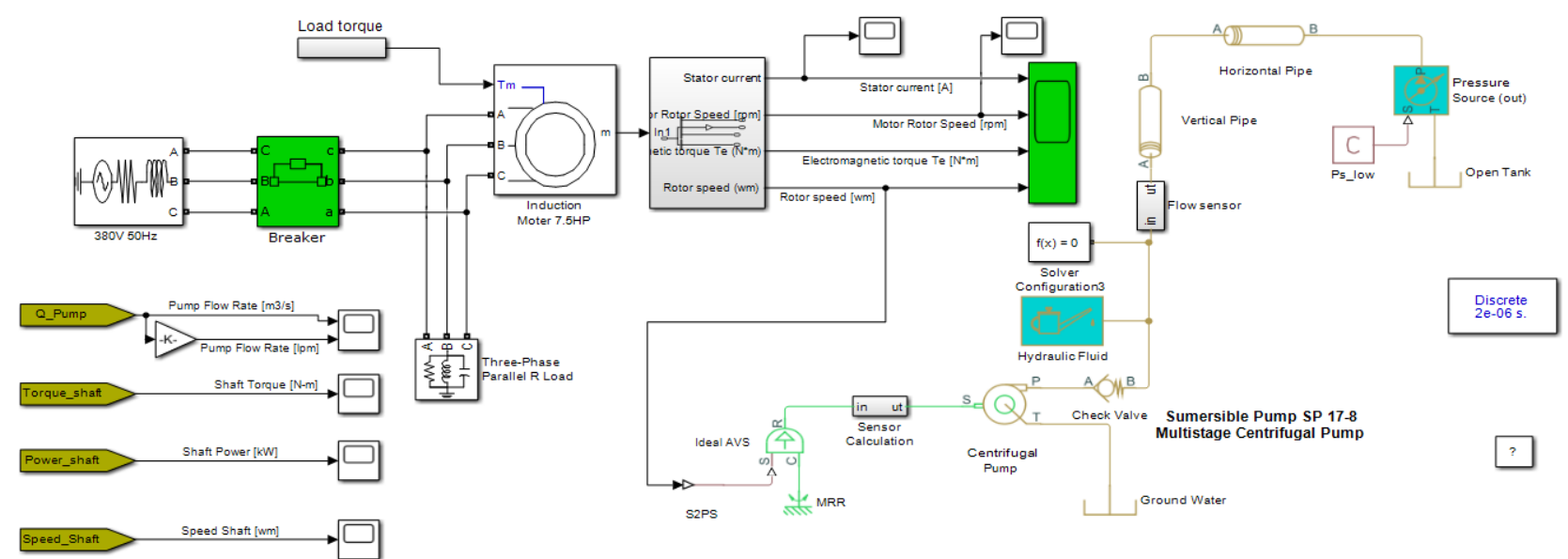

Figure 15. Model 2: MATLAB/Simulink complete model of induction motor without drive operated using ideal source.

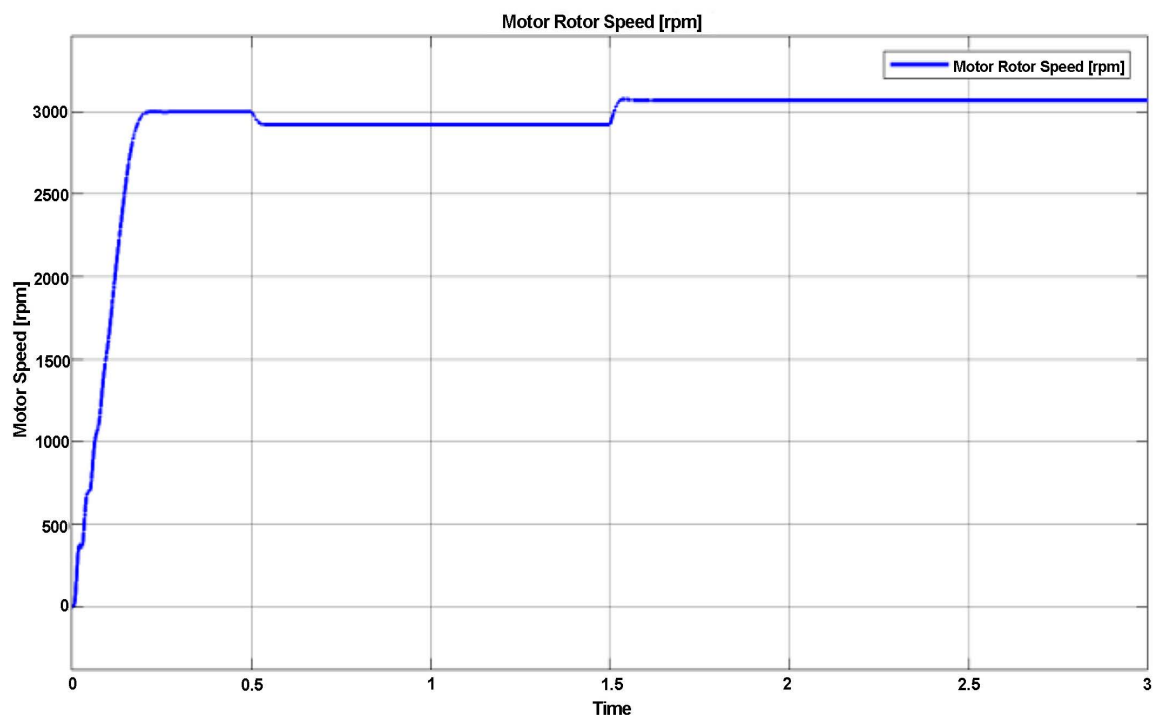

Figure 16. Rotor speed of motor. 


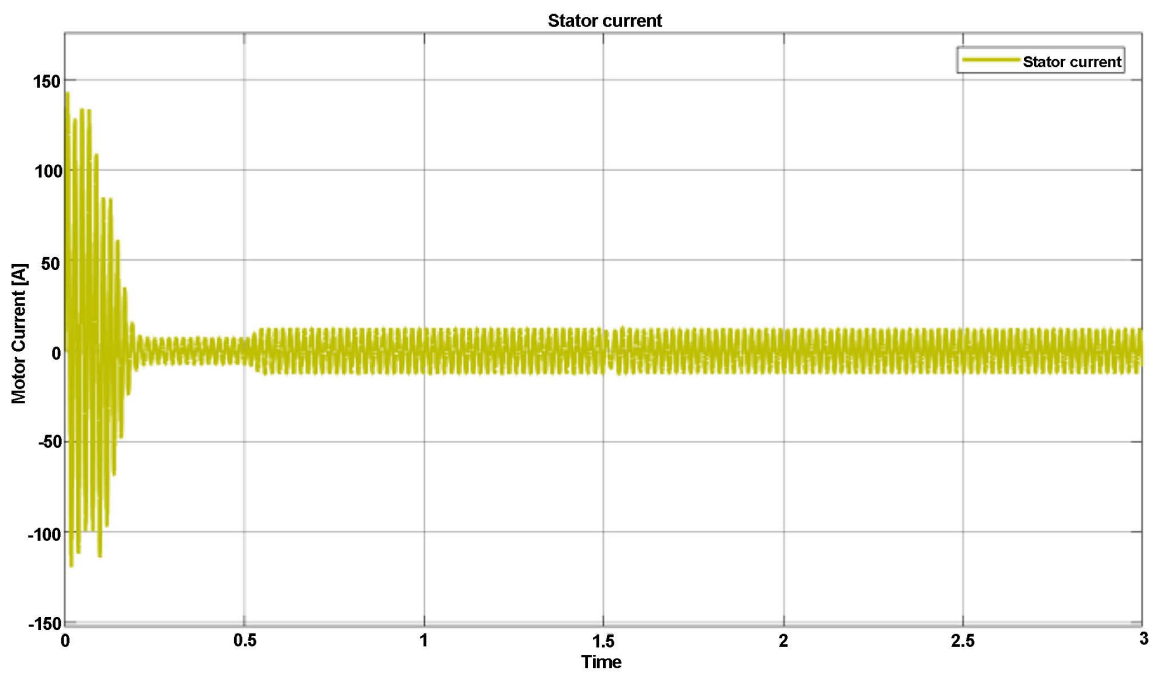

Figure 17. Stator motor current.

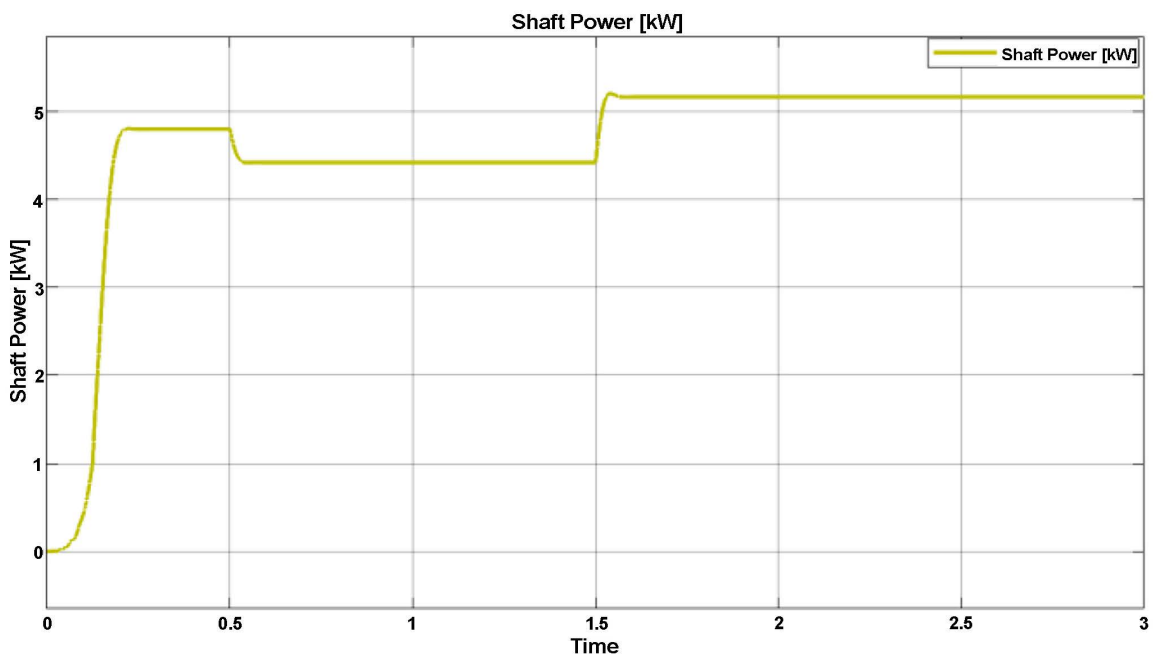

Figure 18. Shaft power of pump.

the figure. The total power of the shaft is $5.16 \mathrm{~kW}$. Figure 19 illustrates the shaft torque of the pump $[\mathrm{N}-\mathrm{m}]$ versus time, in sec. The results show the shaft power and adjusts its value accordingly. The total torque of the pump is calculated to be $14[\mathrm{~N}-\mathrm{m}]$ and then increased to $16[\mathrm{~N}-\mathrm{m}]$.

Figure 20 shows the pump flow rate in both cubic meter per sec and liter per minute. Both curves show that the pump starts to deliver the water after almost $0.12 \mathrm{sec}$, which is too fast. The pump flow rate is $5.35 \times 10^{-3}\left[\mathrm{~m}^{3} / \mathrm{sec}\right]$ and 320 [lpm], respectively, which then increases to $5.85 \times 10^{-3}\left[\mathrm{~m}^{3} / \mathrm{sec}\right]$ and $350[\mathrm{lpm}]$, which is slightly higher than the actual calculated value.

\subsection{Model 3: Induction Motor with Drive Operated Using PV System}

Figure 21 shows the system components of an induction motor with drive operated using a PV system. The PV system with the boost converter and IGBT inverter feed the induction motor with a PWM VSI drive. 


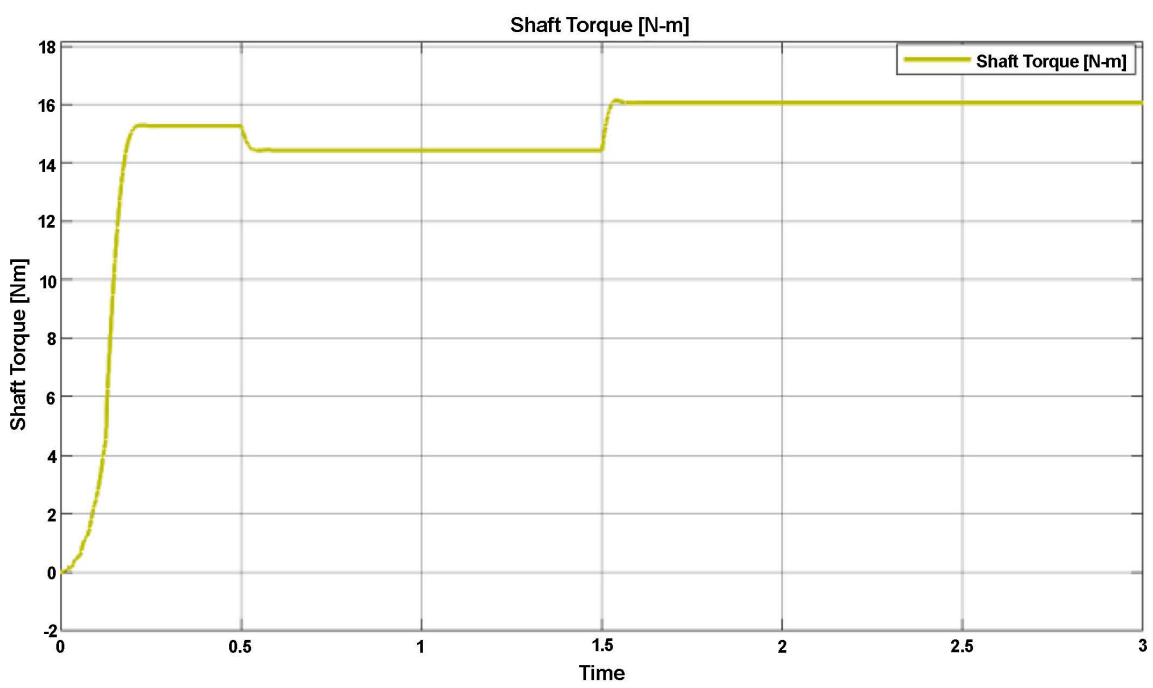

Figure 19. Shaft torque of pump.
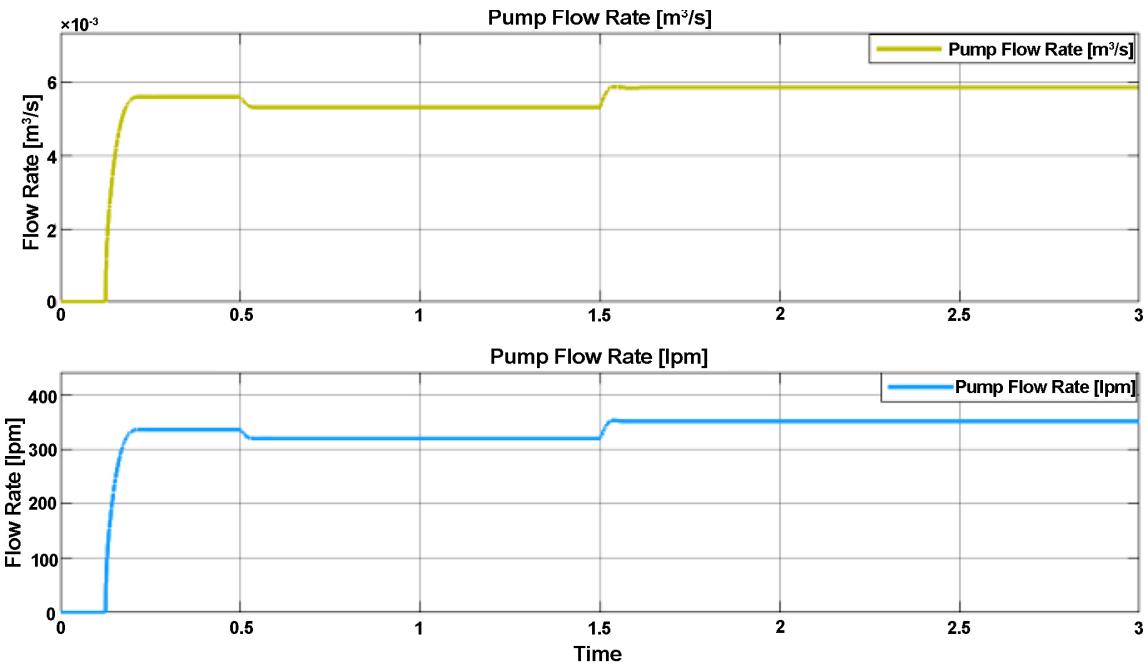

Figure 20. Pump flow rate in $\left[\mathrm{m}^{3} / \mathrm{s}\right]$ and $[\mathrm{lpm}]$.

\subsection{Results and Discussion: Model 3}

From the simulation of the dynamic system Model 3, the following results were found and plotted. The MPPT algorithm was used to obtain better power output from the PV system, as shown in Figure 22. Furthermore, the PV output voltage is around $350 \mathrm{~V}$ with different changes in solar radiation. From the figure, it can be seen that PV power could be $10.8 \mathrm{~kW}$ with $1000 \mathrm{~W} / \mathrm{m}^{2}$ but drops to $6.5 \mathrm{~kW}$ if irradiance decreases to $600 \mathrm{~W} / \mathrm{m}^{2}$. Figure 23 illustrates the angular velocity of the shaft $[\mathrm{rad} / \mathrm{sec}]$ versus the pump speed $[\mathrm{rad} / \mathrm{sec}]$ and the reference speed of the motor. From the figure, it can be seen that the motor speed stabilizes at 150 $[\mathrm{rad} / \mathrm{sec}]$ and slightly over $300[\mathrm{rad} / \mathrm{sec}]$.

Figure 24 demonstrates a one-phase stator motor current [A] over three seconds. From the figure, it can be seen that the motor speed causes the current to change until it reaches a steady-state current, at which point it then decreases to around $12.62 \mathrm{~A}$. 


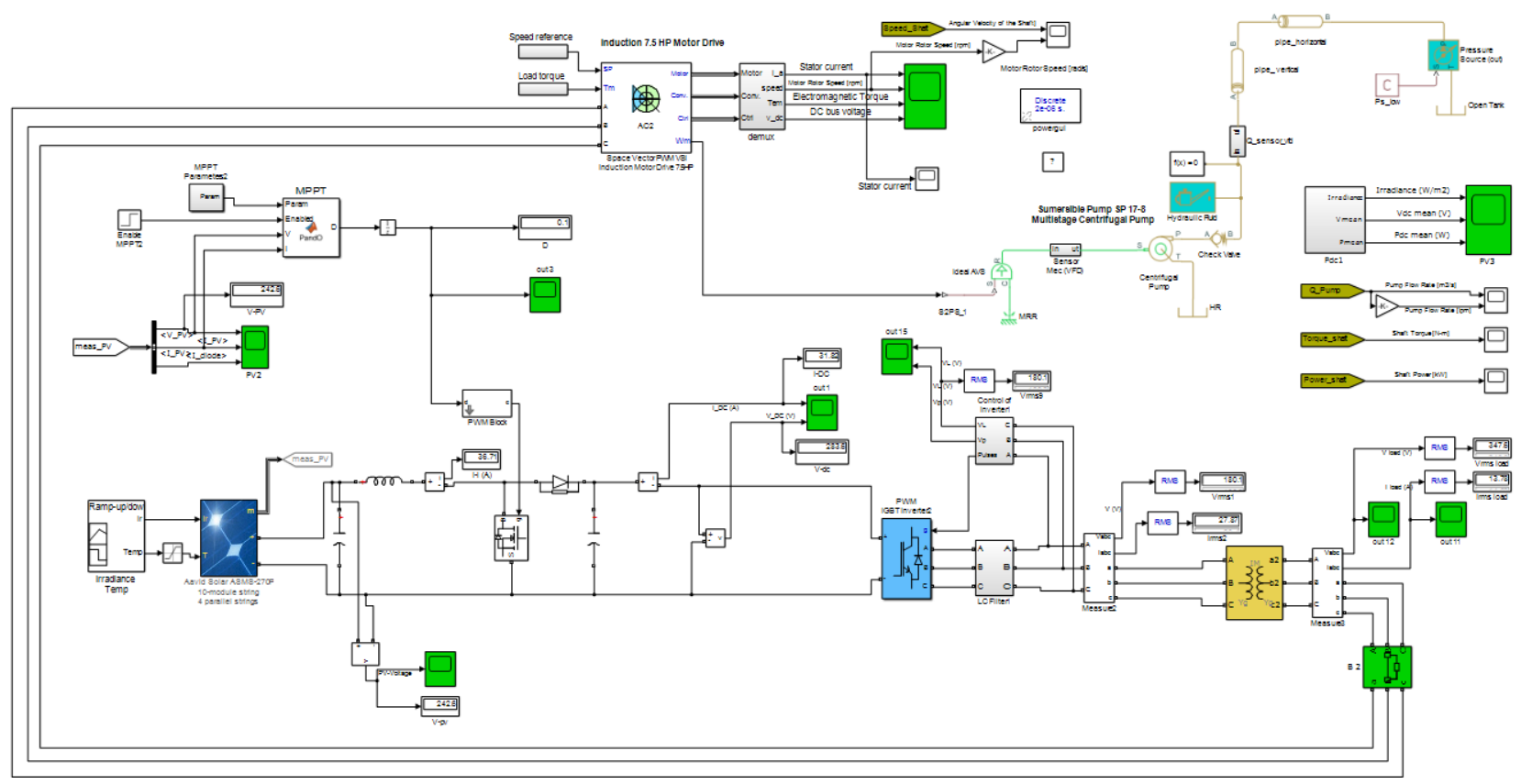

Figure 21. Model 3: Complete model of induction motor with drive operated using PV system.
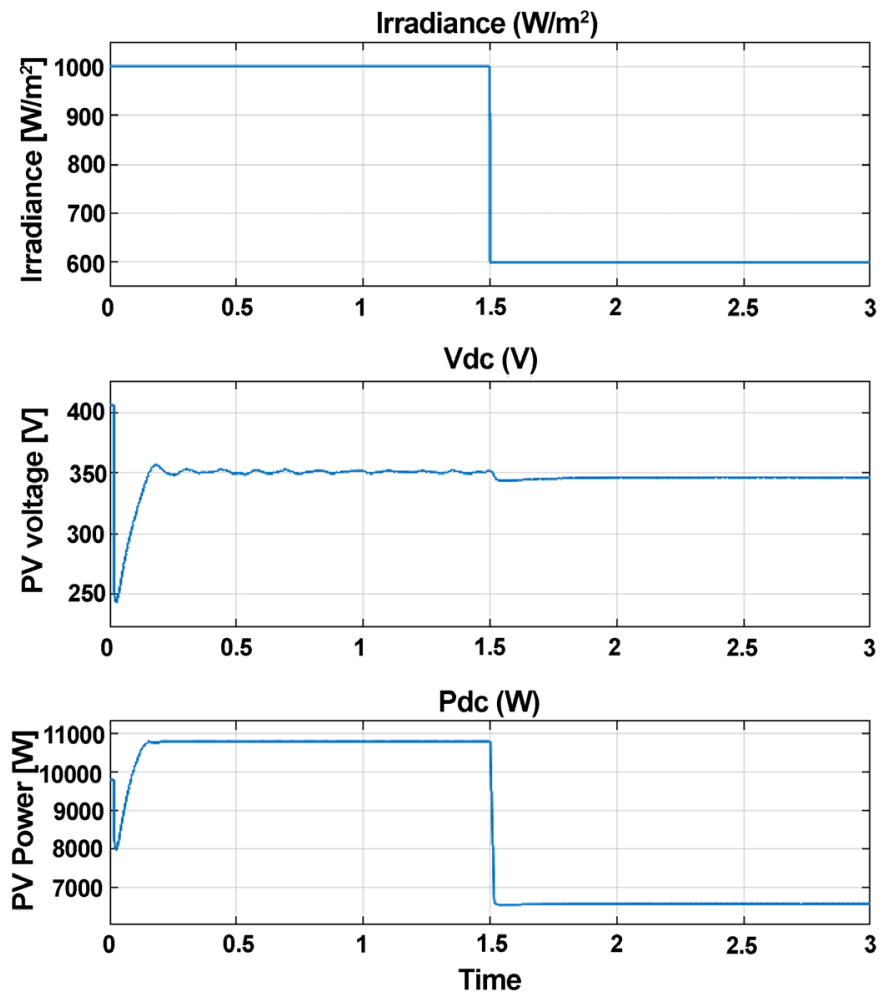

Figure 22. PV irradiance, DC voltage and power.

Figure 25 shows the shaft power of the pump [kW] versus time [sec]. The shaft power of the pump gives the same results as the motor speed, as shown in the figure. The total power of the shaft is $4.5 \mathrm{~kW}$. Figure 26 illustrates the shaft torque of the pump $[\mathrm{N}-\mathrm{m}]$ versus time, in sec. The results show the shaft power 

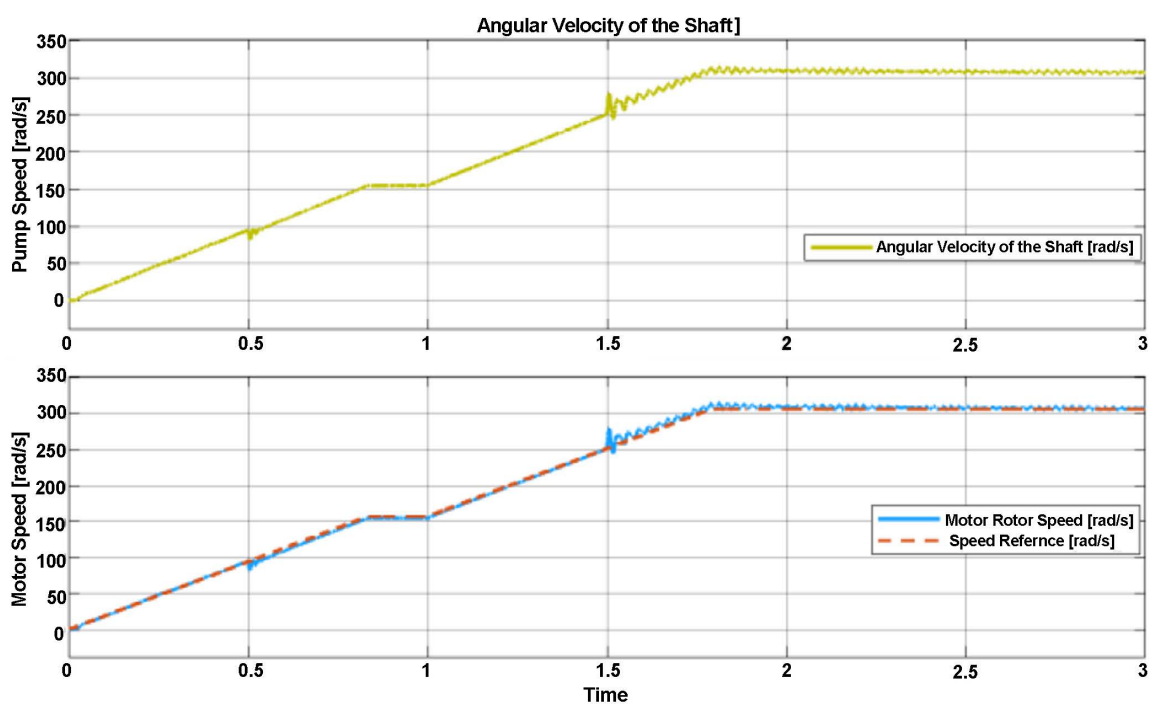

Figure 23. Angular velocity of shaft.

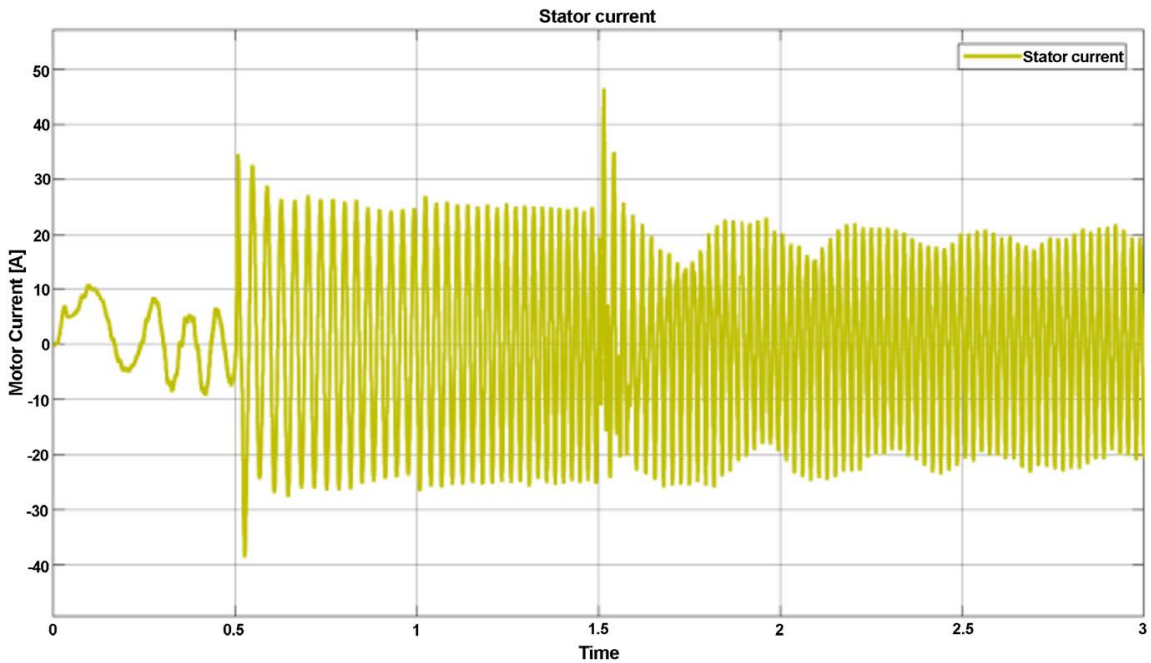

Figure 24. Stator motor current.

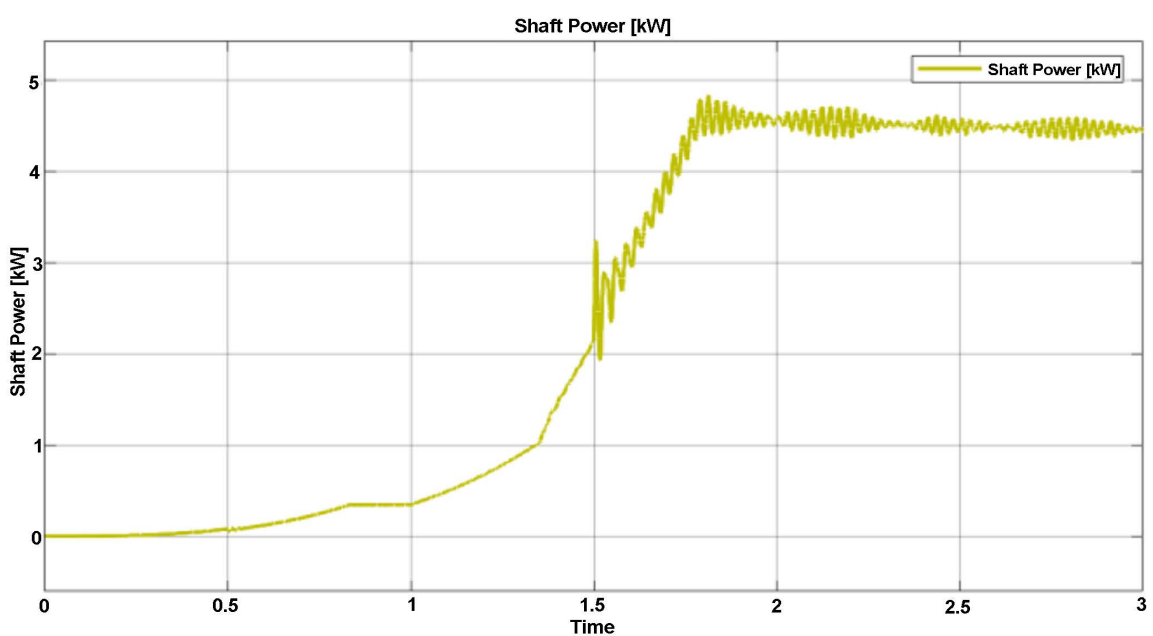

Figure 25. Shaft power of pump. 


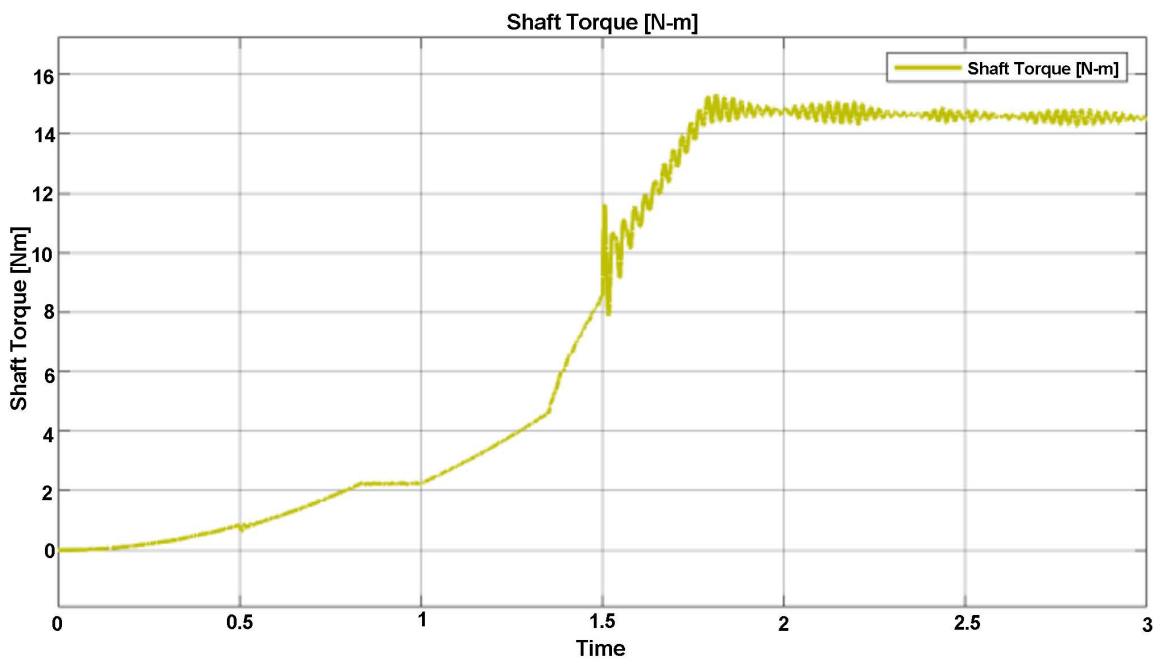

Figure 26. Shaft torque of pump.

and adjusts its value accordingly. The total torque of the pump is 15 [N-m], which then decreases to 14.5 [N-m].

Figure 27 shows the pump flow rate in both cubic meter per sec and liter per minute. Both curves show the pump starts to deliver the water after almost 1.35 sec. It can be seen that the pump flow rate is $5.4 \times 10^{-3}\left[\mathrm{~m}^{3} / \mathrm{sec}\right]$ and $325[\mathrm{lpm}]$, respectively, which is slightly higher than the actual calculated value.

Figure 28 shows a load's (motor's) three-phase output voltage. It is obvious that the voltage waves are smooth and stable around $350 \mathrm{~V}$, which is lower than the desired voltage. Furthermore, in Figure 29, the original three-phase load current is stable and reduces to $16 \mathrm{~A}$ after $1.5 \mathrm{sec}$.

Figure 30 shows the output line and phase voltages of the IGBT inverter as a function of time, in sec. The phase voltage is $158 \mathrm{~V}$, which again is less than the desirable value. As a result, a transformer is needed to increase the voltage to the calculated value.

Figure 31 shows the DC output voltage and current of the boost converter versus time, in sec. The DC voltage is stable around $400 \mathrm{~V}$. The same behavior is shown in the current curve, where it was stabilized at between 20 and $30 \mathrm{~A}$.

\subsection{Model 4: Induction Motor without Drive Operated Using PV System}

In this model, the induction motor has been used without a drive to initiate the pump. The high value of resistance has to be connected in parallel with the transformer to make the simulation run, as shown in Figure 32. From this figure, the system components of the induction motor operated using a PV system can be seen. The PV system with the boost converter and IGBT inverter are feeding the induction motor which operates the pump.

\subsection{Results and Discussion: Model 4}

The following results were calculated and plotted based on the simulation of the dynamic system for Model 4. Figure 33 shows three fundamental functions. 

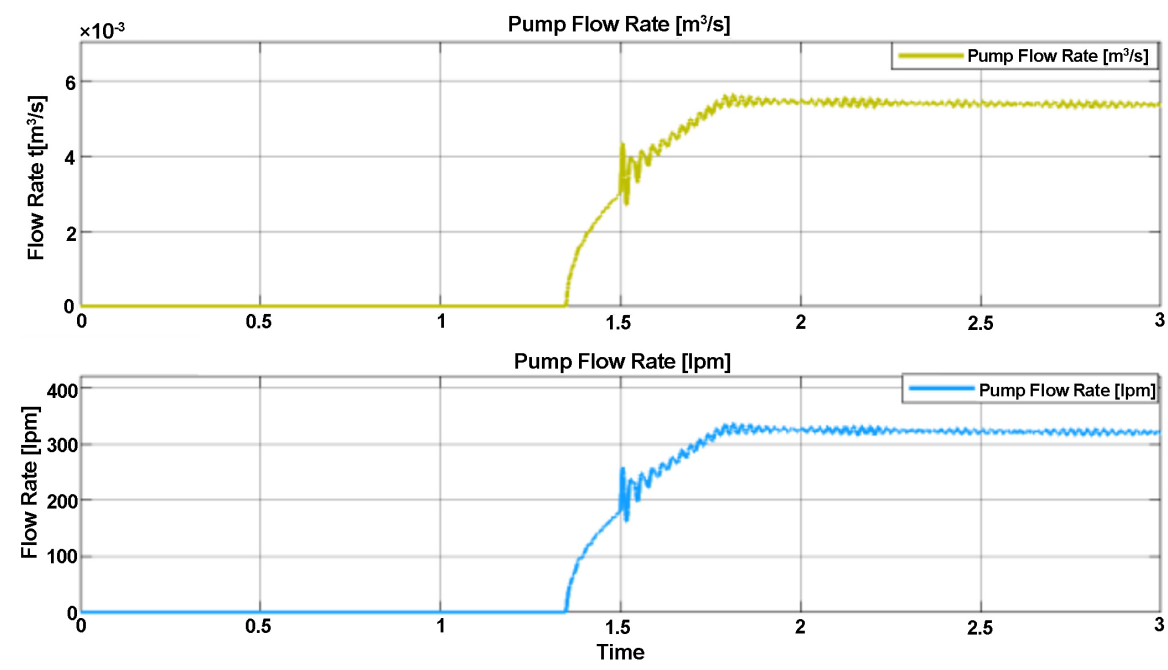

Figure 27. Pump flow rate in $\left[\mathrm{m}^{3} / \mathrm{s}\right]$ and $[\mathrm{lpm}]$.

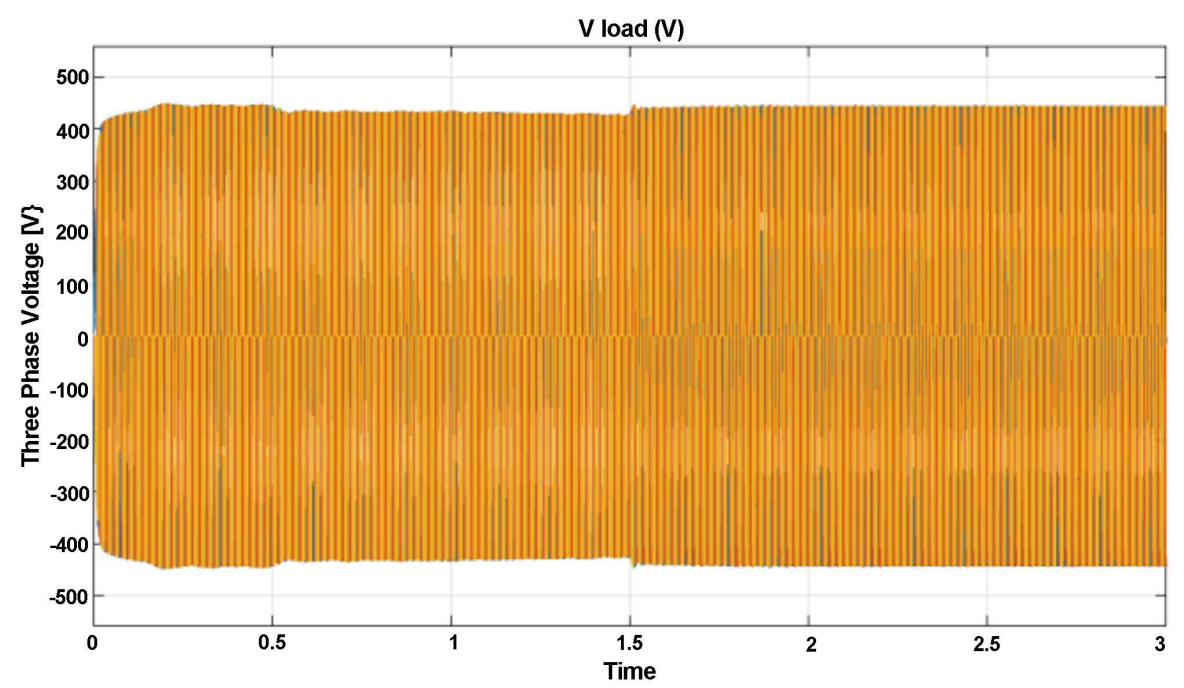

Figure 28. Load three-phase voltage.

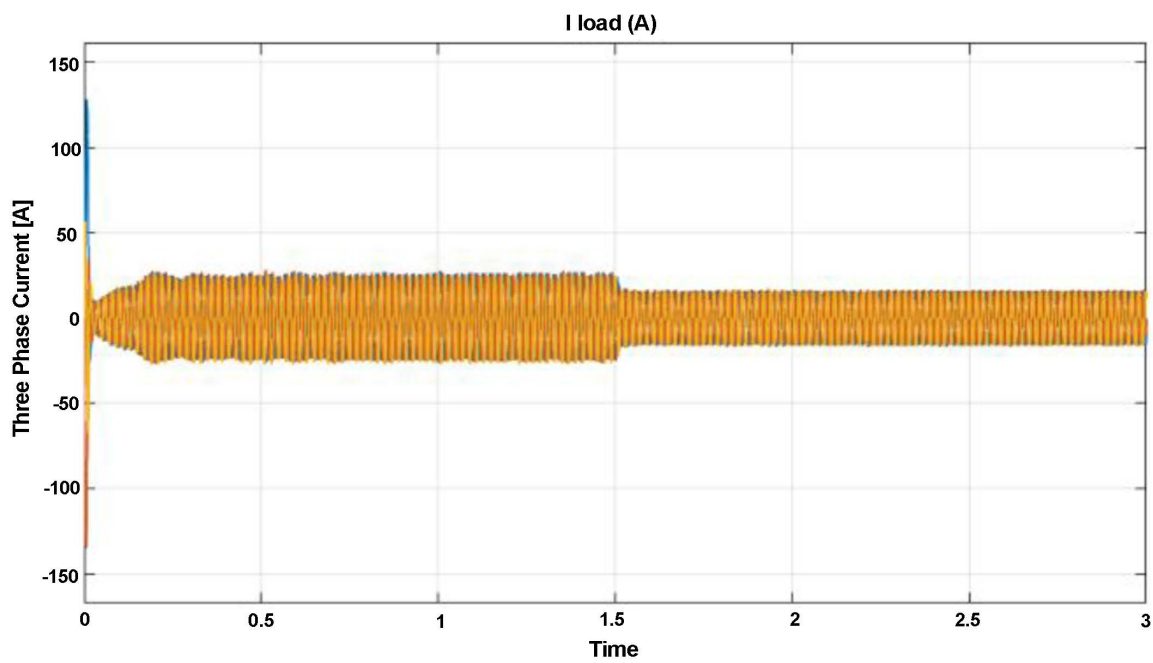

Figure 29. Load three-phase current. 

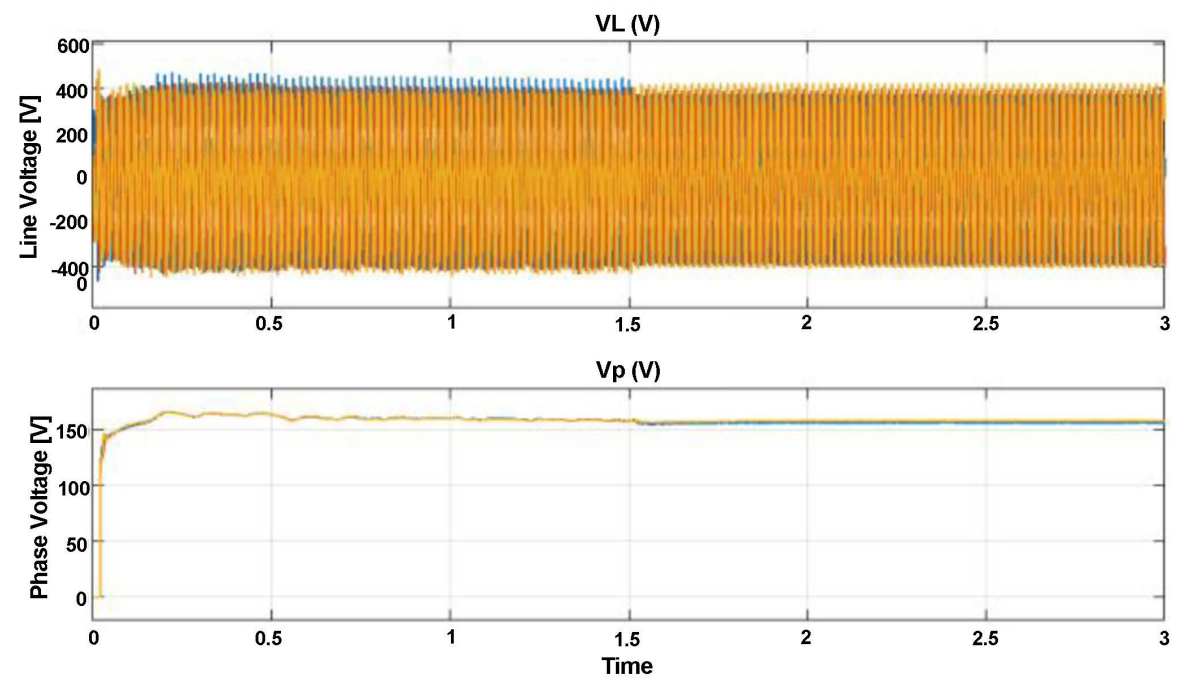

Figure 30. Output line and phase voltage of invertor.
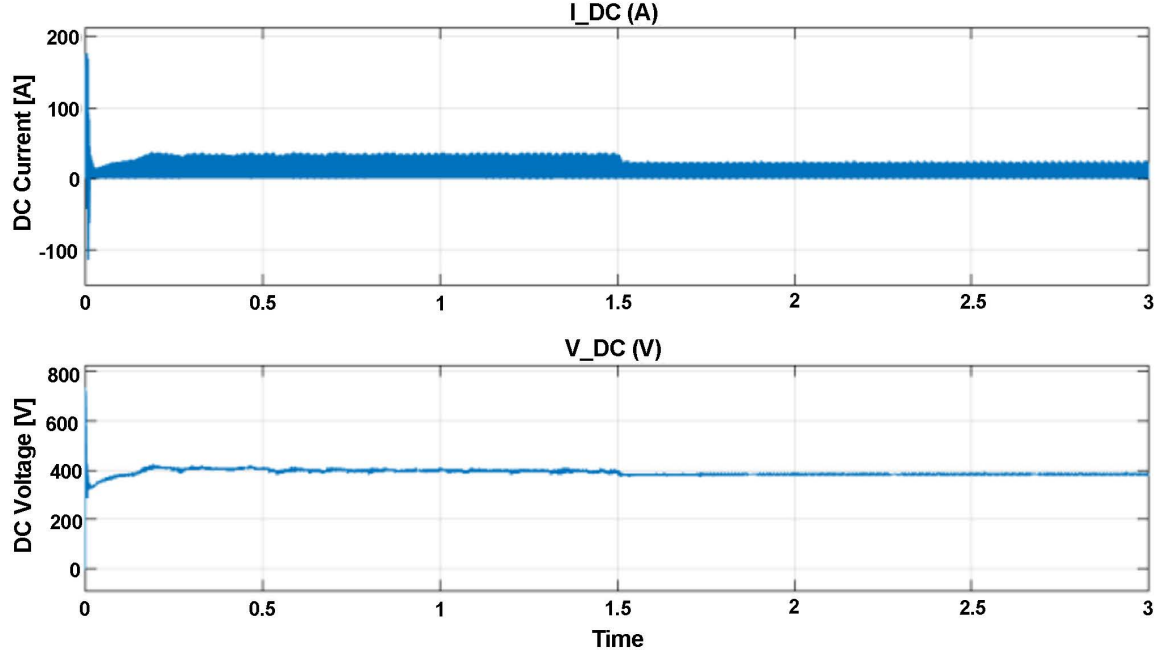

Figure 31. DC output voltage and current of boost convertor.

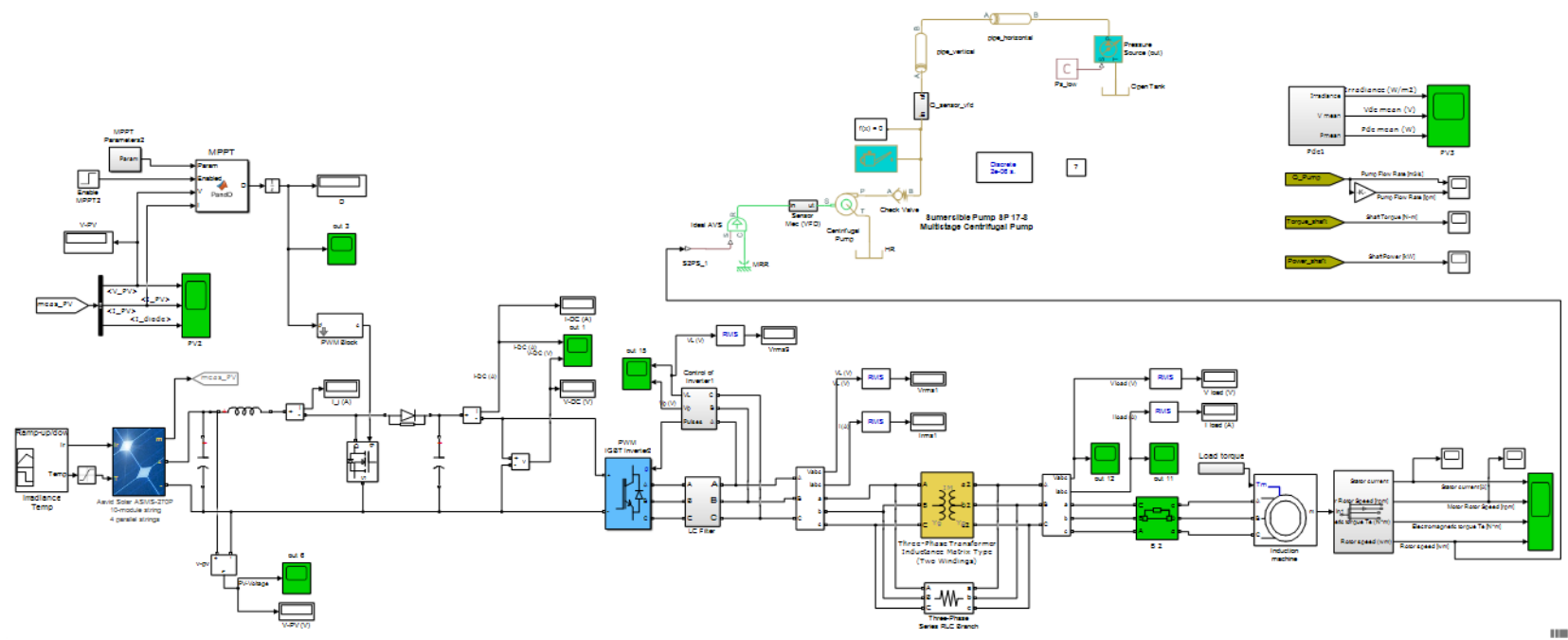

Figure 32. Model 4 MATLAB/Simulink complete model of induction motor without drive operated PV system. 

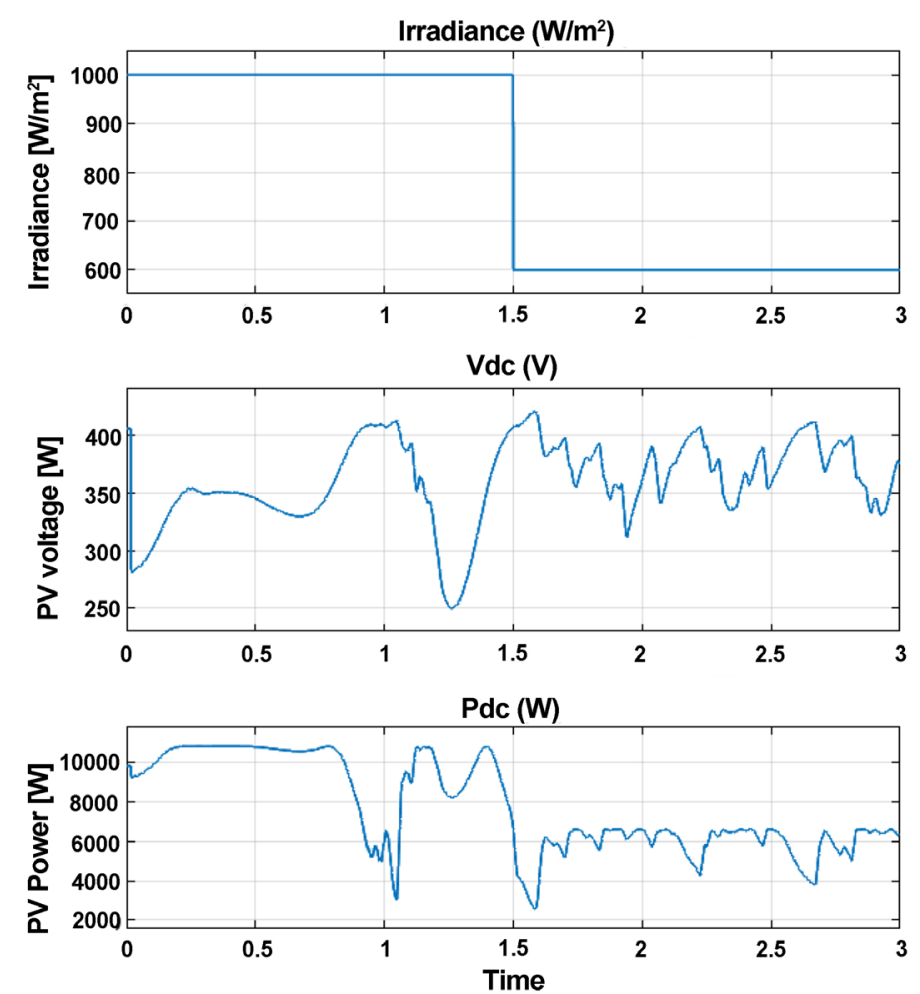

Figure 33. PV irradiance, DC voltage and power.

First, the output power of the PV array was not as stable as that in Model 3. At an irradiance of $1000 \mathrm{~W} / \mathrm{m}^{2}$, the PV output power was around $10.5 \mathrm{~kW}$. However, at around $1 \mathrm{sec}$, it dropped sharply to $3.5 \mathrm{~kW}$, and when the irradiance reduced to $600 \mathrm{~W} / \mathrm{m}^{2}$, the PV output power fluctuated around $6 \mathrm{~kW}$. Moreover, at an irradiance of $1000 \mathrm{~W} / \mathrm{m}^{2}$, the PV voltage was unstable, fluctuating in a wide range between 250 to $425 \mathrm{~V}$, whereas the PV voltage was in range of 350 to 400 $\mathrm{V}$ when the irradiation was $600 \mathrm{~W} / \mathrm{m}^{2}$. Figure 34 explains the motor rotor speed [rpm] over three seconds. From the figure, it can be seen that the motor speed varied around $3000[\mathrm{rpm}]$ and was not stable.

Figure 35 shows a one-phase current of the stator motor current $[\mathrm{A}]$ over a time of three seconds. It can be seen that the motor speed causes the single current to keep changing, especially after $1.5 \mathrm{sec}$, where the current fluctuates in a range of 12 to $100 \mathrm{~A}$. The change in the current is due to the change in the voltage, as presented in Figure 36. As can be seen, this is caused by the change in the three-phase output voltage.

Furthermore, Figure 37 shows the original three-phase motor current, which the same behavior as that has shown in Figure 35. Figure 38 shows the output line and phase voltages of the inverter, and it also shows the same behavior as the previous figures. Thus, figures $35,36,37$, and 38 explain how the system is unstable, especially after $1.5 \mathrm{sec}$. The reason is the sudden change in the solar radiation from 1000 to $600 \mathrm{~W} / \mathrm{m}^{2}$, which causes a shortage in the power to operate the system appropriately. 


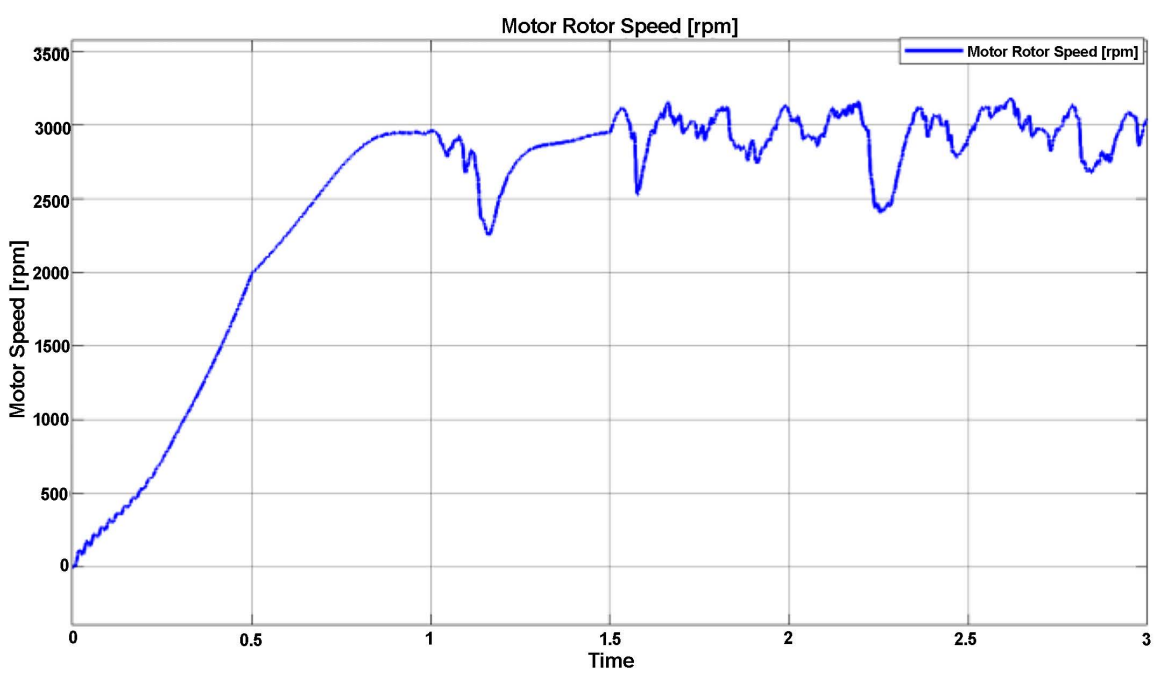

Figure 34. Rotor speed of motor.

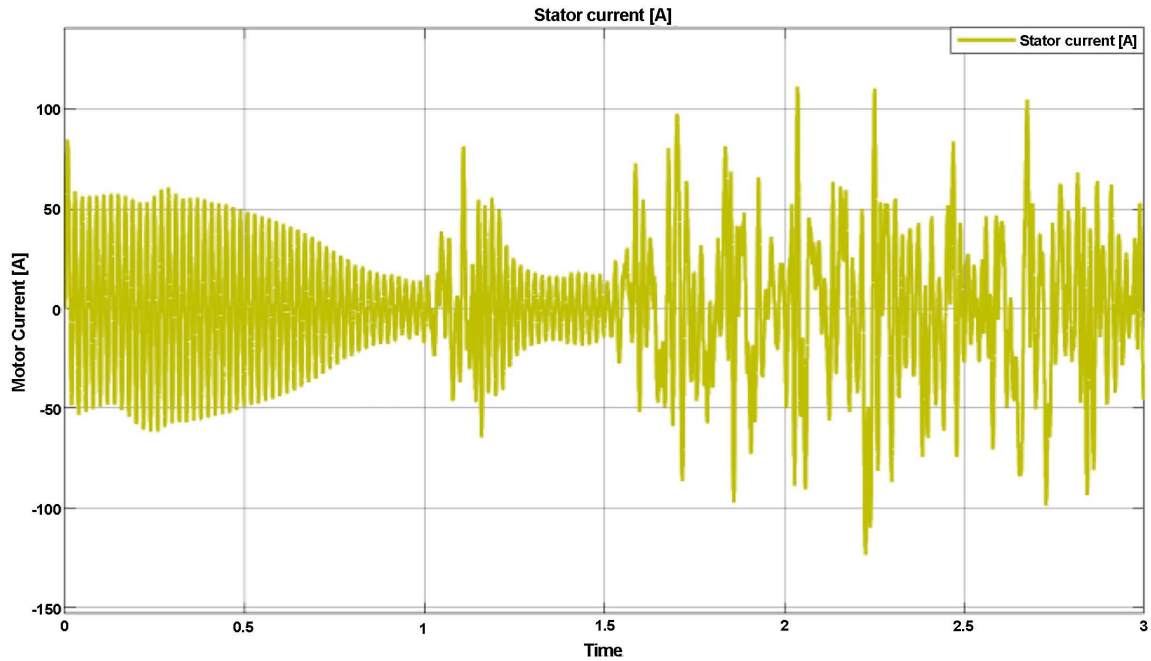

Figure 35. Stator motor current.

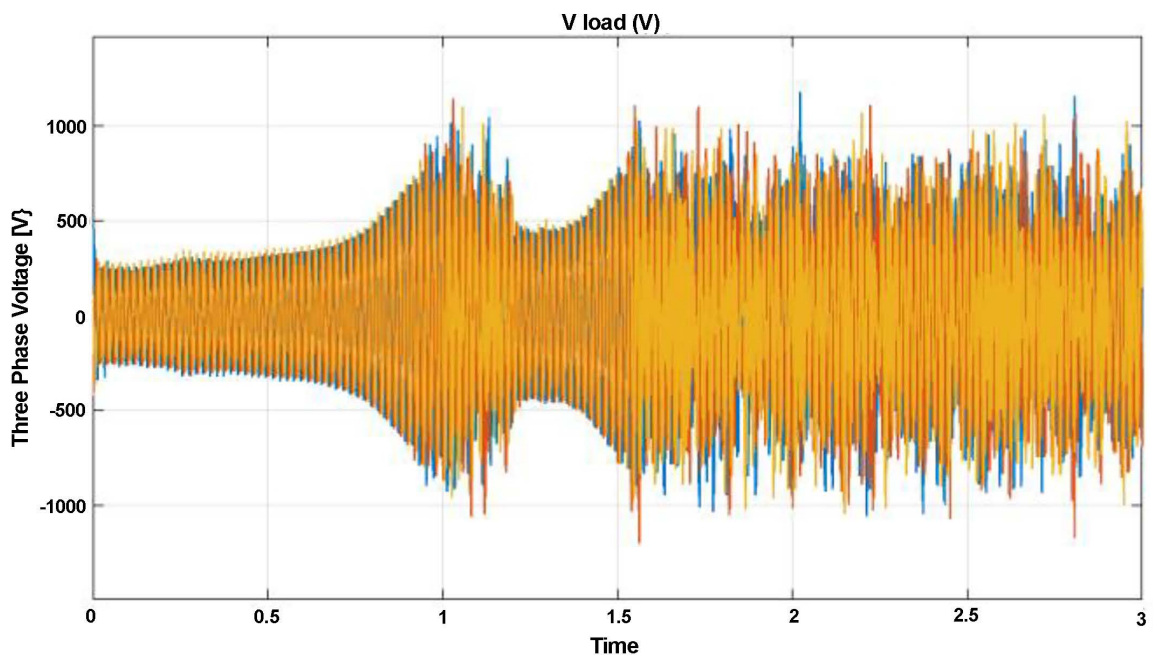

Figure 36. Load of three-phase voltage. 


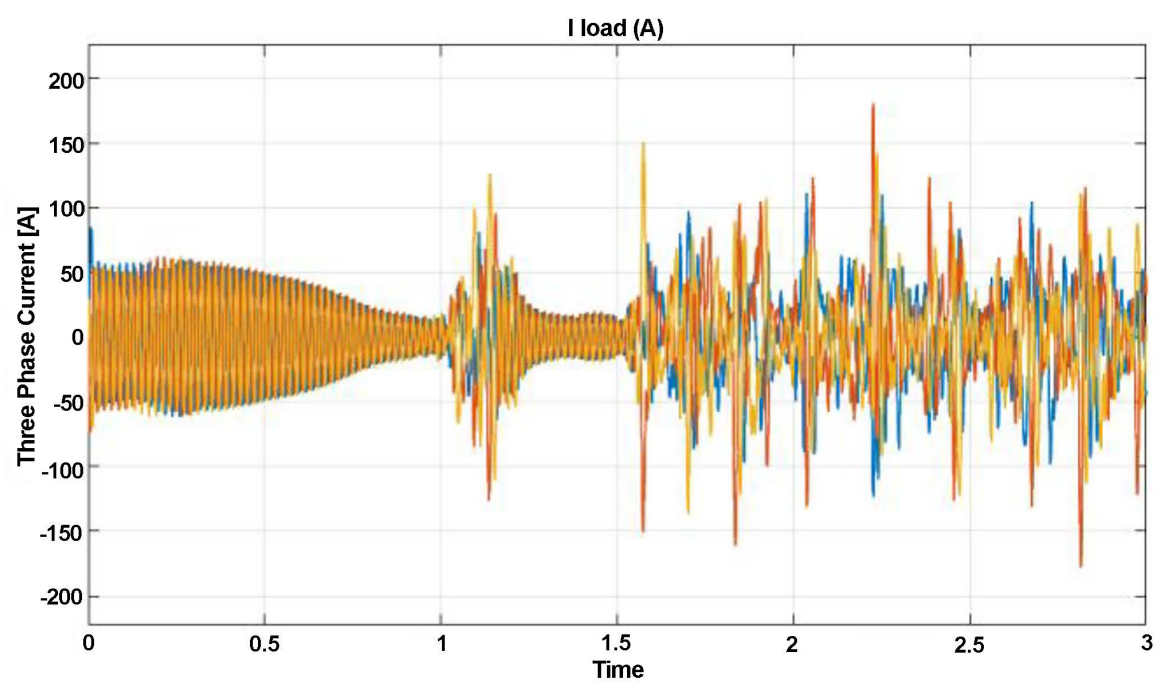

Figure 37. Load of three-phase current.
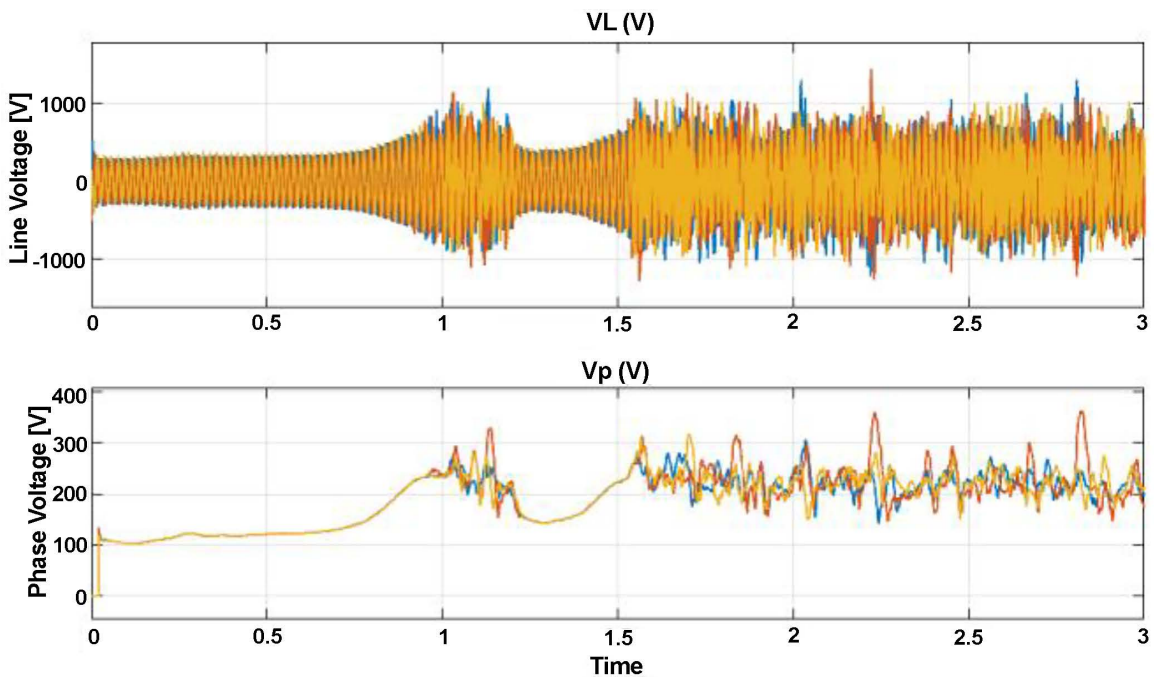

Figure 38. Output line and phase voltage of inverter.

Figure 39 shows the shaft power of the pump [kW] against time [sec]. The shaft power of the pump gives the same results as the motor speed, as shown in Figure 34. The power curve of the shaft fluctuates between 3 and $5.5 \mathrm{~kW}$. Figure 40 demonstrates the shaft torque of the pump $[\mathrm{N}-\mathrm{m}]$ versus time, in sec. The results show the shaft power and adjusts its value accordingly. The total torque of the pump according to the figure ranges between 12 and 17 [N-m].

Figure 41 shows the pump flow rate in cubic meters per sec as well as in liters per minute. Both curves display that the pump starts to deliver the water after $0.55 \mathrm{sec}$. It can be seen that the pump's maximum flow rate is $6 \times 10^{-3}\left[\mathrm{~m}^{3} / \mathrm{sec}\right]$ and 364 [lpm], respectively, which exceeds the actual calculated value.

Figure 42 shows the DC output voltage and current of the boost converter versus time, in sec. The DC voltage before 1.5 was about $400 \mathrm{~V}$, while after the drop in radiation it fluctuated between 1500 and $500 \mathrm{~V}$. The same behavior appears in the current curve, which becomes unstable after $1.5 \mathrm{sec}$. 


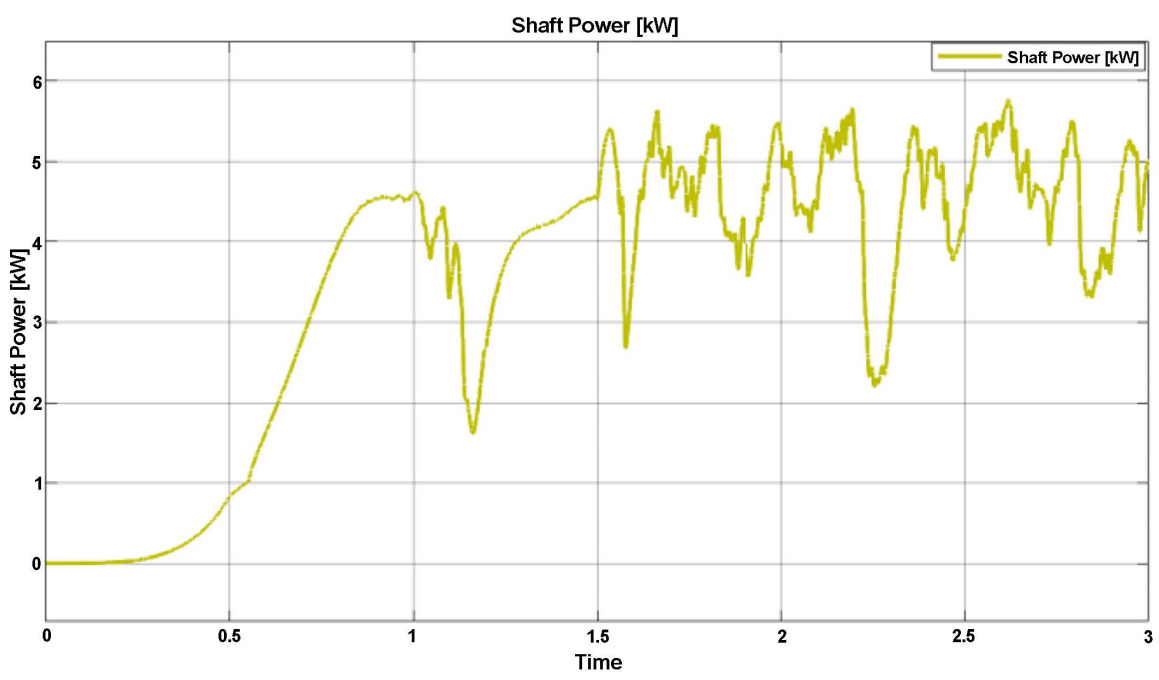

Figure 39. Shaft power of pump.

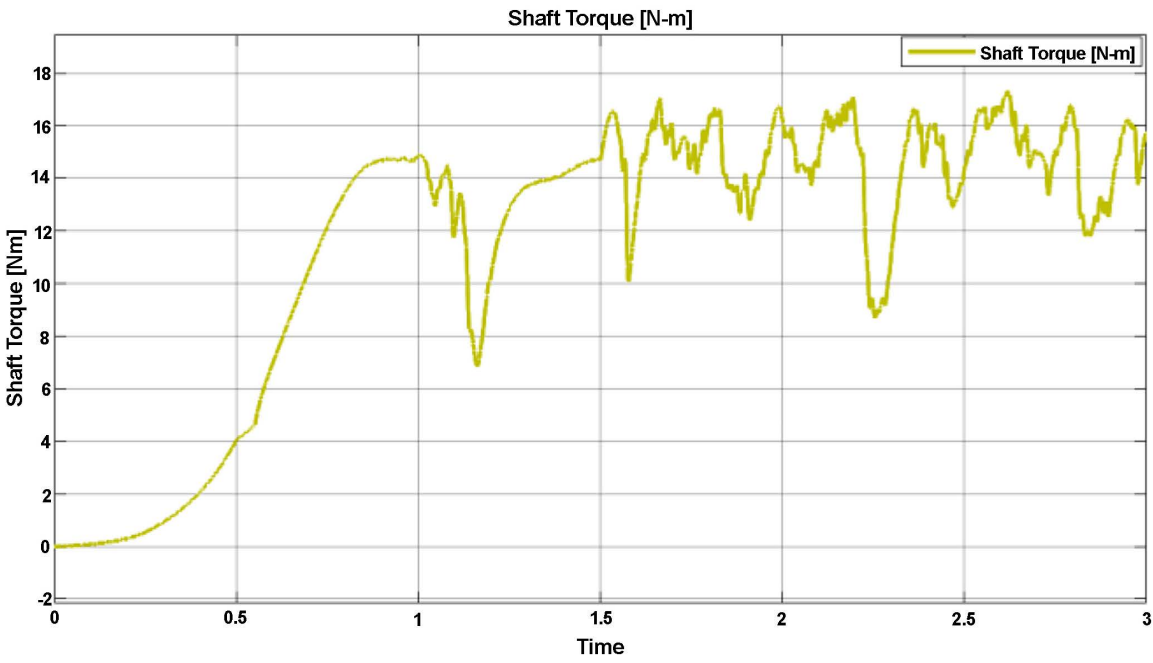

Figure 40. Shaft torque of pump.
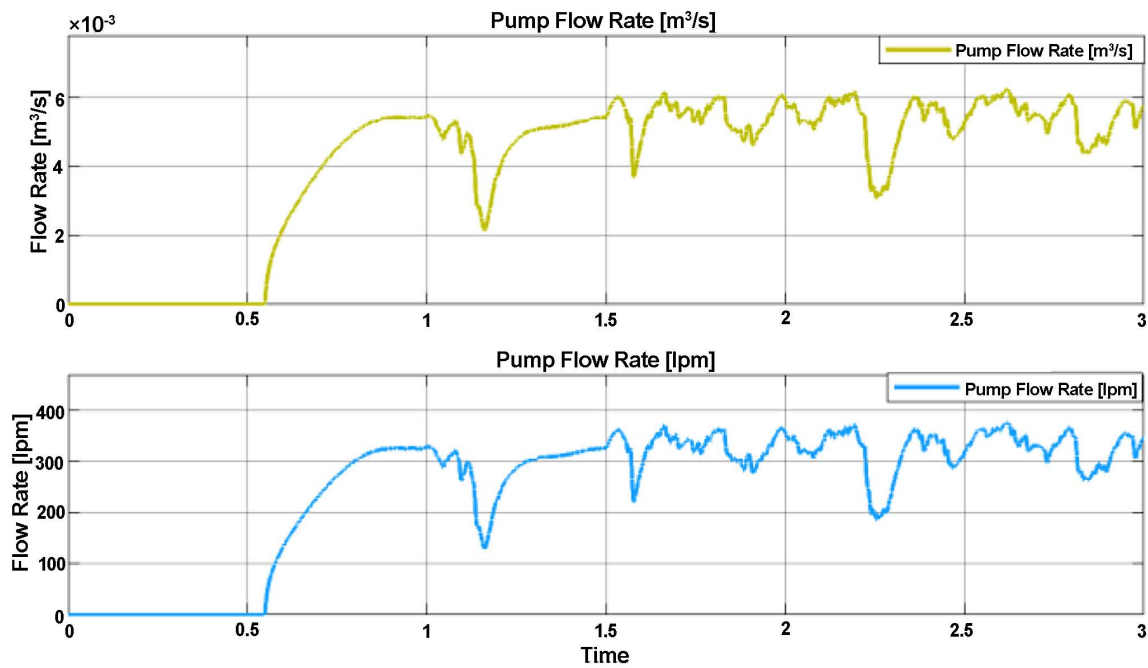

Figure 41. Pump flow rate in $\left[\mathrm{m}^{3} / \mathrm{s}\right]$ and $[\mathrm{lpm}]$. 

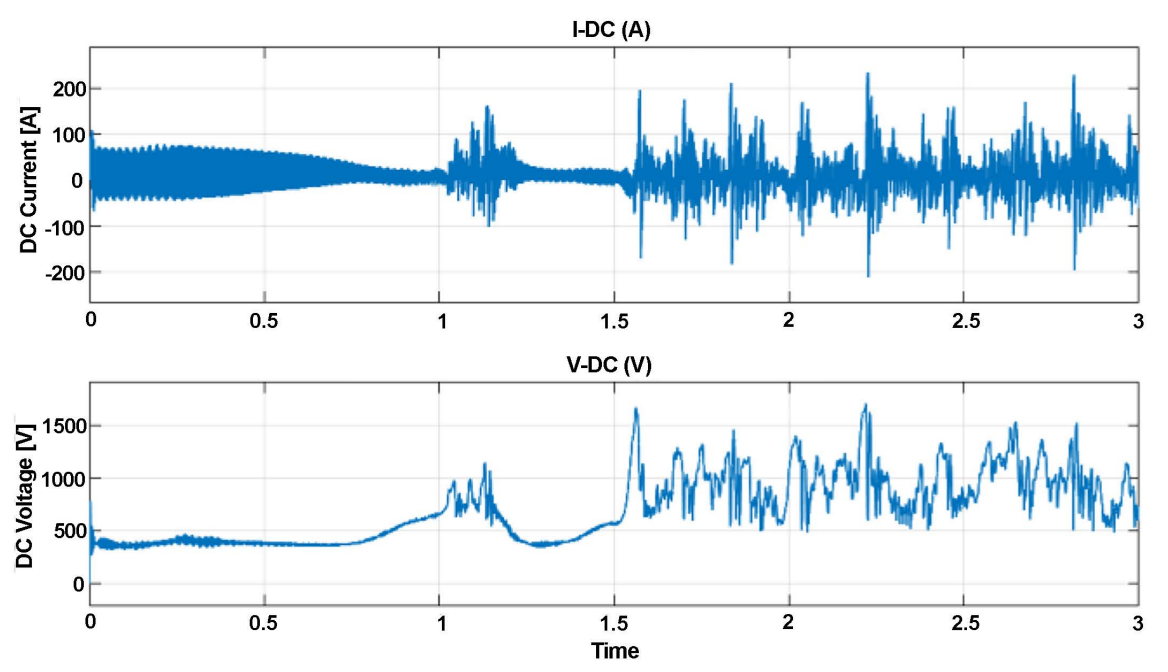

Figure 42. DC output voltage and current of boost converter.

\subsection{Model 5: Induction Motor with Drive Operated Using a PV System with a Battery Bank}

Figure 43 shows the system components of an induction motor with a drive operated using a PV system and a battery bank. The model is similar to Model 3, except a battery has been added to the system. The reason for adding the battery is to stabilize the voltage source and to have a pick-up unit to restore the operating energy. The PV system with the boost converter, the battery bank, and IGBT inverter are feeding the induction motor with a PWM VSI drive.

\subsection{Results and Discussion: Model 5}

The following results were intended and plotted based on the simulation of the dynamic system Model 5. Figure 44 shows the output power of the PV array remained stable at both radiation levels. At an irradiance of $1000 \mathrm{~W} / \mathrm{m}^{2}$, the PV output power was around $10.5 \mathrm{~kW}$, and at an irradiance of $600 \mathrm{~W} / \mathrm{m}^{2}$, the power dropped sharply to $6.5 \mathrm{~kW}$. Moreover, at both irradiance levels, the PV voltage was stable at around $325 \mathrm{~V}$. Figure 45 illustrates the angular velocity of the shaft $[\mathrm{rad} / \mathrm{sec}]$ versus the pump speed $[\mathrm{rad} / \mathrm{sec}]$ and the reference speed of the motor. From the figure, it is observed that the motor speed has the same behavior as Model 3, stabilizing at $150[\mathrm{rad} / \mathrm{sec}]$ and then around $300[\mathrm{rad} / \mathrm{sec}]$.

Figure 46 reveals a one-phase stator motor current [A] over three seconds, while Figure 47 shows a three-phase load current stabilized at around $23 \mathrm{~A}$. From Figure 46, we can see that the motor speed causes the motor current to reach a steady state current of around $12.85 \mathrm{~A}$.

Figure 48 shows the load (motor) of a three-phase output voltage. The results indicate that the voltage waves are smooth and stable around $380 \mathrm{~V}$, which is exactly consistent with the desired voltage. Furthermore, Figure 49 shows the output line and phase voltages of the IGBT inverter as a function of time, in sec. The phase voltage is $148 \mathrm{~V}$, which again is less than the desired value. Consequently, a transformer is needed to increase the voltage to the calculated value. 


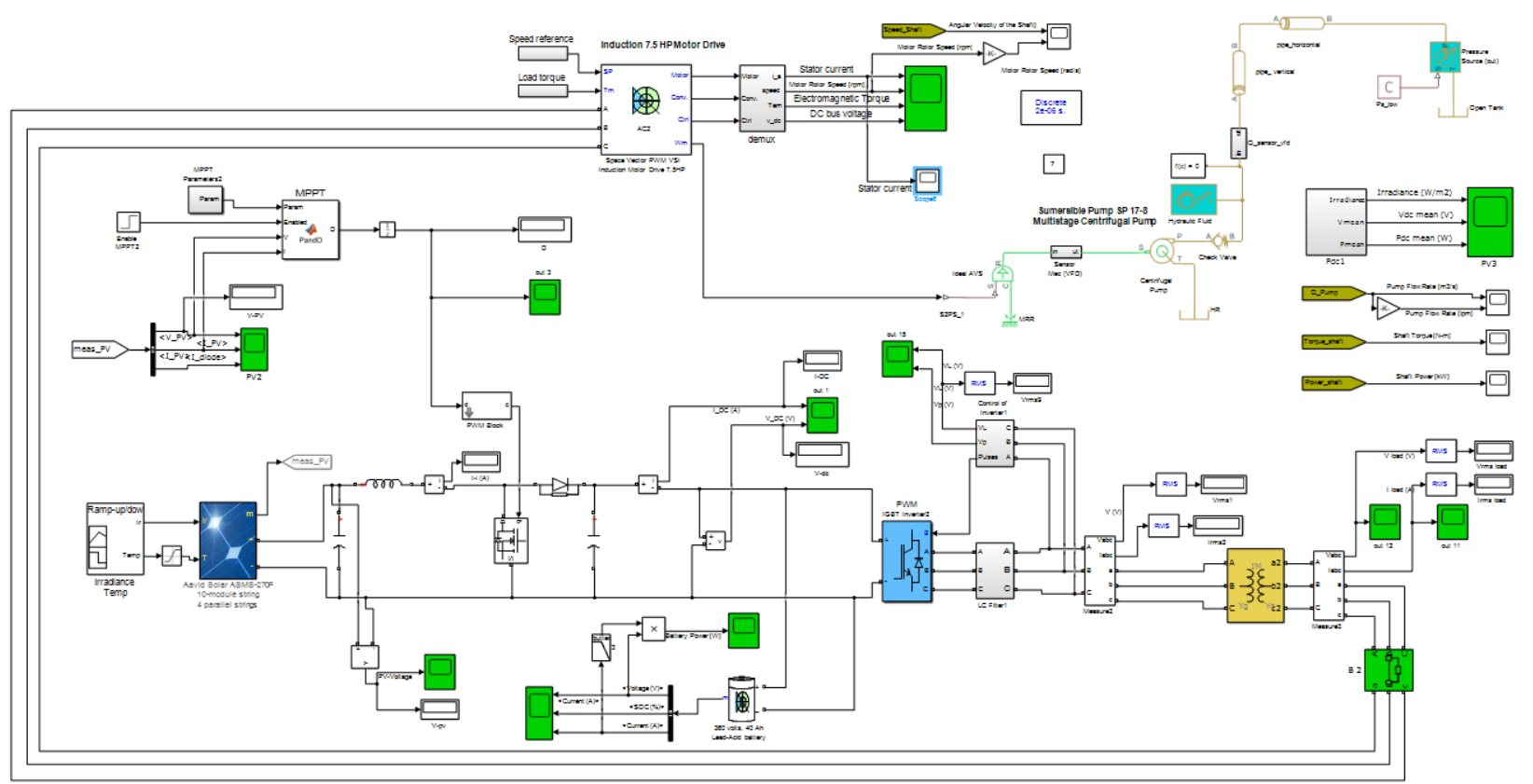

Figure 43. Model 5: Complete model of induction motor with drive operated using PV system with battery bank.
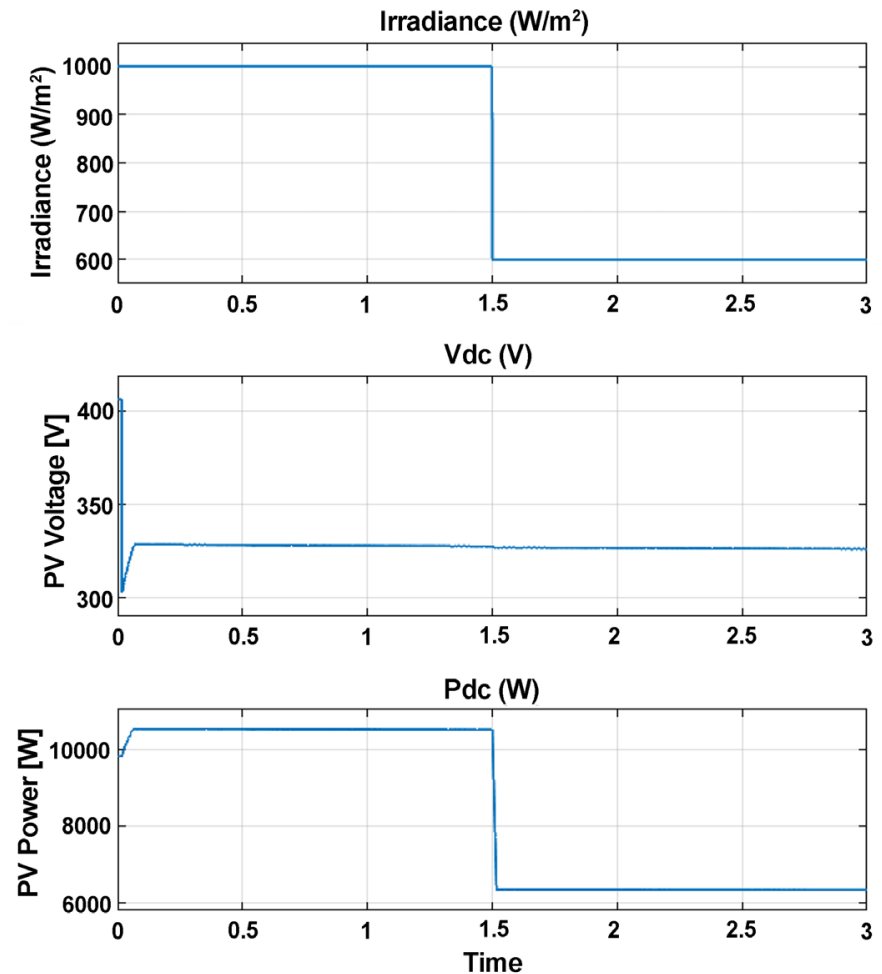

Figure 44. PV irradiance, DC voltage and power.

Figure 50 shows the shaft power of the pump [kW] versus time [sec]. The shaft power of the pump gives the same results as the motor speed, as shown in the figure. The total power of the shaft is $4.4 \mathrm{~kW}$. Moreover, Figure 51 shows the shaft torque of the pump $[\mathrm{N}-\mathrm{m}]$ versus time, in sec. The results present the 

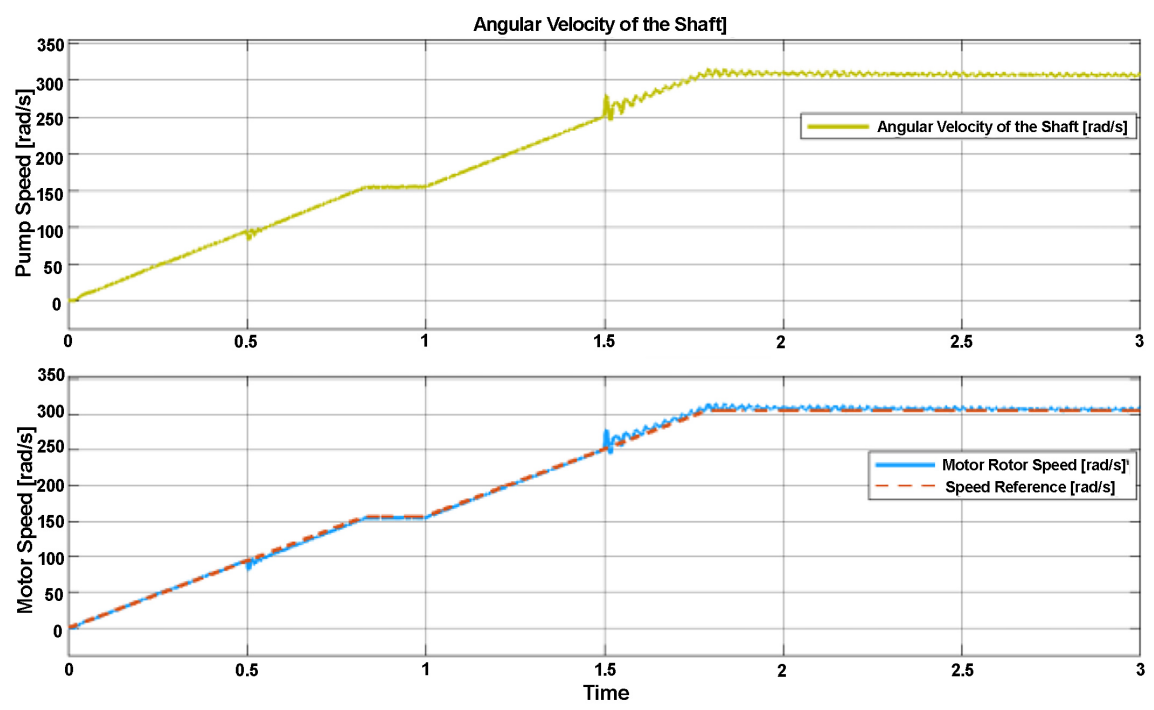

Figure 45. Angular velocity of shaft.

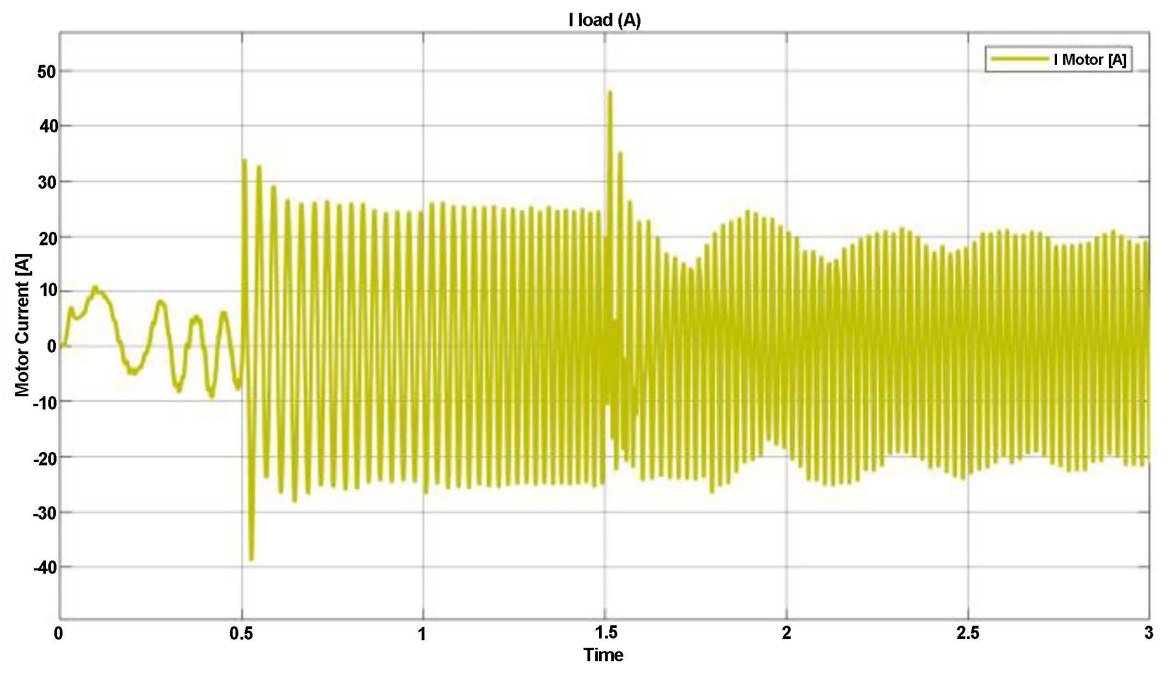

Figure 46. Stator motor current.

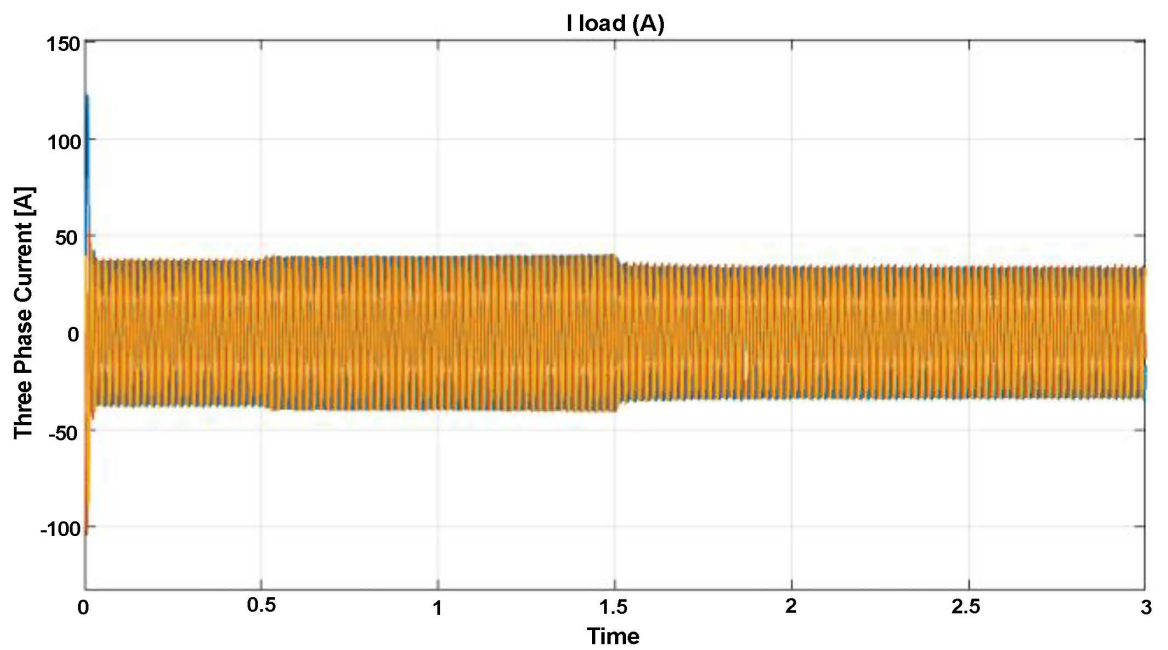

Figure 47. Load of three-phase current. 


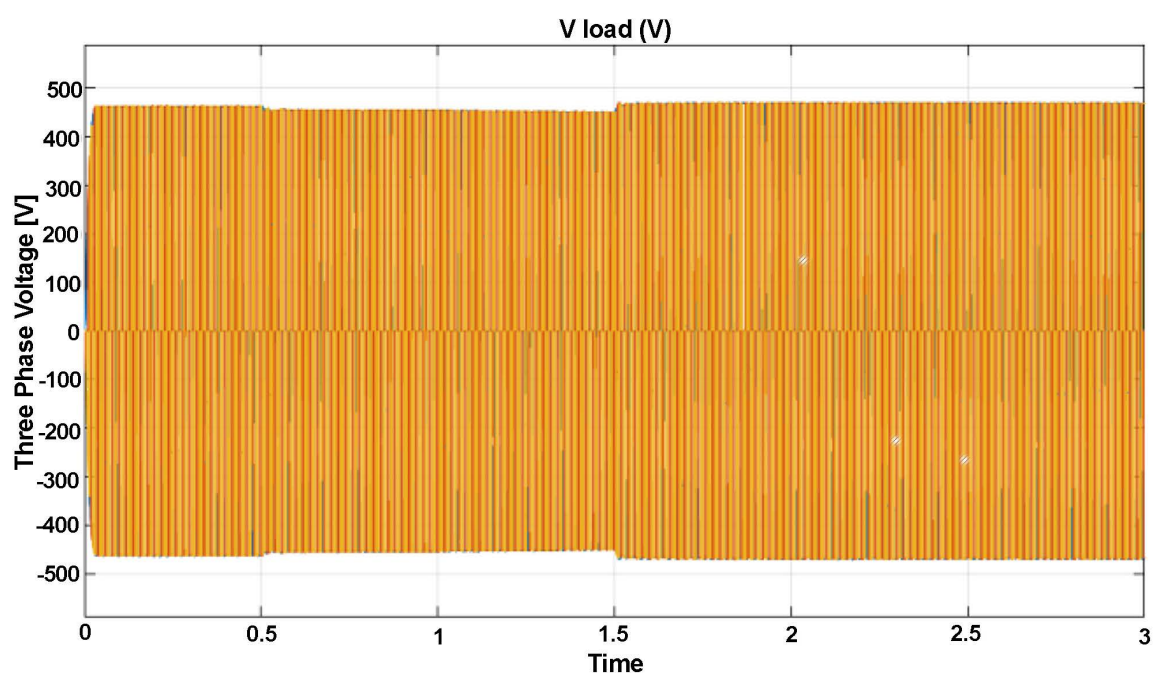

Figure 48. Load of three-phase voltage.
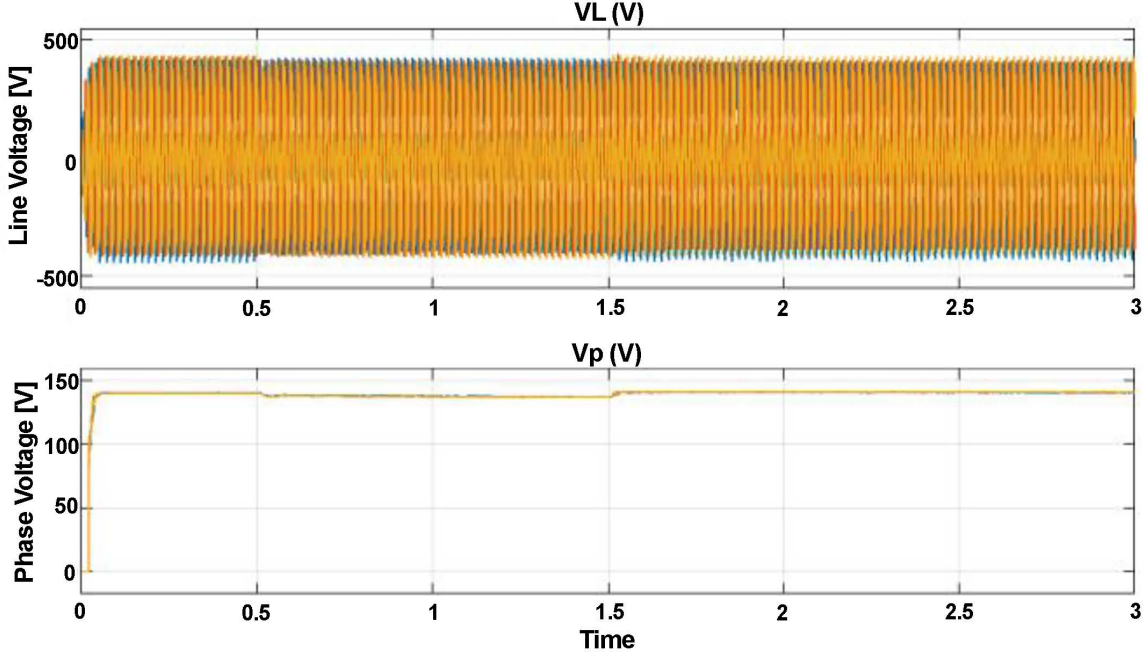

Figure 49. Output line and phase voltage of invertor.

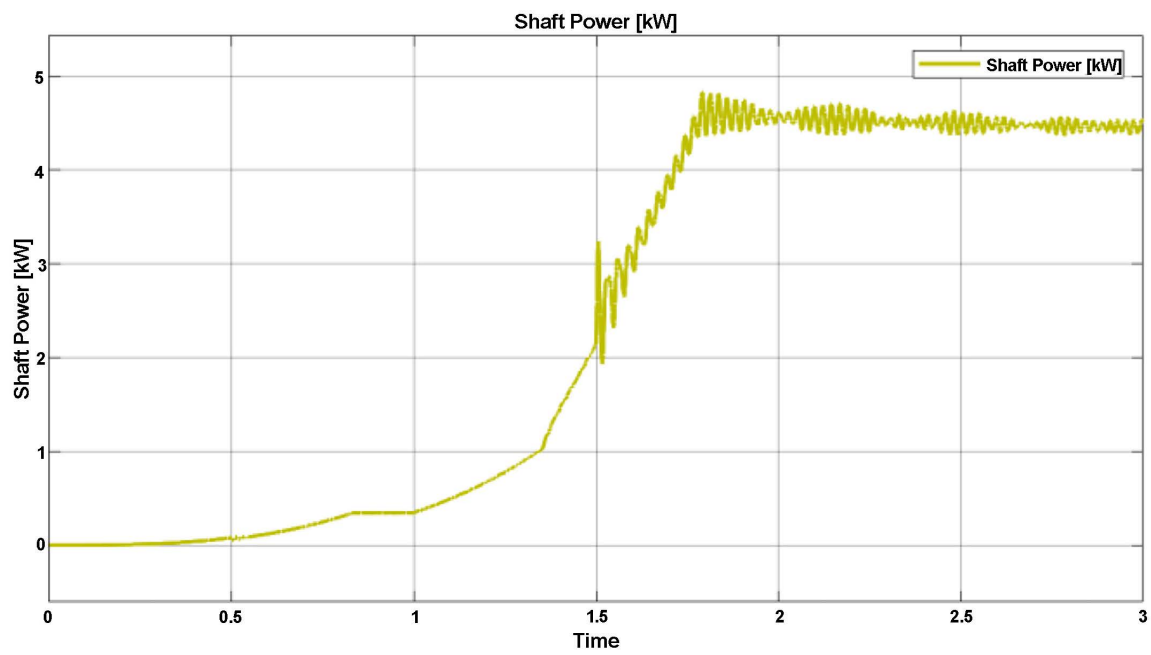

Figure 50. Shaft power of pump. 


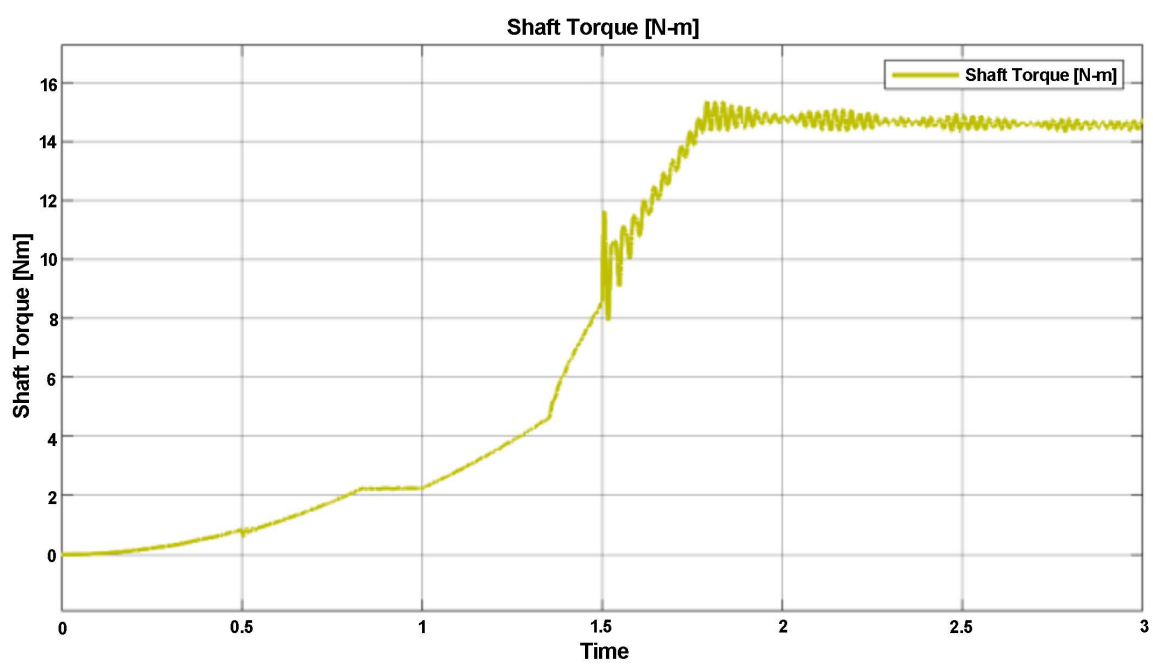

Figure 51. Shaft torque of pump.

shaft power and adjusts its value. The total torque of the pump starts at 15 [N-m] and then decreases to $14.5[\mathrm{~N}-\mathrm{m}]$.

Figure 52 shows the pump flow rate in the various units of [liter per minute] and [cubic meter per sec] as a function of time. Both curves show the pump starts to deliver the water after almost $1.35 \mathrm{sec}$. The pump flow rate is $5.4 \times 10^{-3}$ $\left[\mathrm{m}^{3} / \mathrm{sec}\right]$ and $325[\mathrm{lpm}]$, respectively, which is somewhat higher than the actual values.

Figure 53 shows the DC output voltage and current of the boost converter versus time, in sec. The DC voltage is stable at around $361 \mathrm{~V}$. The current curve shows similar behavior, stabilizing at around $23 \mathrm{~A}$.

Figure 54 shows the power of the battery bank in [W] versus time in [sec]. The power starts at $14 \mathrm{~kW}$, and then at a period of time under $1000 \mathrm{~W} / \mathrm{m}^{2}$ the radiation stabilizes at $7.2 \mathrm{~kW}$. However, when the radiation reduces to 600 $\mathrm{W} / \mathrm{m}^{2}$, the power increases and stabilizes at $8.9 \mathrm{~kW}$.

Figure 55 shows the battery voltage, SOC, and current versus time, in [sec]. As can be seen, the battery voltage is the same as the DC voltage in Figure 53. Also, the SOC of the battery is assumed to start at $80 \%$ charge; after $3 \mathrm{sec}$, we cannot see the charge/discharge of the battery. However, the figure indicates that the battery has started to discharge, which is understood due to the shortage of the required power to operate the load. Note that the current of the battery is around $28 \mathrm{~A}$.

\subsection{Model 6: Induction Motor without Drive Operated Using a PV System with a Battery Bank}

Figure 56 introduces the flowchart for Model 6. As can be seen, the operating system components include an induction motor that uses a PV system and a battery bank. Model 6 is similar to Model 4, except that a battery has been added to the system. The reason for adding the battery is to stabilize the voltage source and as a pick-up unit to restore the operating energy. The PV system with the 

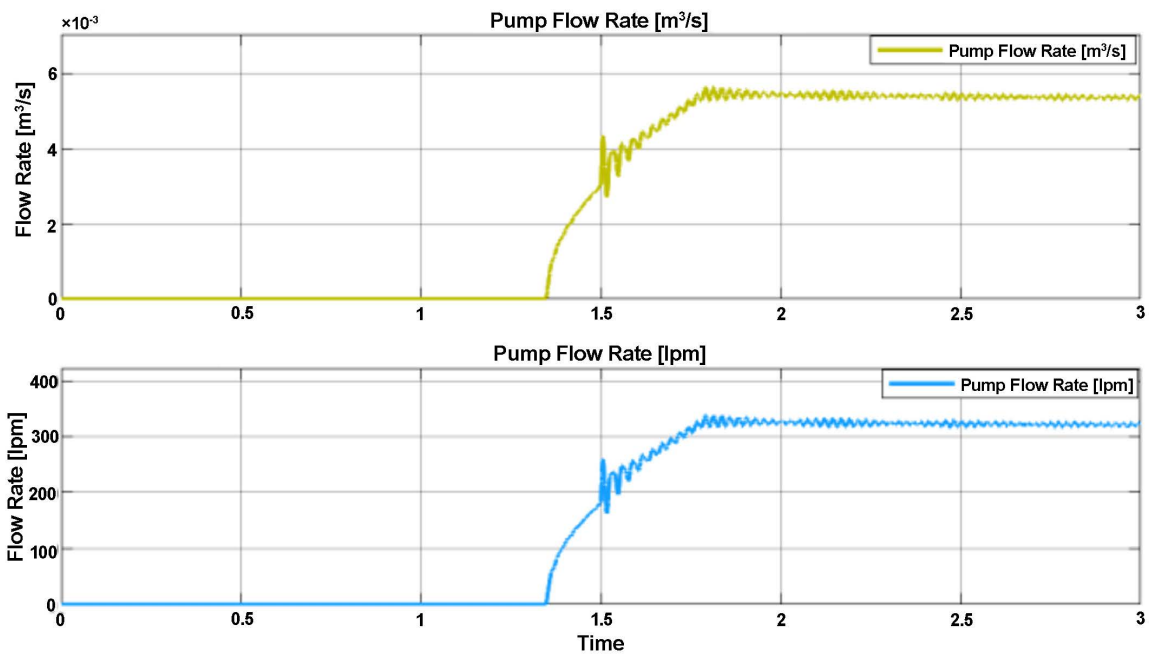

Figure 52. Pump flow rate in $\left[\mathrm{m}^{3} / \mathrm{s}\right]$ and $[\mathrm{lpm}]$.
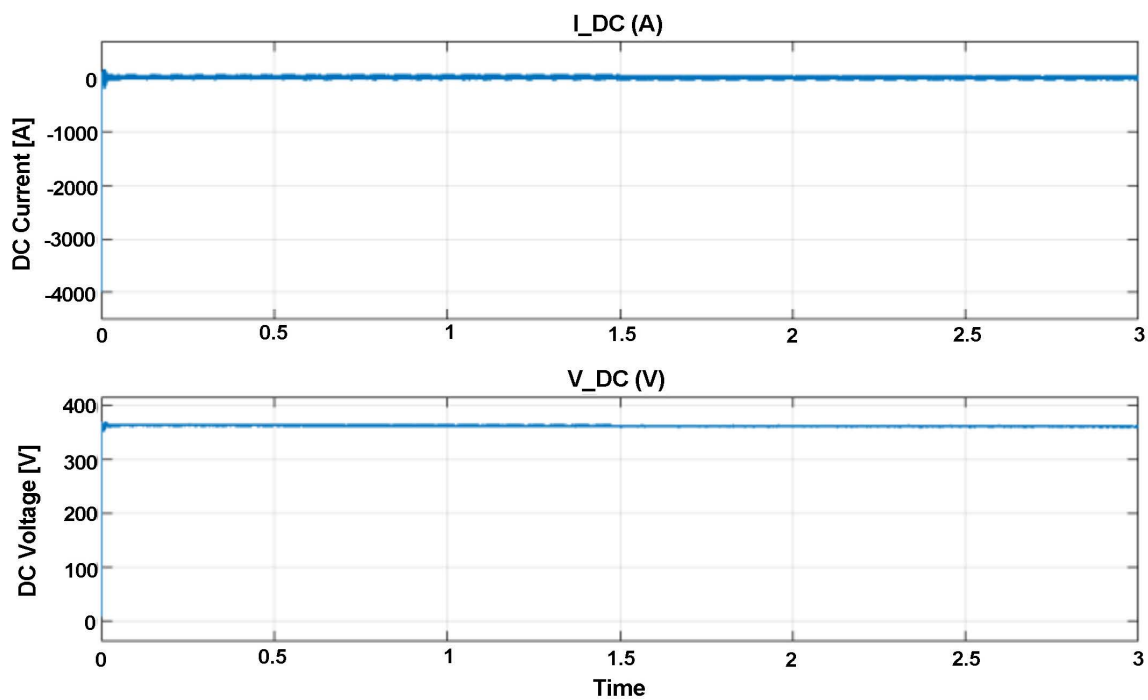

Figure 53. DC output voltage and current of boost convertor.

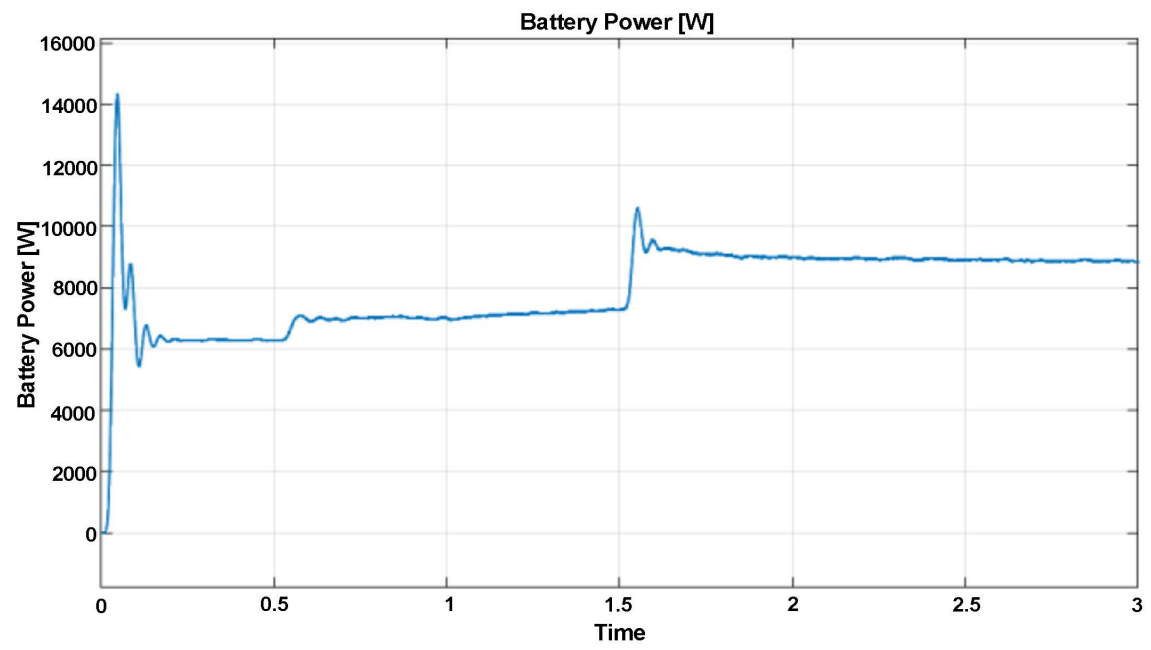

Figure 54. Battery power. 

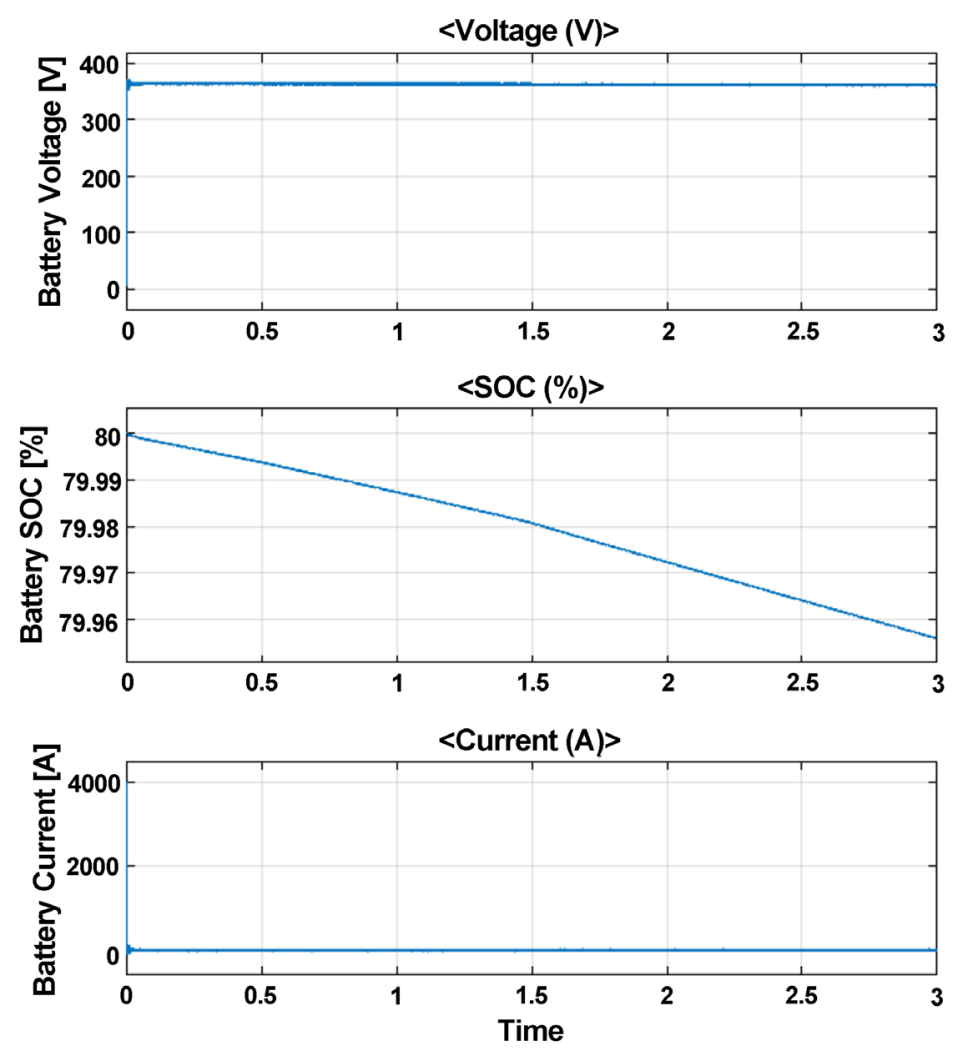

Figure 55. Voltage, SOC, and battery current.

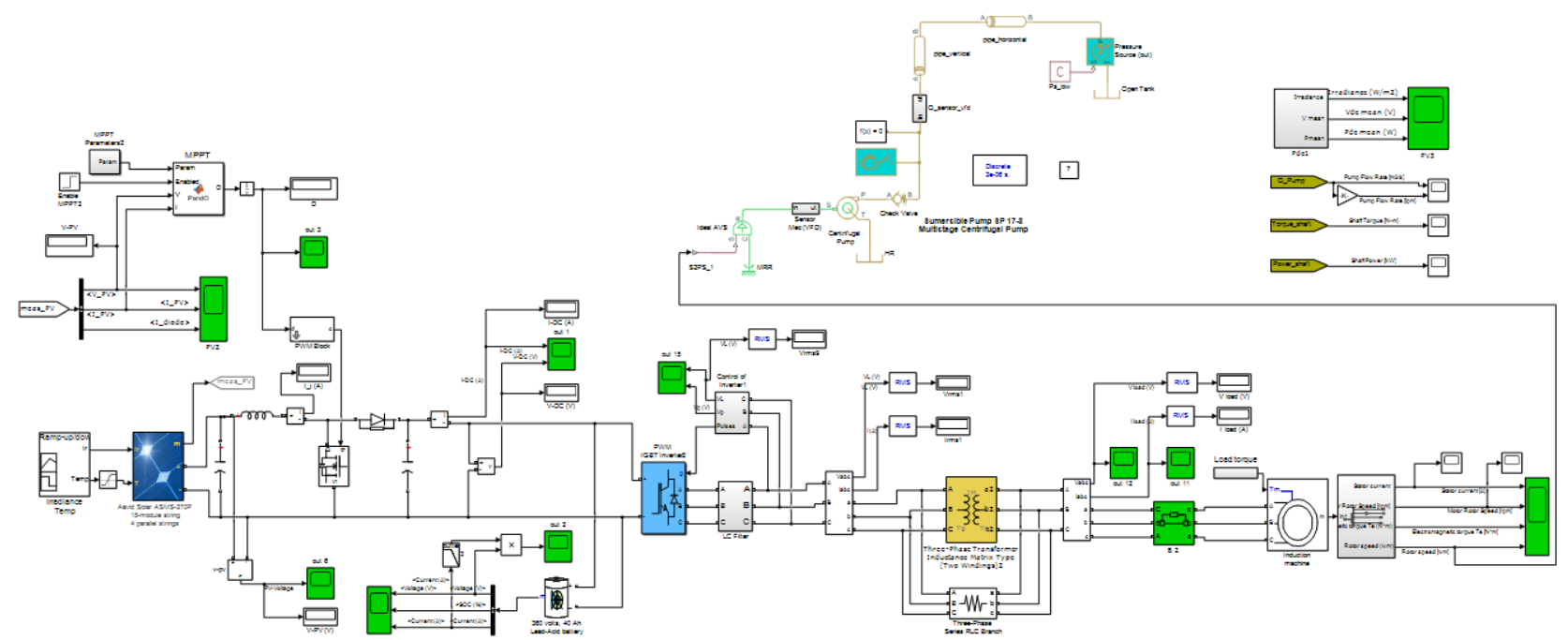

Figure 56. Model 6: Complete model of induction motor without drive operated using PV system with battery bank.

boost converter, the battery bank and IGBT inverter are feeding the induction motor.

\subsection{Results and Discussion: Model 6}

The following results were intended and plotted based on the simulation of the dynamic system model 6 . Figure 57 shows that the output power of the PV array 

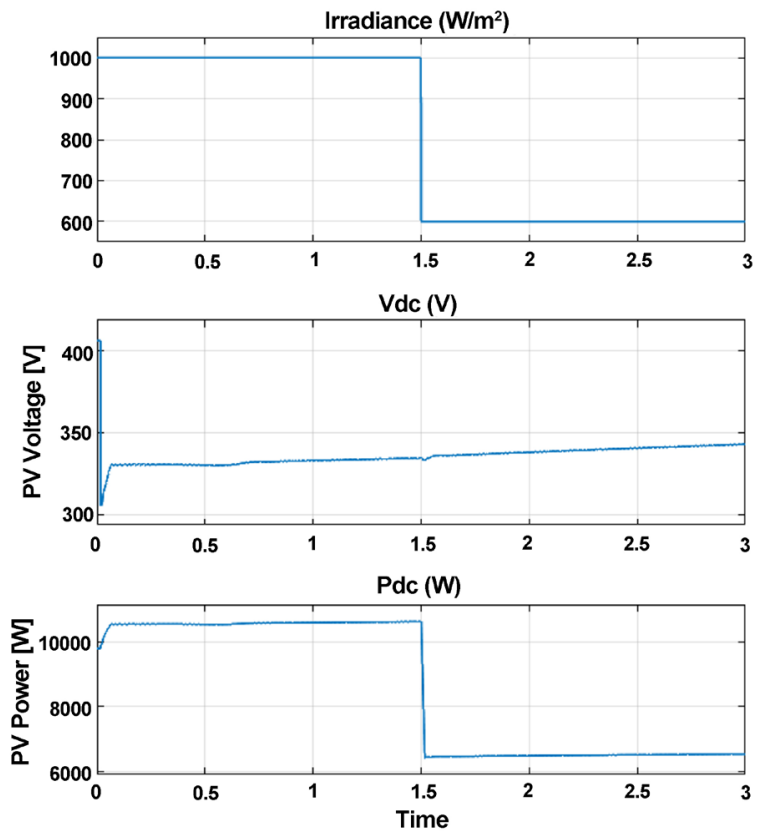

Figure 57. PV irradiance, DC voltage and power.

is stable at both radiations. Specifically, at an irradiance of $1000 \mathrm{~W} / \mathrm{m}^{2}$, it is around $10.6 \mathrm{~kW}$, while at an irradiance of $600 \mathrm{~W} / \mathrm{m}^{2}$, the PV output power drops sharply to $6.55 \mathrm{~kW}$. In addition, the PV voltage increases smoothly from around $320 \mathrm{~V}$ to $343 \mathrm{~V}$. Figure 58 demonstrates the motor rotor speed [rpm] over three seconds. From the figure, we can see that the motor speed stabilizes at 2920 [rpm] when the radiation is $1000 \mathrm{~W} / \mathrm{m}^{2}$. However, when the radiation is 600 $\mathrm{W} / \mathrm{m}^{2}$, the motor rotor speed increases to around $3060[\mathrm{rpm}]$.

Figure 59 reveals a one-phase stator motor current [A] over three seconds. It can be seen that the motor speed causes the motor current to reach a steady-state current at around 8.8 A. Figure 60 shows a three-phase load current that stabilizes at the same current (around $8.8 \mathrm{~A}$ ), as the system has only one load-the motor load.

Figure 61 shows the load (motor) of three-phase output voltage versus time, in [sec]. The results present that the voltage waves are smooth and stable at around $390 \mathrm{~V}$, which is acceptable to run the motor. Furthermore, Figure 62 shows the output line and phase voltages of the IGBT inverter as a function of time, in sec. As can be seen in the figure, the phase voltage is $146 \mathrm{~V}$, which is again less than the desirable value. As a result, a transformer is needed to increase the voltage to the designed value.

Figure 63 shows the shaft power of the pump [kW] versus time [sec]. The shaft power of the pump gives the same results as the motor speed. The total power of the shaft stabilizes at $4.4 \mathrm{~kW}$ but then increases to $5.14 \mathrm{~kW}$. Moreover, Figure 64 shows the shaft torque of the pump $[\mathrm{N}-\mathrm{m}]$ versus time, in sec. The results present the shaft power and adjust its value. The total torque of the pump starts at $14.5[\mathrm{~N}-\mathrm{m}]$ and then increases to $16[\mathrm{~N}-\mathrm{m}]$. 


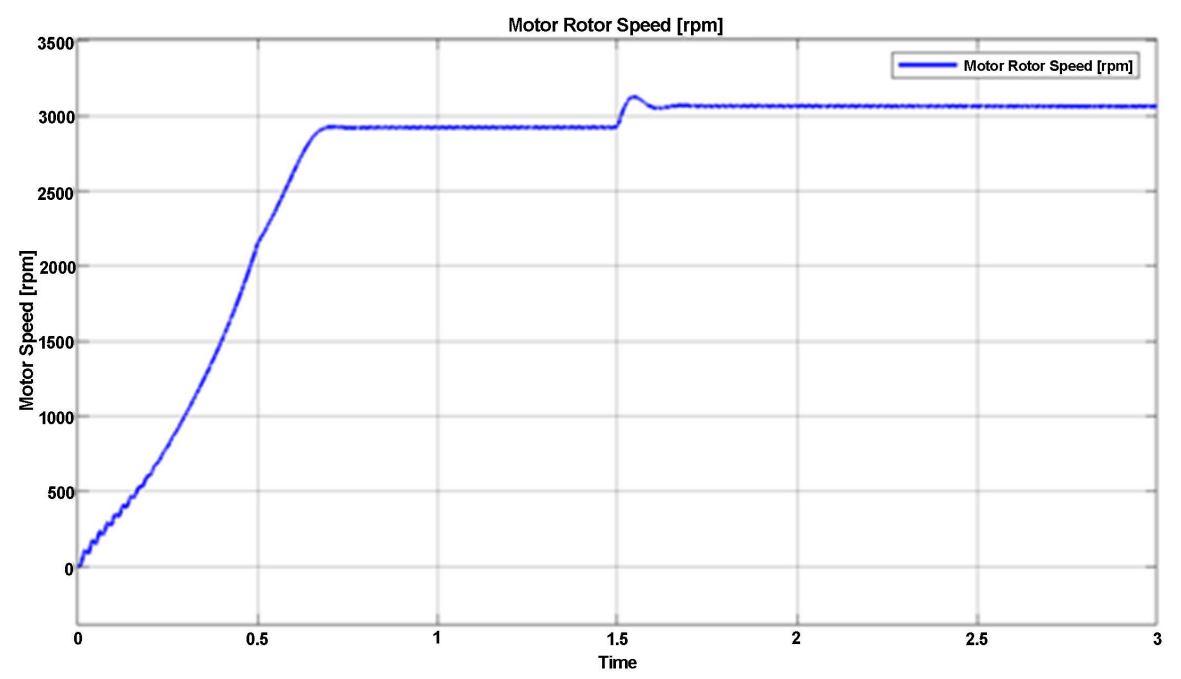

Figure 58. Rotor speed of motor.

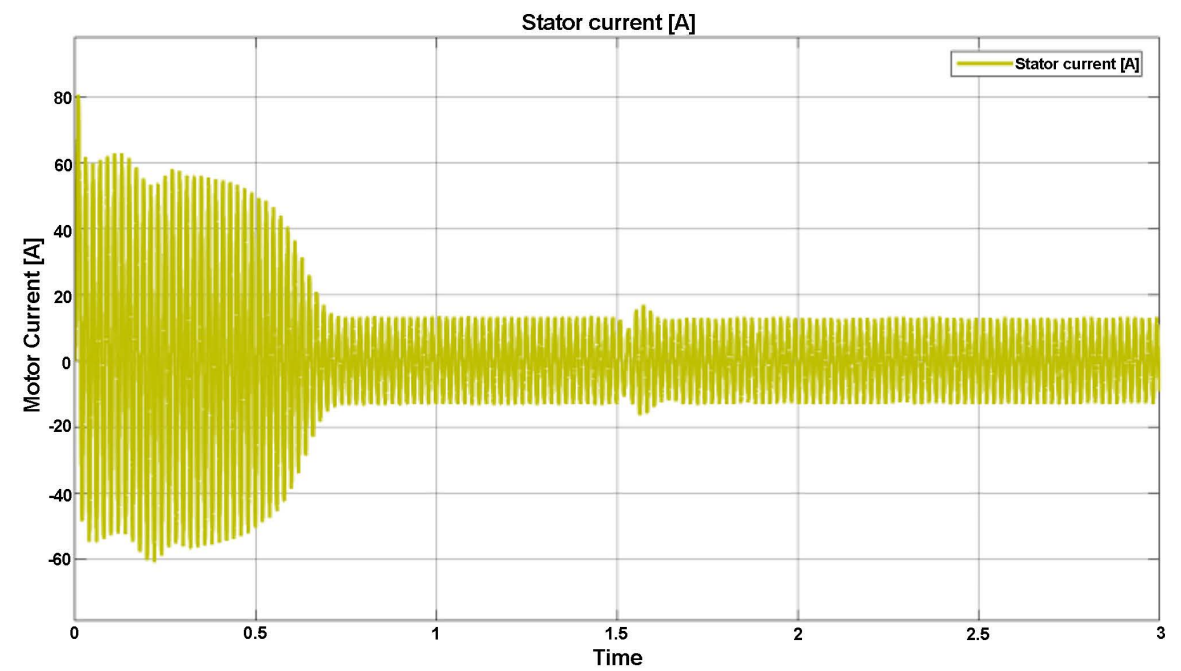

Figure 59. Stator motor current.

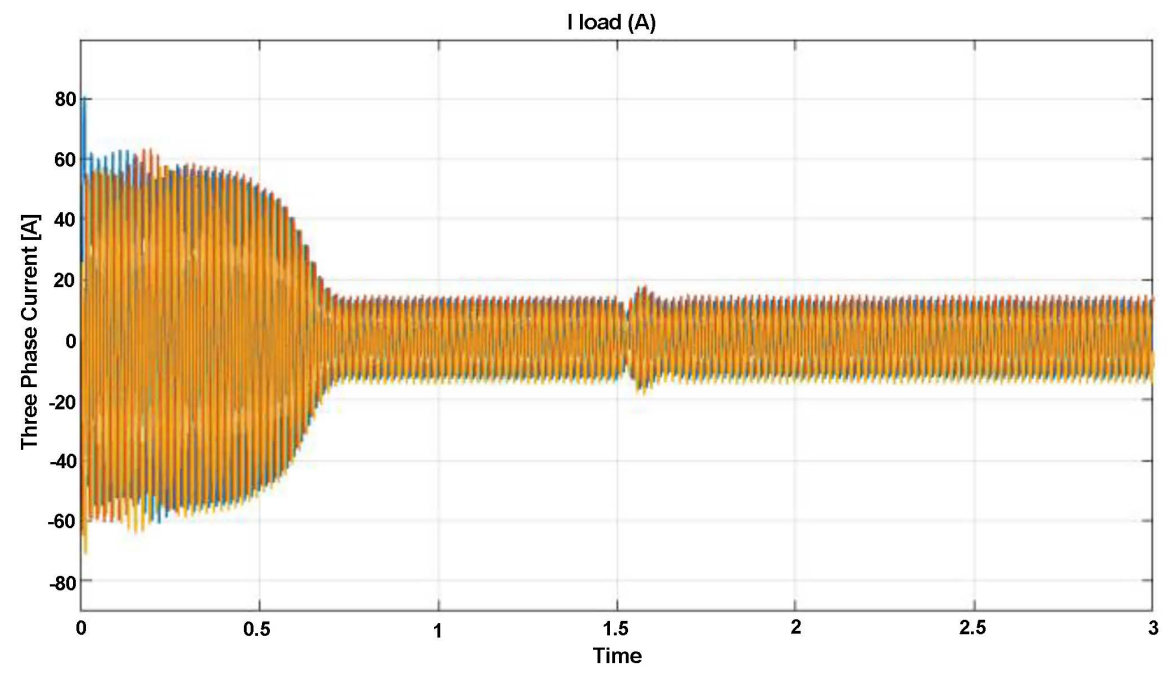

Figure 60. Load of three-phase current. 


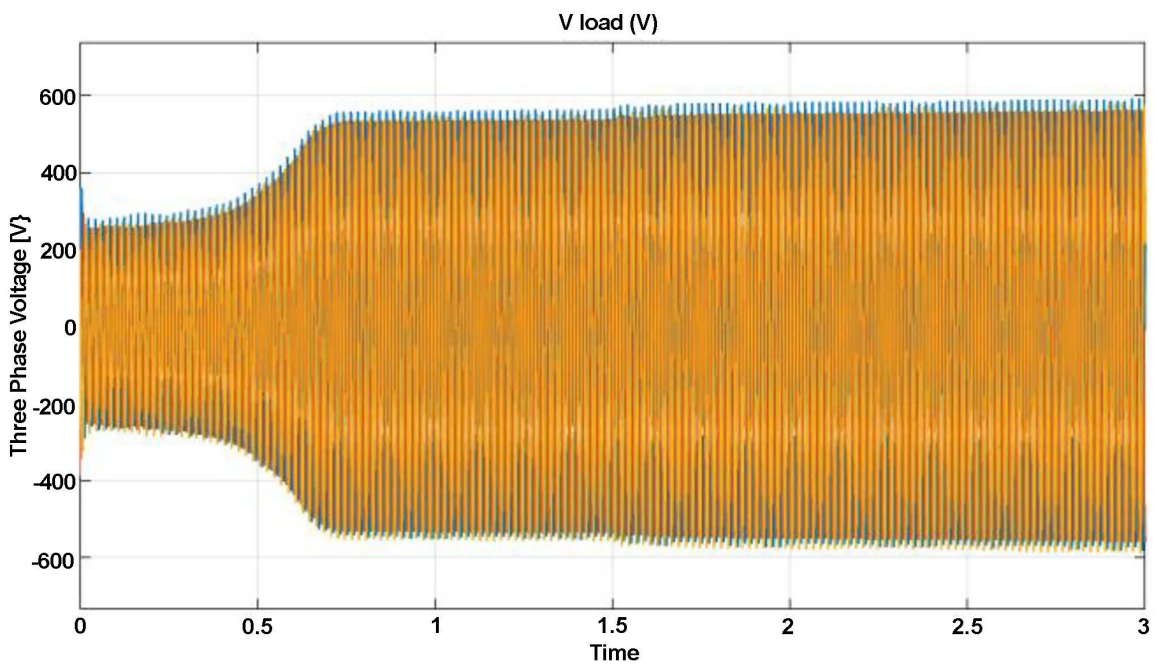

Figure 61. Load of three-phase voltage.
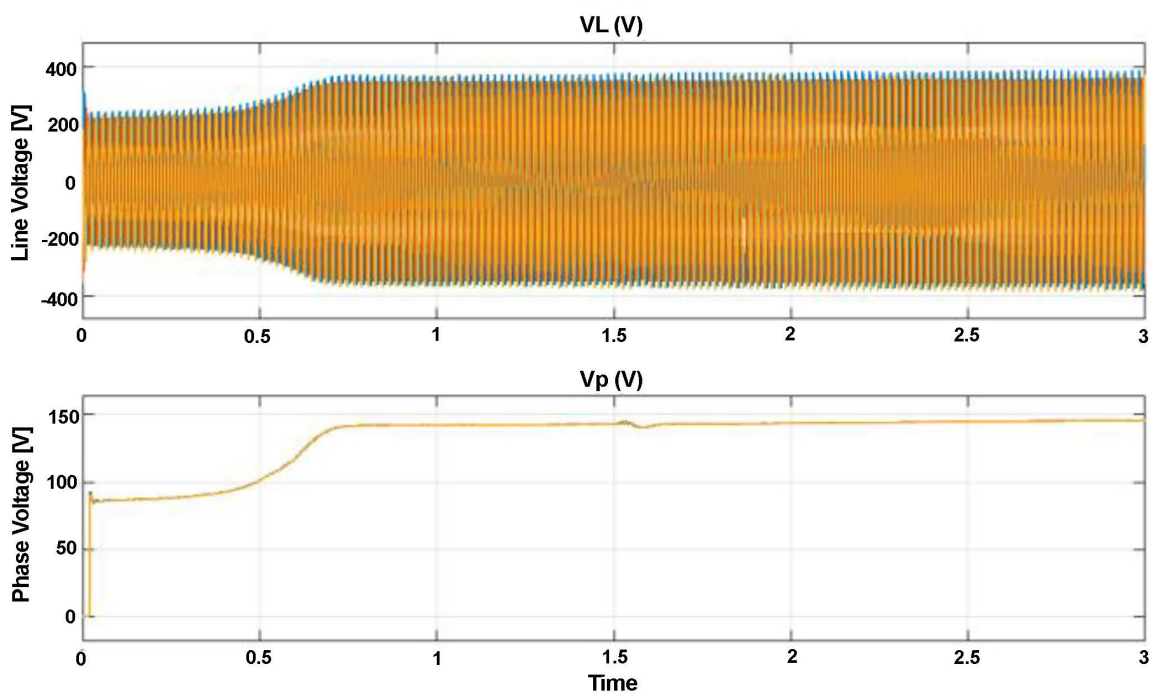

Figure 62. Output line and phase voltage of IGBT inverter.

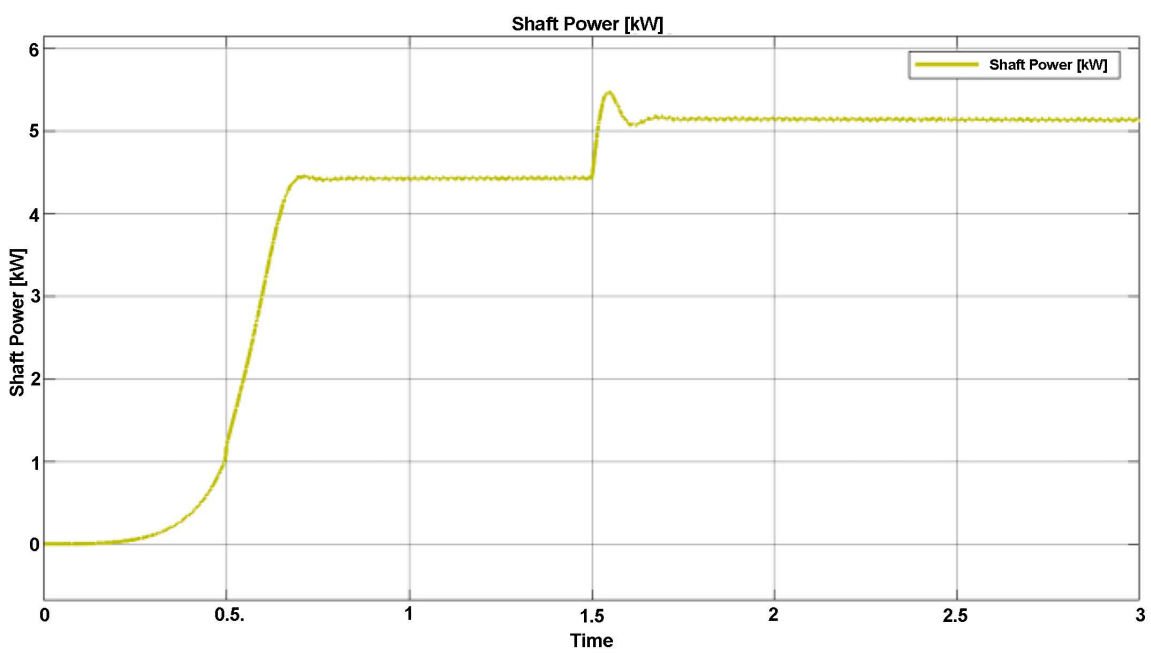

Figure 63. Shaft power of pump. 


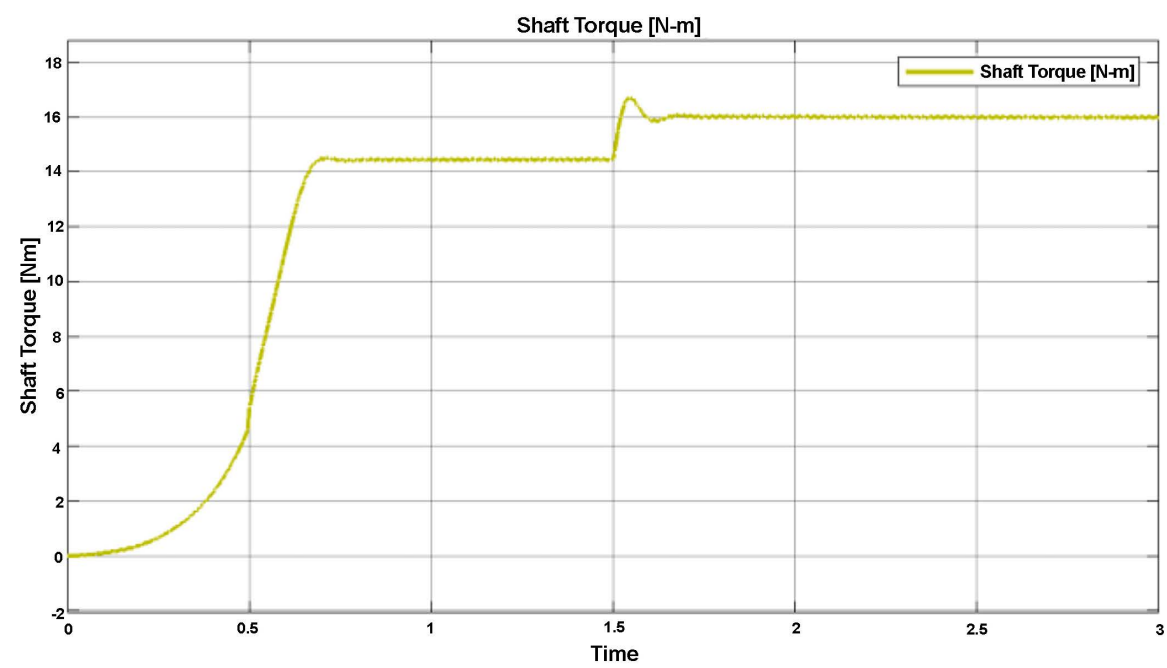

Figure 64. Shaft torque of pump.

Figure 65 shows the pump flow rate in different units [liter per minute] and [cubic meter per sec] as a function of time. Both curves show that the pump starts to deliver the water after almost $0.5 \mathrm{sec}$. Similarly, the pump flow rate first stabilizes at $5.3 \times 10^{-3}\left[\mathrm{~m}^{3} / \mathrm{sec}\right]$ and $320[\mathrm{lpm}]$ and then increases to $5.84 \times 10^{-3}$ $\left[\mathrm{m}^{3} / \mathrm{sec}\right]$ and $350[\mathrm{lpm}]$. The increase is due to the rise in the operating voltage, which in turn leads to an increase in the motor rotor speed.

Figure 66 shows the DC output voltage and current of the boost converter versus time, in sec. The DC voltage is stable at around $380 \mathrm{~V}$, and the current curve is stabilized at around $15.7 \mathrm{~A}$.

Figure 67 shows the power of the battery bank in [W] versus time, in [sec]. The power starts at $5 \mathrm{~kW}$, and then (between 0.2 and 0.6 ) the battery charges. After that, when still under the period of time of $1000 \mathrm{~W} / \mathrm{m}^{2}$ radiation, it stabilizes at $-5.63 \mathrm{~kW}$. However, when the radiation reduces to $600 \mathrm{~W} / \mathrm{m}_{2}$, the power decreases and stabilizes at $-10 \mathrm{~kW}$.

Figure 68 shows the battery voltage, SOC and current versus time in [sec]. Three points can be noticed. First, the battery voltage is the same as that in the DC voltage in Figure 66. Second, the SOC of the battery is assumed to start at $80 \%$ charge. From the figure, it can be indicated that the battery starts to charge due to extra power and voltage in the system. Third, the current of the battery stabilizes at around $-22 \mathrm{~A}$.

\section{Conclusions}

Six systems of submersible water pumps driven by a PWM inverter and threephase induction motor were modeled and simulated in MATLAB/Simulink. The six models were then tested and compared. The following points show the unique designs of the six models:

1) Induction model with a drive operated using a general network.

2) Induction model without a drive operated using a general network.

3) Induction model with a drive operated using a PV system. 

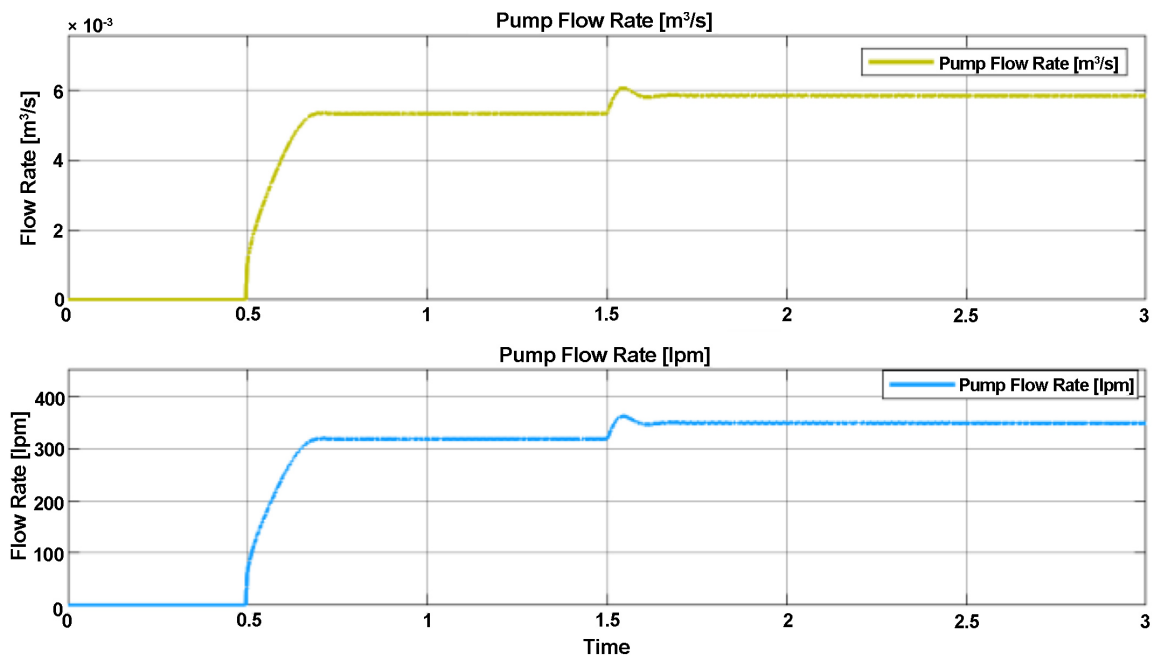

Figure 65. Pump flow rate in $\left[\mathrm{m}^{3} / \mathrm{s}\right]$ and $[\mathrm{lpm}]$.
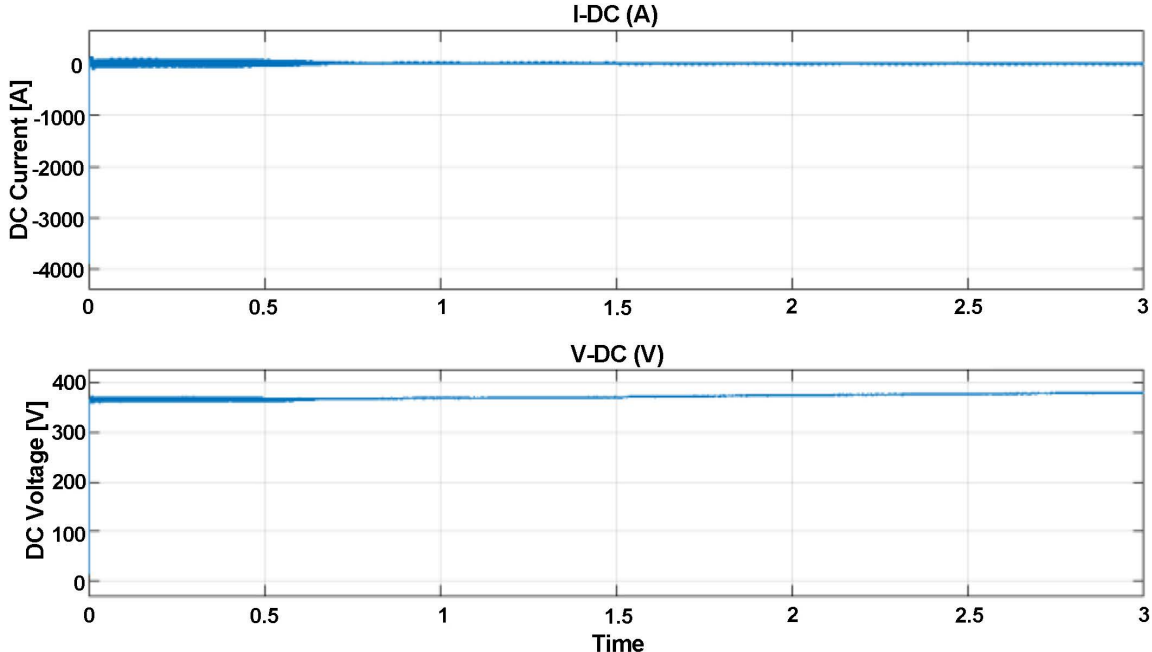

Figure 66. DC output voltage and current of boost convertor.

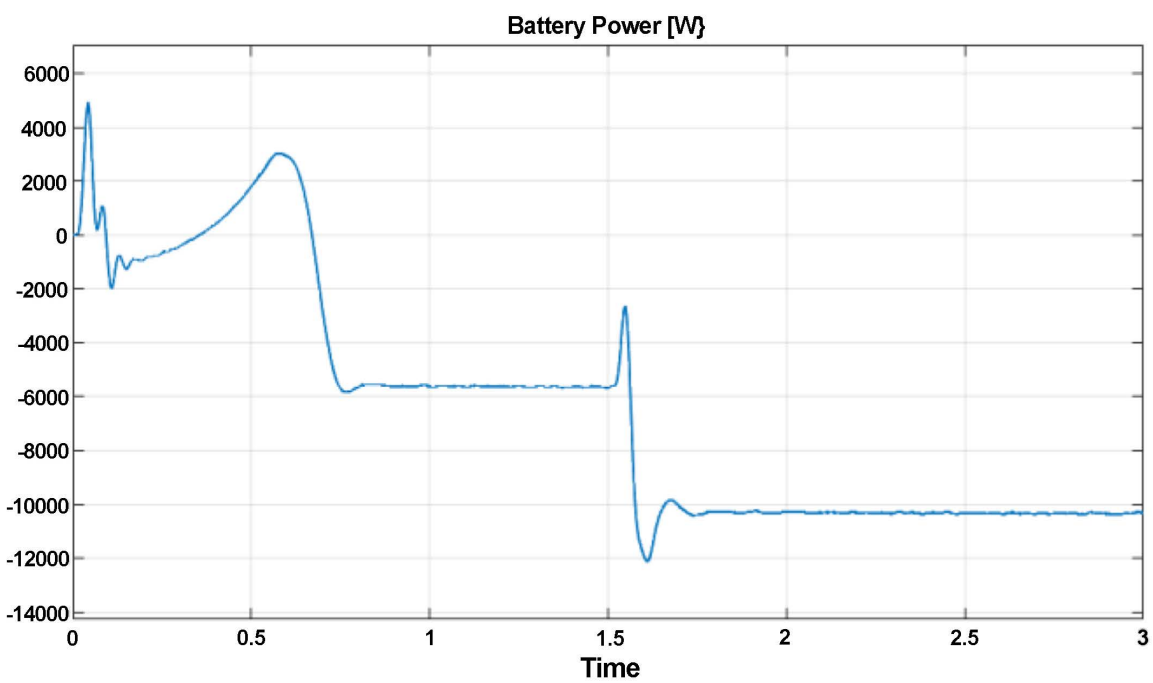

Figure 67. Battery power. 

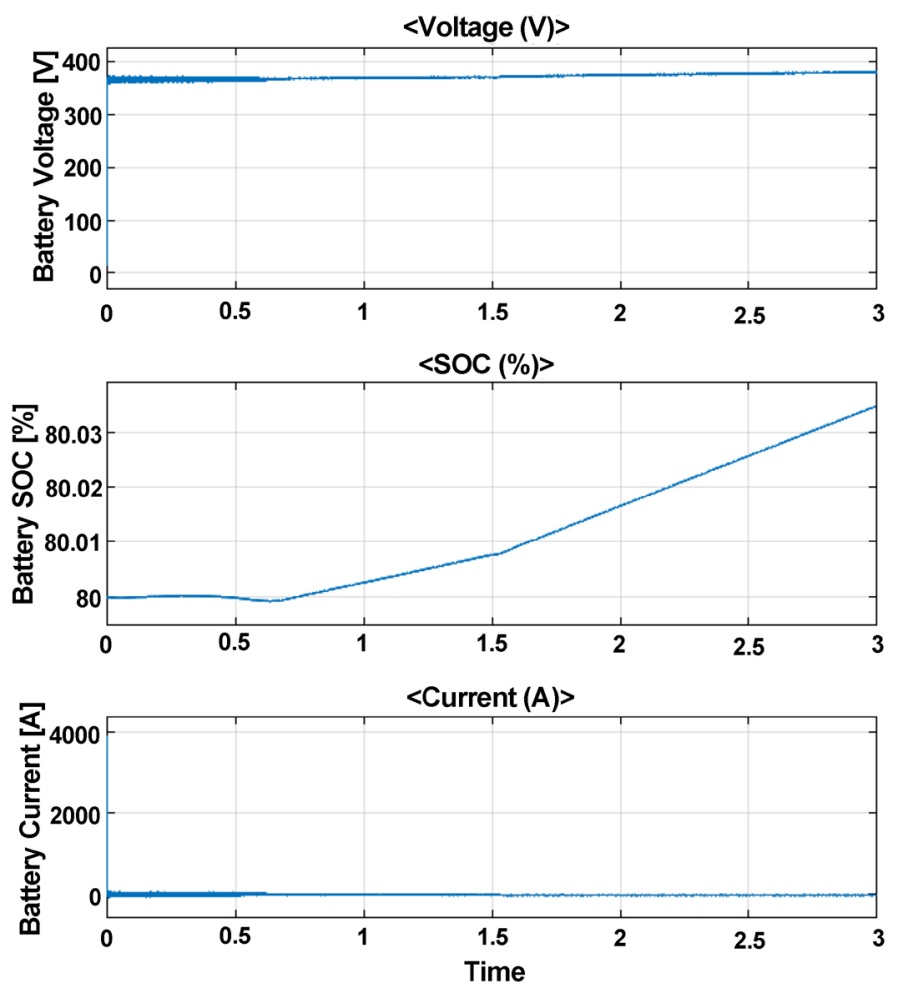

Figure 68. Voltage, SOC, and current of battery.

4) Induction model without a drive operated using a PV system.

5) Induction model with a drive using a PV system with a battery bank.

6) Induction model without a drive using a PV system with a battery bank.

Based on the simulation's outcomes, there were slight differences in the results between the calculated values stated in the manufacturer's data and those from the simulations. These differences can be caused by factors such as the effects of fluid inertia and moment of inertia of the motor on the pump, friction loss, and the check valve effect. Moreover, significant conclusions are described below:

- Models 1 and 2 were considered as reference models for the other simulations. Through these models, the performance of the induction motor and submersible water pump were optimized based on the ideal operated source, which is the general electrical network with $380 \mathrm{~V}$.

- Models 3 and 4, which operated using a PV system, the performance of the system indicated that the induction motor with a drive gave better results than the one without a drive. However, the system with a drive gave lower voltage, which affected the system over a period of time.

- Models 5 and 6 operated using a PV system with a battery bank. Although one model had a drive and the other did not, both results were acceptable when compared with the reference models. However, the model with the drive indicated that the battery was discharging, whereas the model without a drive showed the battery was charging.

Finally, the results indicated that the PV system with the battery should be used to operate similar models due to the stability in the voltage and the power 
of the system. Overall, for comparing results in simulations and cases, MATLAB/ Simulink is a highly useful tool.

\section{Acknowledgements}

The authors thank the Libyan government for financial support of this research.

\section{Conflicts of Interest}

The authors declare no conflicts of interest regarding the publication of this paper.

\section{References}

[1] Alo, B.T. (2017) Different Types of Water Bodies. The Balance. https://www.thebalance.com/different-types-of-water-pumps-844599

[2] Muhsen, D.H., Khatib, T. and Nagi, F. (2017) A Review of Photovoltaic Water Pumping System Designing Methods, Control Strategies and Field Performance. Renewable and Sustainable Energy Reviews, 68, 70-86. https://doi.org/10.1016/j.rser.2016.09.129

[3] Chandel, S.S., Naik, M.N. and Chandel, R. (2017) Review of Performance Studies of Direct Coupled Photovoltaic Water Pumping Systems and Case Study. Renewable and Sustainable Energy Reviews, 76, 163-175. https://doi.org/10.1016/j.rser.2017.03.019

[4] Djeriou, S., Kheldoun, A. and Mellit, A. (2018) Efficiency Improvement in Induction Motor-Driven Solar Water Pumping System Using Golden Section Search Algorithm. Arabian Journal for Science and Engineering, 43, 3199-3211. https://doi.org/10.1007/s13369-017-2972-6

[5] Akhila, V.T. and Arun, S. (2018) Review of Solar PV Powered Water Pumping System Using Induction Motor Drive. IOP Conference Series: Materials Science and Engineering, 396, Article ID: 012047. https://doi.org/10.1088/1757-899X/396/1/012047

[6] Muhsen, D.H., Khatib, T. and Abdulabbas, T.E. (2018) Sizing of a Standalone Photovoltaic Water Pumping System Using Hybrid Multi-Criteria Decision Making Methods. Solar Energy, 159, 1003-1015. https://doi.org/10.1016/j.solener.2017.11.044

[7] Iqbal, M.M. and Islam, K. (2017) Design And Simulation Of A PV System With Battery Storage Using Bidirectional DC-DC Converter Using Matlab Simulink. International Journal of Scientific \& Technology Research, 6, 403-410.

[8] Yadav, K., Kumar, A., Sastry, O.S. and Wandhare, R. (2019) Solar Photovoltaics Pumps Operating Head Selection for the Optimum Efficiency. Renewable Energy, 134, 169-177. https://doi.org/10.1016/j.renene.2018.11.013

[9] Aliyu, M., Hassan, G., Said, S.A., Siddiqui, M.U., Alawami, A.T. and Elamin, I.M. (2018) A Review of Solar-Powered Water Pumping Systems. Renewable and Sustainable Energy Reviews, 87, 61-76. https://doi.org/10.1016/j.rser.2018.02.010

[10] Rathore, P.K.S., Das, S.S. and Chauhan, D.S. (2018) Perspectives of Solar Photovoltaic Water Pumping for Irrigation in India. Energy Strategy Reviews, 22, 385-395. https://doi.org/10.1016/j.esr.2018.10.009

[11] Rubio-Aliaga, A., García-Cascales, M.S., Sánchez-Lozano, J.M. and Molina-García, A. (2019) Multidimensional Analysis of Groundwater Pumping for Irrigation Purposes: Economic, Energy and Environmental Characterization for PV Power Plant 
Integration. Renewable Energy, 138, 174-186. https://doi.org/10.1016/j.renene.2019.01.077

[12] Abdelkader, H. and Mohammed, Y. (2018) Solar System Design for Water Pumping. Proceedings of The Sixth International Congress "Water, Waste and Environment", 37, 1-10. https://doi.org/10.1051/e3sconf/20183706001

[13] Singh, B., Sharma, U. and Kumar, S. (2018) Standalone Photovoltaic Water Pumping System Using Induction Motor Drive With Reduced Sensors. IEEE Transactions on Industry Applications, 54, 3645-3655. https://doi.org/10.1109/TIA.2018.2825285

[14] Singh, B. and Shukla, S. (2018) Induction Motor Drive for PV Water Pumping with Reduced Sensors. IET Power Electronics, 11, 1903. https://doi.org/10.1049/iet-pel.2017.0856

[15] Yahyaoui, I. (2017) Renewable Energies and Irrigation. In: Specifications of Photovoltaic Pumping Systems in Agriculture, Elsevier, Amsterdam, 1-14. https://doi.org/10.1016/B978-0-12-812039-2.00001-6

[16] Niranjan, B.S. and Pandey, A. (2018) Mathematical Modelling of a Hybrid Solar-Wind Power Generator. International Research Journal of Engineering and Technology, 5, 188-193.

[17] Alkarrami, F., Iqbal, T. and Pope, K. (2016) Optimal Sizing of a Stand-Alone Hybrid Energy System for Water Pumping in Sirte, Libya. 2016 IEEE Electrical Power and Energy Conference, Ottawa, 12-14 October 2016, 6-7. https://doi.org/10.1109/EPEC.2016.7771679

[18] Hussein, A.K. (2015) Applications of Nanotechnology in Renewable Energies-A Comprehensive Overview and Understanding. Renewable and Sustainable Energy Reviews, 42, 460-476. https://doi.org/10.1016/j.rser.2014.10.027

[19] Hussein, A.K. (2016) Applications of Nanotechnology to Improve the Performance of Solar Collectors-Recent Advances and Overview. Renewable and Sustainable Energy Reviews, 62, 767-792. https://doi.org/10.1016/j.rser.2016.04.050

[20] Hussein, A.K., Li, D., Kolsi, L., Kata, S. and Sahoo, B. (2017) A Review of Nano Fluid Role to Improve the Performance of the Heat Pipe Solar Collectors. Energy Procedia, 109, 417-424. https://doi.org/10.1016/j.egypro.2017.03.044

[21] Hussein, A.K., Walunj, A.A. and Kolsi, L. (2016) Applications of Nanotechnology to Enhance the Performance of the Direct Absorption Solar Collectors. Journal of Thermal Engineering, 2, 529-540.

[22] Li, D., Li, Z., Zheng, Y., Liu, C., Hussein, A.K. and Liu, X. (2016) Thermal Performance of a PCM-Filled Double-Glazing Unit with Different Thermophysical Parameters of PCM. Solar Energy, 133, 207-220. https://doi.org/10.1016/j.solener.2016.03.039

[23] Jain, S., Karampuri, R. and Somasekhar, V.T. (2016) An Integrated Control Algorithm for a Single-Stage PV Pumping System Using an Open-End Winding Induction Motor. IEEE Transactions on Industrial Electronics, 63, 956-965. https://doi.org/10.1109/TIE.2015.2480765

[24] Vazeos, E., Avaritsiotis, J.N. and Rakopoulos, C.D. (1988) Photovoltaic Water Pumping From Deep Wells. Proceedings of the Biennial Congress of the International Solar Energy Society, Hamburg, Federal Republic of Germany, 13-18 September 1987, 2495-2499. https://doi.org/10.1016/B978-0-08-034315-0.50458-4

[25] Pelikan, B. (2009) The Pump Book: A Pump Installer's Guide to the Design Installation and Servicing of Groundwater Pumping Systems. Lulu Press, Morrisville, NC.

[26] Pal, N. and Sikder, P. (2018) A Comparison between Directly Connected and MPPT Connected Solar Powered Water Pumping System Using PMDC Motor. Journal of 
Power Technologies, 98, 80-88.

[27] Exploration, N. (2014) Submersible Pump Sizing \& Selection. New York.

[28] Matter, P.S. (2015) The Use of Variable Speed Drives with Solar Water Pumping Systems.

[29] Gopal, C., Mohanraj, M., Chandramohan, P. and Chandrasekar, P. (2013) Renewable Energy Source Water Pumping Systems-A Literature Review. Renewable and Sustainable Energy Reviews, 25, 351-370. https://doi.org/10.1016/j.rser.2013.04.012

[30] Daud, A.K. and Mahmoud, M.M. (2005) Solar Powered Induction Motor-Driven Water Pump Operating on a Desert Well, Simulation and Field Tests. Renewable Energy, 30, 701-714. https://doi.org/10.1016/j.renene.2004.02.016

[31] Raju, A.B., Kanik, S.R. and Jyoti, R. (2008) Maximum Efficiency Operation of a Single Stage Inverter Fed Induction Motor PV Water Pumping System. 2008 First International Conference on Emerging Trends in Engineering and Technology, Nagpur, 16-18 July 2008, 905-910. https://doi.org/10.1109/ICETET.2008.64

[32] Pulfrey, D.L., Ward, P.R.B. and Dunford, W.G. (1987) A Photovoltaic-Powered System for Medium-Head Pumping. Solar Energy, 38, 255-265. https://doi.org/10.1016/0038-092X(87)90047-8

[33] Anis, W., Kerbache, T., Mertens, R. and Van Overstraeten, R. (1984) Detailed Analyses For Photovoltais Powered Water Pumping Systems. Solar \& Wind Technology, 1, 197-205. https://doi.org/10.1016/0741-983X(84)90015-8

[34] Lujara, N.K., Van Wyk, J.D. and Materu, P.N. (1999) Loss Models of Photovoltaic Water Pumping Systems. 1999 IEEE Africon. 5th Africon Conference in Africa, Cape Town, 28 September-1 October 1999, 965-970.

[35] Ramya, K. and Rama Reddy, S. (2012) Design and Simulation of a Photovoltaic Induction Motor Coupled Water Pumping System. 2012 International Conference on Computing, Electronics and Electrical Technologies, Kumaracoil, India, 21-22 March 2012, 32-39. https://doi.org/10.1109/ICCEET.2012.6203793

[36] Ev, M., Vokas, G.A. and Kaldellis, J.K. (2015) Theoretical Simulation and Experimental Analysis of a PV-Based Water Pumping System. MedPower 2008, 6th Mediterranean Conference and Exhibition on Power Generation, Transmission and Distribution, Thessalonica, Greece, No. 1.

[37] Sontake, V.C. and Kalamkar, V.R. (2016) Solar Photovoltaic Water Pumping System-A Comprehensive Review. Renewable and Sustainable Energy Reviews, 59, 1038-1067. https://doi.org/10.1016/j.rser.2016.01.021

[38] Bellil, A. and Meroufel, A. (2012) VSI PWM Inverter Feed Induction Machine Using Volts Per Hertz Control Scheme. Przeglad Elektrotechniczny, 88, 128-131.

[39] Atoyebi, A.A. (2015) Total Dynamic Head Determination Model for Submersible Pumps Installation. International Journal of Applied Science and Technology, 5, 95-102.

[40] Grundfos SP 17-8 Pump. http://product-selection.grundfos.com/product-detail.product-detail.html?custid=G MA\&productnumber $=12$ A01908\&qcid $=147665649$

[41] Grundfos (2018) GRUNDFOS Data Booklet, AP SP A, Sp, Submersible Pumps, Motors and Accessories $50 \mathrm{~Hz}$.

[42] Remli, A., Aouzellag, D. and Ghedamsi, K. (2015) Stand Alone PV System with Battery Energy Storage. The 2nd International Conference on Power Electronics and Their Applications (ICPEA 2015), Djelfa University, Algeria.

[43] Betka, A. and Attali, A. (2010) Optimization of a Photovoltaic Pumping System 
Based on the Optimal Control Theory. Solar Energy, 84, 1273-1283.

https://doi.org/10.1016/j.solener.2010.04.004

[44] Hauke, B. (2009) Basic Calculation of a Boost Converter's Power Stage. Texas Instruments, Application Report, 1-9.

[45] AC2-Space Vector PWM VSI Induction 3HP Motor Drive-MATLAB \& Simulink.

https://www.mathworks.com/help/physmod/sps/examples/ac2-space-vector-pwm-v si-induction-3hp-motor-drive.html

[46] Fara, L. and Craciunescu, D. (2017) Output Analysis of Stand-alone PV Systems: Modeling, Simulation and Control. Energy Procedia, 112, 595-605.

https://doi.org/10.1016/j.egypro.2017.03.1125 


\section{Appendix}

1) Friction loss in equivalent number of feet of straight pipe [39]

\begin{tabular}{|c|c|c|c|c|c|c|c|c|}
\hline \multirow{3}{*}{$\begin{array}{l}\text { TYPE OF FITTING } \\
\text { AND APPLICATION }\end{array}$} & \multirow{3}{*}{$\begin{array}{l}\text { PIPE AND } \\
\text { FITTING }\end{array}$} & \multicolumn{7}{|c|}{ NOMINAL SIZE OF FITTING AND PIPE } \\
\hline & & $1 / 2 "$ & $3 / 4 "$ & $1 "$ & 11/4" & $11 / 2 "$ & 2" & 21/2" \\
\hline & & \multicolumn{7}{|c|}{ EQUIVALENT LENGTH OF PIPE (IN FEET) } \\
\hline Insert Coupling & Plastic & 3 & 3 & 3 & 3 & 3 & 3 & 3 \\
\hline $\begin{array}{l}\text { Threaded Adapter } \\
\text { (Plastic to Thread) }\end{array}$ & Plastic & 3 & 3 & 3 & 3 & 3 & 3 & 3 \\
\hline $90^{\circ}$ Standard Elbow & $\begin{array}{l}\text { Steel } \\
\text { Plastic }\end{array}$ & $\begin{array}{l}2 \\
2\end{array}$ & $\begin{array}{l}2 \\
2\end{array}$ & $\begin{array}{l}3 \\
3\end{array}$ & $\begin{array}{l}4 \\
4\end{array}$ & $\begin{array}{l}4 \\
4\end{array}$ & $\begin{array}{l}5 \\
5\end{array}$ & $\begin{array}{l}6 \\
6 \\
\end{array}$ \\
\hline $\begin{array}{c}\text { Standard Tee } \\
\text { (Flow Through Run) }\end{array}$ & $\begin{array}{l}\text { Steel } \\
\text { Plastic }\end{array}$ & $\begin{array}{l}1 \\
1\end{array}$ & $\begin{array}{l}2 \\
2\end{array}$ & $\begin{array}{l}2 \\
2\end{array}$ & $\begin{array}{l}3 \\
3\end{array}$ & $\begin{array}{l}3 \\
3\end{array}$ & $\begin{array}{l}4 \\
4\end{array}$ & $\begin{array}{l}4 \\
4\end{array}$ \\
\hline $\begin{array}{c}\text { Standard Tee } \\
\text { (Flow Through Side) }\end{array}$ & $\begin{array}{l}\text { Steel } \\
\text { Plastic }\end{array}$ & $\begin{array}{l}4 \\
4\end{array}$ & $\begin{array}{l}5 \\
5\end{array}$ & $\begin{array}{l}6 \\
6\end{array}$ & $\begin{array}{l}7 \\
7\end{array}$ & $\begin{array}{l}8 \\
8\end{array}$ & $\begin{array}{l}11 \\
11\end{array}$ & $\begin{array}{l}13 \\
13\end{array}$ \\
\hline Gate Valve $^{1}$ & Steel & 1 & 1 & 1 & 1 & 2 & 2 & 2 \\
\hline Swing Check Valve ${ }^{1}$ & Steel & 5 & 7 & 9 & 12 & 13 & 17 & 21 \\
\hline
\end{tabular}

2) Frictional loss in feet of head per 100 feet (30.48 m) of pipe [39]

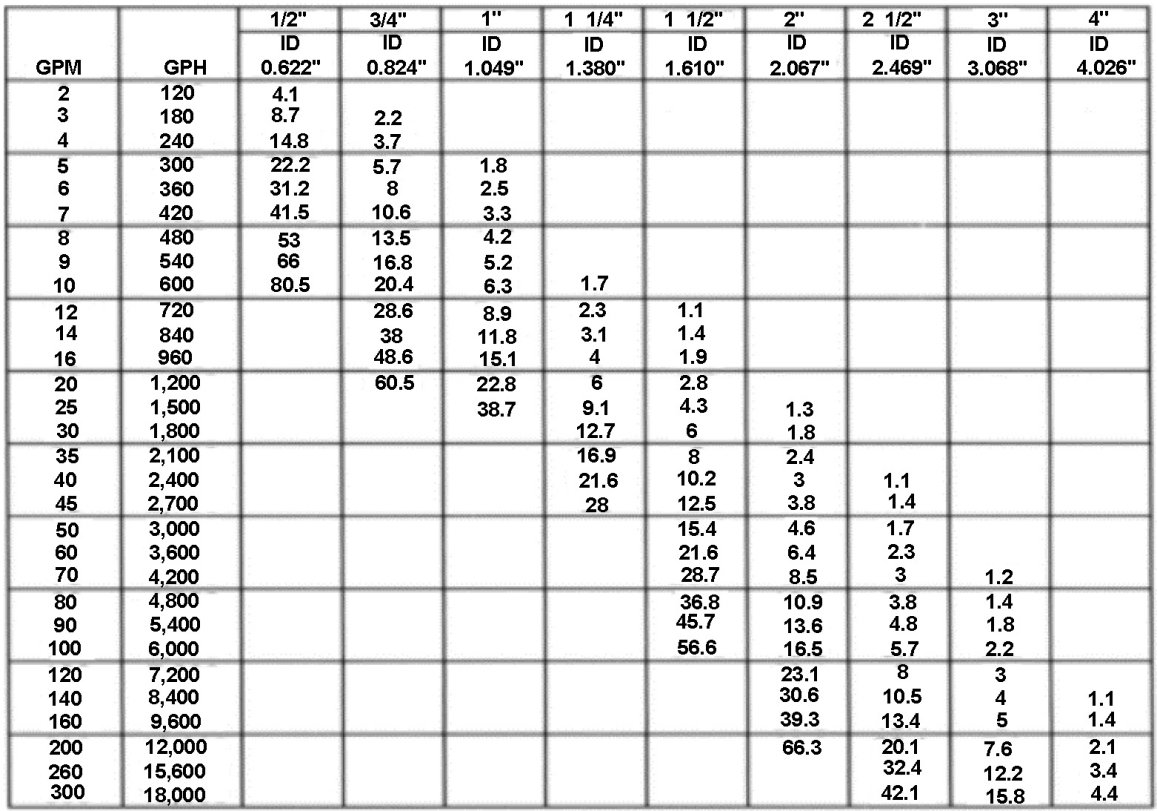

